Aus der Abteilung Neuropathologie

(Prof. Dr. med. W. Brück)

im Zentrum Pathologie

der Medizinischen Fakultät der Universität Göttingen

\title{
Epigenetische Kontrolle der Remyelinisierung bei Multipler Sklerose
}

\author{
INAUGURAL-DISSERTATION \\ zur Erlangung des Doktorgrades \\ der Medizinischen Fakultät \\ der Georg-August-Universität zu Göttingen
}

vorgelegt von

\section{Anna Theresia Herget}

aus

Stockholm, Schweden 
Dekan: Prof. Dr. med. C. Frömmel

I. Berichterstatterin: Prof. Dr. med. Stadelmann-Nessler

II. Berichterstatter: Prof. Dr. rer. nat. Reuss

III. Berichterstatter/in:

Tag der mündlichen Prüfung: 27.06.2012 


\section{Inhaltsverzeichnis}

1. EINLEITUNG [..................................................................... 1

1.1. Multiple Sklerose ......................................................................................1

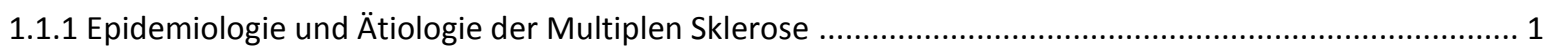

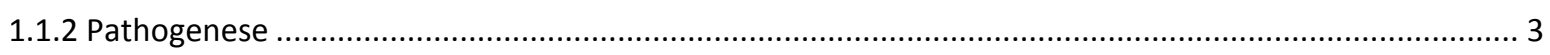

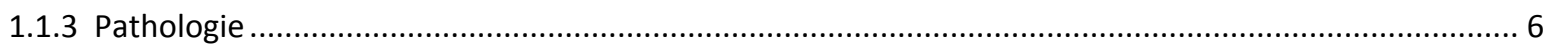

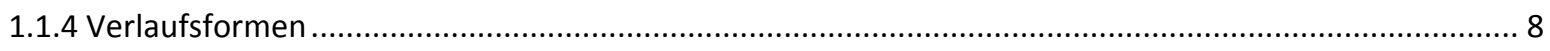

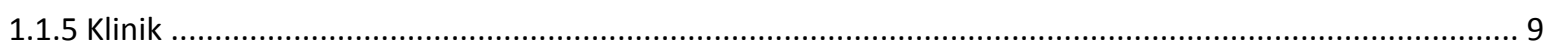



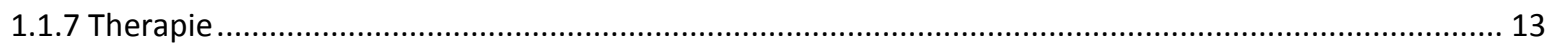

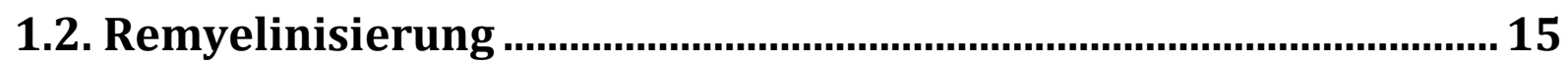

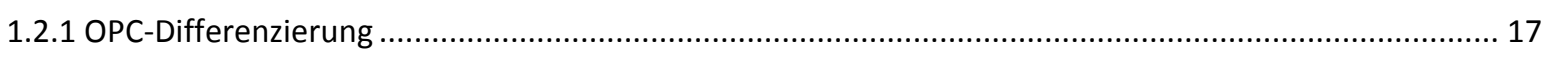

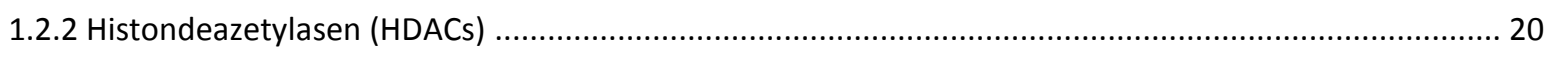

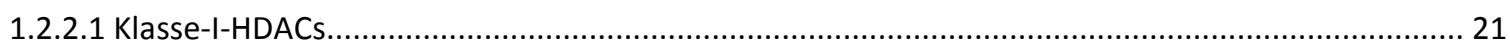

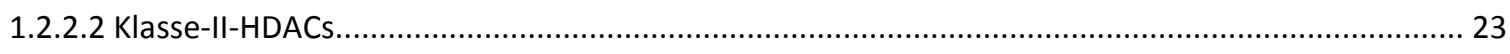

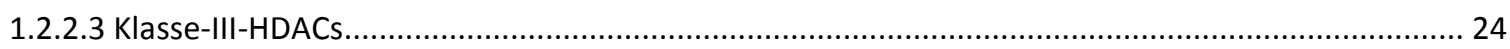

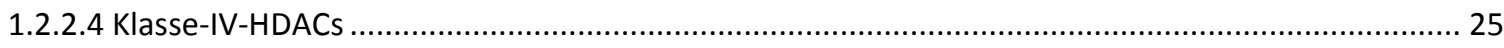

1.3 Fragestellung

2. MATERIAL UND METHODEN ............................................... 27

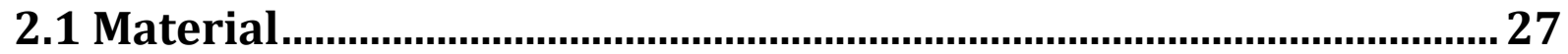

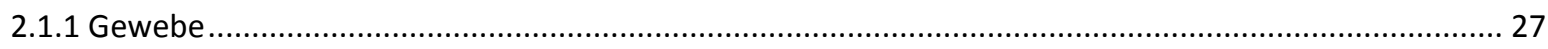

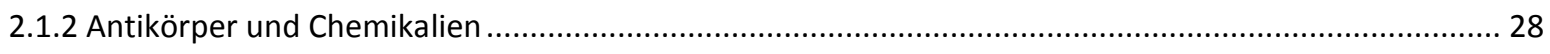

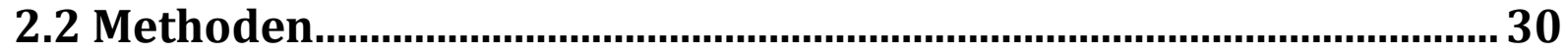

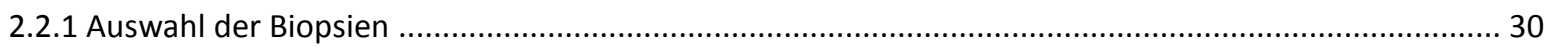

2.2.2 Einteilung der MS-Biopsien in Stadien der Entmarkungsaktivität und der Remyelinisierung ................ 31

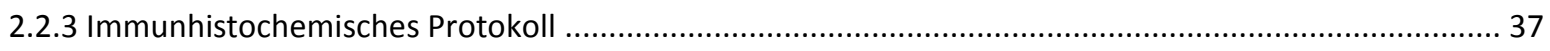

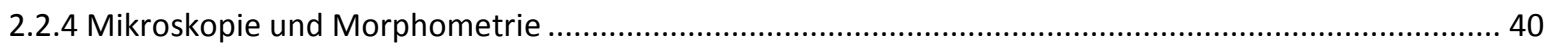

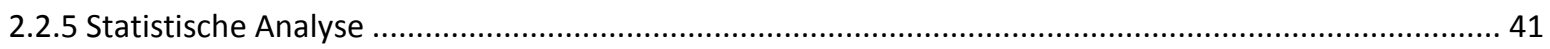

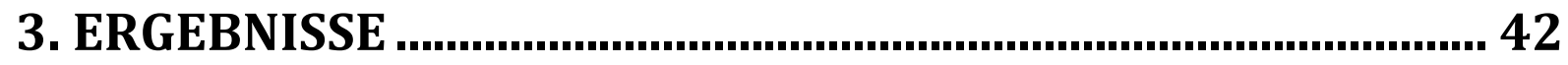

3.1 Einteilungen in Stadien .................................................................... 42

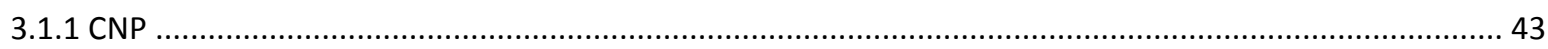

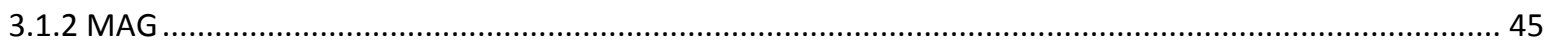




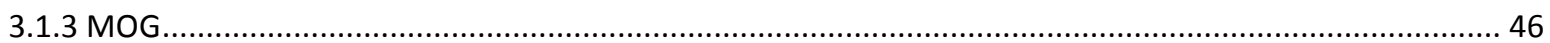

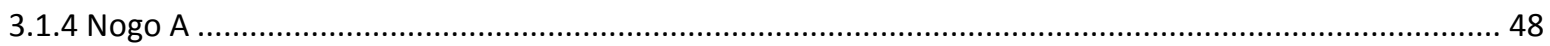

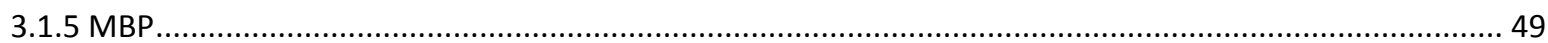

3.1.6 Tabellarische Zusammenfassung der Dichte oligodendroglialer Zellen und Myelinfasern .....................51

3.2 HDAC1-Expression in Oligodendrozyten ....................................52

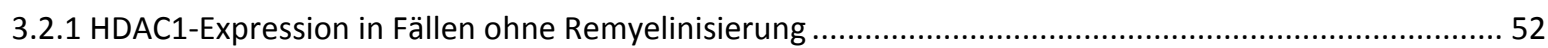

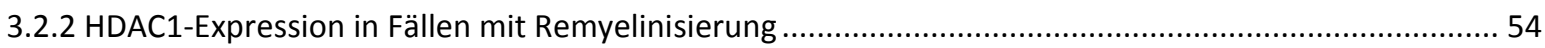

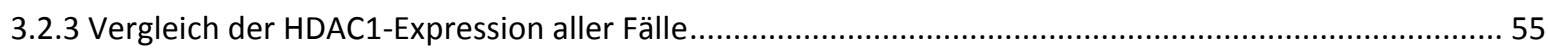

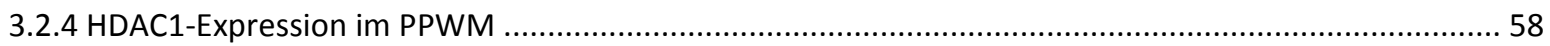

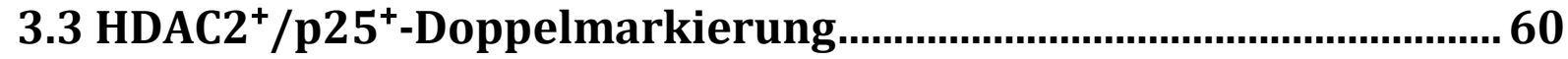

4.DISKUSSION ................................................................................. 61

4.1 Überblick ...................................................................................................... 61

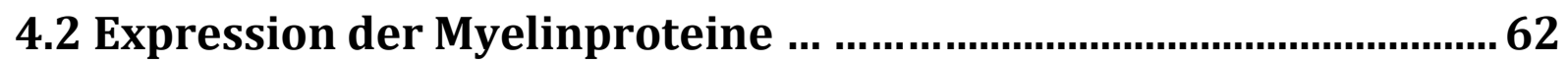

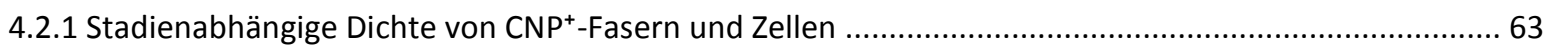



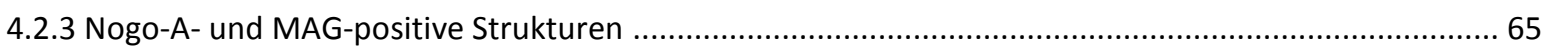

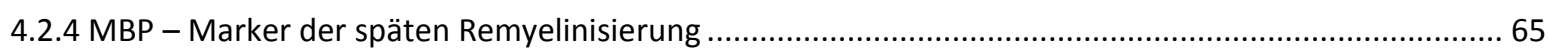

4.2.5 Zusammenfassung der Kriterien zur Einteilung der untersuchten Läsionen in Stadien der

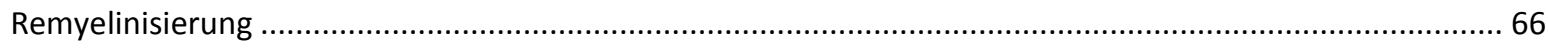

\subsection{Unterschiede in der HDAC1-Expression zwischen verschiedenen}

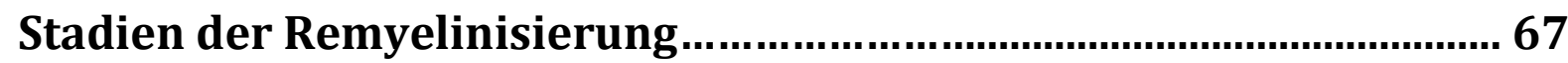

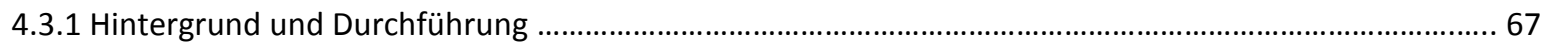

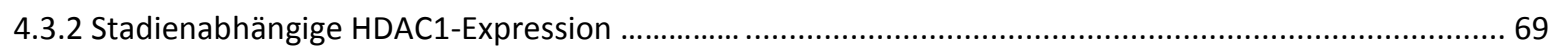

4.3.3 Dichte HDAC1/Nogo-A-positiver Oligodendrozyten im PPWM .................................................... 71

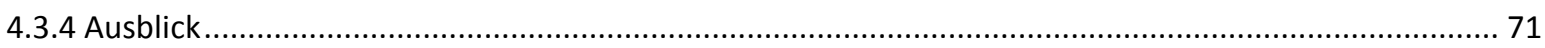

5. ZUSAMMENFASSUNG.................................................................. 73

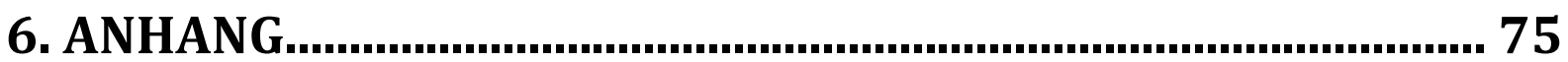

7. LITERATURVERZEICHNIS ............................................................ 82 


\section{Abkürzungsverzeichnis}

\begin{tabular}{|c|c|}
\hline Abb. & Abbildung \\
\hline $\mathrm{Ag}$ & Antigen \\
\hline $\mathrm{Ak}$ & Antikörper \\
\hline APAAP & Alkalische Phosphatase-anti-alkalische Phosphatase \\
\hline APP & amyloid precursor protein (Amyloid-Vorläuferprotein) \\
\hline bidest. & bidestillata (zweifach destilliert) \\
\hline $\mathrm{CD} 4+/ 8+$ & $\begin{array}{l}\text { cluster of differentiation 4-/8- positive } \\
\text { (Differenzierungsmuster 4-/8-positiv) }\end{array}$ \\
\hline DAB & 3-3'-Diaminobenzidin-Tetrahydrochlorid \\
\hline dest. & destillata (destilliert) \\
\hline CNP & $\begin{array}{l}\text { 2'-3'-cyclic-nucleotide-3'-phosphodiesterase } \\
\text { (2'-3'-zyklische-Nukleotid-3'- Phosphodiesterase) }\end{array}$ \\
\hline DNS & Desoxyribonukleinsäure \\
\hline EDSS & $\begin{array}{l}\text { expanded disability status scale } \\
\text { (Skala der Schwere der Behinderung bei der MS nach Kurtzke) }\end{array}$ \\
\hline FCS & fetal calf serum (fetales Kälberserum) \\
\hline GC & Galaktocerebrosid \\
\hline ggf. & gegebenenfalls \\
\hline $\mathrm{H}_{2} \mathrm{O}_{2}$ & Wasserstoffperoxid \\
\hline HAT & Histonazetylase \\
\hline HDAC & Histondeazetylase \\
\hline HHV & human herpes virus (Humanes Herpesvirus) \\
\hline HMT & Histonmethyltransferase \\
\hline
\end{tabular}


HOP

ICAM

IFN

$\operatorname{Ig}$

IL

LFB

MAG

MBP

MEF

MHC

MOG

mRNA

MRT

MS

NAD

NES

Nogo

OL

OPC

PAS

PBS

PLP

PP-MS

PPWM homodomain-only protein

intercellular adhesion molecule (interzelluläres Adhäsionsmolekül)

Interferon

Immunglobulin

Interleukin

luxol-fast-blue

myelin-associated glycoprotein (Myelin-assoziiertes Glykoprotein)

myelin-basic protein (Myelin-basisches Protein)

myocyte enhancer factor

major histocompatibility complex (Haupthistokompatibilitätskomplex)

myelin oligodendrocyte glycoprotein

(Myelin-Oligodendroglia-Glykoprotein)

messenger RNA (Boten-RNA)

Magnetresonanztomographie

Multiple Sklerose

Nikotinsäureamid- Adenin-Dinukleotid

nuclear export signal (nukleäres Exportsignal)

neurite outgrowth inhibitory protein

(Neuriten-wachstumshemmendes Protein)

Oligodendrozyt(-en)

oligodendrocyte precursor cell (Oligodendrozyten-Vorläuferzelle)

periodic-acid-Schiff-reaction (Perjodsäure-Schiff-Reaktion)

phosphate buffered saline (Phosphat-gepufferte Salzlösung)

proteolipid protein (Proteolipid-Protein)

primary-progressive multiple sclerosis

(primär chronisch-progrediente Multiple Sklerose)

periplaque white matter (die Läsion umgebende weiße Substanz) 
PR-MS

progressive-relapsing multiple sclerosis

(progredient-schubförmige Multiple Sklerose)

$\mathrm{RM}$

Remyelinisierung

RR-MS

relapsing-remitting multiple sclerosis

(schubförmige Multiple Sklerose)

SD

standard deviation (Standardabweichung)

SP-MS

secondary-progressive multiple sclerosis

(sekundär chronisch-progrediente Multiple Sklerose)

TBS

TRIS buffered saline (Tris-gepufferte Salzlösung)

Tн1-Zellen

T-Helfer-1-Zellen

TNF

tumor necrosis factor (Tumornekrosefaktor)

VCAM-1

vascular cell adhesion molecule-1 (vaskuläres Zelladhäsionsmolekül-1)

VEP

visuell evoziertes Potenzial

VPA

valproic acid (Valproinsäure)

ZNS

zentrales Nervensystem 


\section{Abbildungsverzeichnis}

Abbildung 1: $\quad$ Darstellung der Remyelinisierung in der LFB-PAS-Färbung

Abbildung 2: $\quad$ Darstellung der Oligodendrozytendifferenzierung mit den stadienabhängig vorkommenden Markern nach Espinosa-Jeffrey et al. (2009) 33

Abbildung 3: $\quad$ Vergleich der CNP-Expression 44

Abbildung 4: $\quad$ Dichte von $\mathrm{CNP}^{+}$-Fasern und -zellen in den jeweiligen Stadien der Remyelinisierung 44

Abbildung 5: Dichte von $\mathrm{MAG}^{+}$-Fasern und -zellen 45

Abbildung 6: Dichte von $\mathrm{MAG}^{+}$-Fasern und $\mathrm{MAG}^{+}$-Zellen in den jeweiligen Stadien der Remyelinisierung 46

Abbildung 7: Dichte von $\mathrm{MOG}^{+}$-Fasern und -zellen 47

Abbildung 8: Dichte von $\mathrm{MOG}^{+}$-Fasern und -zellen in den jeweiligen Stadien der Remyelinisierung 48

Abbildung 9: Stadienunabhängiges Vorhandensein von Nogo- $\mathrm{A}^{+}$- Oligodendrozyten ... 48

Abbildung 10: Dichte von Nogo-A ${ }^{+}$-Zellen in den Stadien der Remyelinisierung ......... 49

Abbildung 11: Dichte von $\mathrm{MBP}^{+}$-Fasern 50

Abbildung 12: Dichte von $\mathrm{MBP}^{+}$-Fasern und $\mathrm{MBP}^{+}$-Zellen in den jeweiligen Stadien der Remyelinisierung

Abbildung 13: Expression von $\mathrm{HDAC1}^{+} / \mathrm{Nogo}^{-} \mathrm{A}^{+}-\mathrm{Zellen}$ in den Stadien ohne Remyelinisierung 53

Abbildung 14: HDAC1/Nogo-A-Doppelmarkierungen in remyelinisierten Läsionen 55 
Abbildung 15: Doppelmarkierungen HDAC1/Nogo A 56

Abbildung 16: Prozentualer Anteil $\mathrm{HDAC1}^{-} \mathrm{Nogo}^{-} \mathrm{A}^{+}$-Zellen an Gesamt-Nogo-A ${ }^{+}$-Zellen in den Läsionen 57

Abbildung 17: Graphische Darstellung der HDAC1-Expression im PPWM 59

Abbildung 18: Graphische Darstellung der $\mathrm{H}^{-} \mathrm{N}^{+}$-Zellen im PPWM 59 


\section{Tabellenverzeichnis}

Tabelle 1: $\quad$ Läsionsaktivität nach Lucchinetti et al. (1996) ........................... 5

Tabelle 2: $\quad$ McDonald-Kriterien zur Diagnose der Multiplen Sklerose .................... 12

Tabelle 3: $\quad$ Klinische Daten der untersuchten Patienten ........................... 27

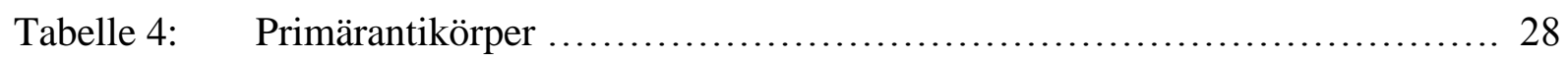

Tabelle 5: $\quad$ Sekundärsysteme für die Immunhistochemie ........................... 28

Tabelle 6: Chromogene, Substrate und sonstige Chemikalien ..................... 29

Tabelle 7: $\quad$ Lösungen und Puffer ................................................ 29

Tabelle 8: $\quad$ Stadien der Remyelinisierung ................................... 42

Tabelle 9: Dichte oligodendroglialer Zellen und Myelinfasern ...................... 51

Tabelle 10: $\quad$ HDAC1-Expression in den Läsionen ................................... 57

Tabelle 11: $\quad$ HDAC1-Expression in den Läsionen, Fälle ohne RM zusammengefasst ...... 57

Tabelle 12: $\quad$ HDAC1-Expression im PPWM ...................................... 58

Tabelle 13: HDAC1-Expression im PPWM, Fälle ohne RM zusammengefasst ........... 59

Tabelle 14: Tabellarische Aufstellung aller untersuchter Biopsien .................... 76

Tabelle 15: Quantifizierung der Myelinproteine ................................. 77

Tabelle 16: HDAC1-Expression in der Läsion (Rohdaten) ......................... 78

Tabelle 17: HDAC1-positive Oligodendrozyten in der Läsion ......................... 79

Tabelle 18: $\quad$ HDAC1-Expression im PPWM (Rohdaten) ........................... 80

Tabelle 19: HDAC1-positive Oligodendrozyten im PPWM .......................... 81 


\section{Einleitung}

\subsection{Multiple Sklerose}

\subsubsection{Epidemiologie und Ätiologie der Multiplen Sklerose}

Bei der Multiplen Sklerose (MS), auch als Polysklerose, Encephalomyelitis disseminata oder Sclerosis multiplex bezeichnet, handelt es sich mit einer Inzidenzrate von 3-7/100.000 und einer Prävalenzrate von bis zu 150:100.000 um eine der häufigsten organischen Krankheiten des zentralen Nervensystems (Poeck und Hacke 2006). Allein in Deutschland verzeichnet man um die 122.000 MS-Fälle, welches einer Prävalenz von 149,1 pro 100.000 Einwohner entspricht (Hein und Hopfenmüller 2000). So leiden rund $8 \%$ der Patienten, die in neurologischen Kliniken in unseren Breitengraden behandelt werden, an Multipler Sklerose. Dabei zeigt sich, dass Frauen an dem schubweisen Verlauf doppelt so häufig erkranken wie Männer, jedoch bei der chronisch progressiven Multiplen Sklerose kein Quantitätsunterschied zu finden ist (Poeck und Hacke 2006).

Die Multiple Sklerose manifestiert sich vornehmlich zwischen dem 20. und 40. Lebensjahr, kann jedoch schon in der Pubertät auftreten, und zeigt eine kontinuierliche Abnahme ab dem 45. Lebensjahr bis zur oberen Grenze von 60 Jahren (Poeck und Hacke 2006).

Weltweit liegen bei der Prävalenz der Multiplen Sklerose geographische Verteilungsschwankungen vor. Grundsätzlich lässt sich dennoch in Europa, Nordamerika und zum Teil in Asien von einem Nordpol-Äquator-Gefälle sprechen, d.h. die Erkrankungshäufigkeit bei zumeist Angehörigen der weißen Rasse nimmt mit der Entfernung zum Äquator zu (Heckl 1994). So liegt die Prävalenz in Europa nördlich des 46. Breitengrades und in den Vereinigten Staaten oberhalb des 38. Breitengrades deutlich höher als südlich davon (Poeck und Hacke 2006). Dieses Gefälle findet sich ebenso in der nichtweißen Bevölkerung, allerdings in viel geringerem Ausmaß, sowie auf der Südhalbkugel. Ein deutliches Südpol-Äquator-Gefälle zeigt sich in Südamerika und insbesondere in Australien und Neuseeland (Skegg et al. 1987). 
Von diesem Verteilungsgrundsatz unabhängig wurden in bestimmten Ländern, vor allem den skandinavischen, Regionen mit starker Häufung von Multiple-Sklerose-Fällen beschrieben, sogenannte clusters (Heckl 1994). Demgegenüber stehen Bevölkerungsgruppen, wie die Maoris in Neuseeland, die Bantus in Südafrika (Dean 1967) oder die Eskimos, bei denen die Multiple Sklerose beinahe unbekannt ist (Skegg et al. 1987).

Mit diesen epidemiologischen Daten als Grundlage kann bei der Ätiologie der Multiplen Sklerose, die bisher noch nicht vollständig geklärt ist, sowohl auf eine genetische Prädisposition als auch auf den exogenen Einfluss von Umweltfaktoren geschlossen werden. Wurden diese beiden Ursachen vor einiger Zeit noch als Alternativen behandelt, geht man heute von einem Zusammenspiel der beiden Faktoren aus.

Hinweise auf den Einfluss der Umwelt geben Migrationsstudien. So tragen Einwanderer, die ihr Geburtsland in frühester Kindheit verlassen, das Erkrankungsrisiko des jeweiligen Einwanderungslandes. Bei einer Migration nach dem 15. Lebensjahr nimmt der Einwanderer das Risiko seines Heimatlandes mit. Dieser Unterschied verwischt mit der folgenden Generation (Dean 1967; Poeck und Hacke 2006). Ob diese geographische Verteilung jedoch mit den Bedingungen der Lebens- und Ernährungsweise oder mit der Exposition gegenüber bestimmten Infektionen zusammenhängt, konnte noch nicht befriedigend geklärt werden. So wurde in vielen Studien der Einfluss unterschiedlichster Erreger, wie des Epstein-BarrVirus (Cepok et al. 2005), der Chlamydia pneumoniae (Tang YW et al. 2009) oder des humanen Herpesvirus 6 (HHV-6) (Clark 2004) untersucht und diskutiert.

Demgegenüber stehen der Beitrag der genetischen Faktoren und die Tatsache, dass eine familiäre Häufung von Multiple-Sklerose-Fällen seit langem bekannt ist. Insbesondere für Verwandte ersten Grades ist das Risiko zu erkranken stark erhöht (Carton et al. 1997). Ebenso zeigen Zwillingsstudien bei monozygoten Zwillingen eine Konkordanzrate von ca. 25\%, bei dizygoten eine von ca. 3\% (Carton et al. 1997; Thorpe et al. 1994). Bei der Identifizierung der betreffenden Gene wurde eine Assoziation zu den MHC-Klasse-IIAllelen DR15 und DQ6 sowie DR4 (Olerup und Hillert 1991) vermutet. 


\subsubsection{Pathogenese}

Wie oben bereits erwähnt, sind die genaue Ätiologie und Pathogenese der Multiplen Sklerose bis dato nicht bekannt. Jedoch weisen viele Befunde darauf hin, dass es sich bei dieser chronisch inflammatorischen Erkrankung um eine T-Zell-vermittelte Autoimmunerkrankung handelt. So ist die Morphologie einer aktiven Läsion, gekennzeichnet durch perivaskuläre Zellinfiltration und vermehrte Lymphozyten, die in das umgebende Parenchym auslaufen, kaum zu unterscheiden von Entzündungsarealen, die bei erwiesenen Autoimmunerkrankungen zu sehen sind. Auch der umgekehrte Rückschluss durch die relativ erfolgreiche Therapie, die auf einer Suppression des Immunsystems basiert, erhärtet die Hypothese einer Autoimmunerkrankung (McAlpine et al. 2005).

Vermutlich kommt es durch ein noch unbekanntes Agens in der Peripherie zu einer Aktivierung autoreaktiver T-Lymphozyten. Als Auslöser werden hierbei Autoantigene, insbesondere das Myelin-Oligodendroglia-Glykoprotein (MOG) (Lindert et al. 1999) sowie das Myelin-basische Protein (MBP) diskutiert. So konnten MBP-spezifische T-Zellen aus dem peripheren Blut von Multiple-Sklerose-Patienten isoliert werden (Pette et al. 1990). Eine zweite Hypothese verweist auf kreuzreaktive Fremdantigene, insbesondere auf Virusinfektionen. Obwohl unlängst mehrere Erreger, unter anderem EBV, HHV-6 und Chlamydia pneumoniae, in Betracht gezogen worden sind, konnte noch kein Beweis erbracht werden (Swanborg et al. 2003).

Wurden die T-Lymphozyten in der Peripherie nun aktiviert, wandern sie Richtung zentrales Nervensystem und überwinden die Blut-Hirn-Schranke, indem sie mittels ihres VLA-4Integrins an die, von den Endothelzellen nun vermehrt exprimierten, Adhäsionsmoleküle, wie VCAM-1 (vascular cell adhesion molecule), binden. Diese Interaktion führt gleichzeitig zu einer Bildung sowie Sekretion von Gelatinase-Enzymen durch T-Lymphozyten, welche es den Lymphozyten erleichtern, die perivaskuläre Basalmembran aufzubrechen und in das umgebende Gewebe einzudringen (Hartung und Kieseier 2000). Im ZNS folgt nach der Erkennung des spezifischen Antigens die Sekretion proinflammatorischer Zytokine, wie IFNY, TNF- $\alpha$ und IL-12, und die konsekutive Aktivierung von Makrophagen und Mikroglia. Hierbei 
konnte gezeigt werden, dass die Expression von IFNY, TNF- $\alpha$ und IL-12 mit der Erkrankungsaktivität und -schwere korreliert (Issazadeh et al. 1998). Die induzierten Gliazellen beginnen daraufhin mit der Synthese und Expression von MHC-Produkten und costimulatorischen Molekülen, sowie die Endothelzellen mit der Hochregulation von Adhäsionsmolekülen wie ICAM (intercellular adhesion molecule) oder VCAM (Vass und Lassmann 1990, Wilcox et al. 1990). Sie gelangen dadurch in einen aktivierten Zustand, der für die folgende Rekrutierung weiterer Entzündungszellen über die Blut-Hirn-Schranke unentbehrlich ist. Nun können andere Bestandteile des Immunsystems, wie B-Zellen, Antikörper oder Komplementfaktoren, eindringen und die Entzündungsreaktion erhalten. Es konnte gezeigt werden, dass CD8+-T-Zellen das T-Lymphozyteninfiltrat einer aktiven Läsion zwar dominieren, jedoch auch CD4+-T-Zellen mit ihrer Sekretion von Zytokinen, wahlweise IFN $\gamma$, TNF- $\alpha$ und IL-2 durch TH1-Zellen zur Rekrutierung von Makrophagen, oder IL-4 und 10 durch TH2- Zellen zur Förderung der B-Zelldifferenzierung und Antikörperproduktion, eine große Rolle spielen (Babbe et al. 2000). Folge ist letztlich die beginnende Demyelinisierung, einerseits durch die direkte Wirkung der zytotoxischen T-Zellen, andererseits durch die toxischen Produkte aktivierter Mikroglia und Makrophagen. Reaktiv kommt es zur Astrogliose mit Zellhypertrophie und erhöhter GFAP-Expression. Später kann in einigen Fällen eine Remyelinisierung beobachtet werden (siehe S. 15).

Neben diesen Charakteristika der Multiplen Sklerose muss ein weiteres Augenmerk auf den Verlust von Axonen und Neuronen, gemeinhin als "Neurodegeneration“ bezeichnet, fallen, welcher bereits in den frühen Phasen, insbesondere in Läsionen mit aktiver Demyelinisierung, zu beobachten ist und das pathologische Substrat der neurologischen Symptome darstellt (Kuhlmann et al. 2002, De Stefano et al. 2001). Weiterhin bleibt die genaue Pathogenese der Multiplen Sklerose jedoch ungeklärt. So wird auch ein Ablauf diskutiert, bei dem Oligodendrozytenverlust und Myelinzerstörung als primäres Ereignis aufgefasst werden, welches von lokaler Mikrogliaaktivierung und Proliferation, und erst zuletzt durch Invasion von Entzündungszellen gekennzeichnet ist (Barnett et al. 2006, Henderson et al. 2009).

Die entstandenen Läsionen lassen sich dabei nach ihrer Aktivität in verschiedene, 
nacheinander ablaufende Stadien unterteilen. Die Einteilung in früh aktive, spät aktive, inaktive, früh remyelinisierende oder spät remyelinisierende Läsionen erfolgt anhand von Myelinabbauprodukten in Makrophagen und der Expression der MakrophagenAktivierungsmarker MRP14 und 27E10 (Brück et al. 1994, 1995; Lucchinetti et al. 1996).

\begin{tabular}{|l|c|c|c|c|c|c|c|}
\hline & MOG & PLP & LFB & PAS & Vakuolen & Makrophagenmarker & Remyel. \\
\hline Früh aktiv & +++ & +++ & ++ & - & - & MRP14/27E10 & - \\
\hline Spät aktiv & - & +++ & ++ & - & - & $27 E 10$ & - \\
\hline Inaktive & - & - & - & $+/-$ & $+/-$ & - & - \\
\hline $\begin{array}{l}\text { Früh } \\
\text { remyelinisierend }\end{array}$ & - & $+/-$ & $+/-$ & + & + & - & ++ \\
\hline $\begin{array}{l}\text { Spät } \\
\text { remyelinisierend }\end{array}$ & - & - & - & $+/-$ & $+/-$ & & +++ \\
\hline
\end{tabular}

Tabelle 1: Läsionsaktivität nach Lucchinetti et al. (1996), S. 262;

MOG = Myelin-Oligodendroglia-Glykoprotein, PLP = Proteolipid-Protein, LFB = luxol-fastblue, $\mathrm{PAS}=$ periodic-acid-Schiff- reaction, Vakuolen = leere Vakuolen (neutrale Lipide)

Früh aktive Läsionen finden sich gehäuft an der Grenze zwischen bereits demyelinisierter Plaque und der weißen Substanz. Sie sind infiltriert von zahlreichen Makrophagen, welche Myelinabbauprodukte enthalten, die sich sowohl mit LFB als auch mit weniger häufigen Myelinproteinen wie CNP (2'-3'-zyklische-Nukleotid-3'-Phosphodiesterase) und MOG anfärben lassen. Ebenso findet sich die Expression der Makrophagen-Aktivierungsmarker MRP14 und 27E10.

Die spät aktiven Läsionen, den früh aktiven sehr ähnlich, zeigen einen bereits fortgeschrittenen Myelinabbau in den Makrophagen. Dadurch ist eine Immunreaktivität der mengenmäßig häufigeren Proteine wie MBP und PLP, deren Abbau bis zu zehn Tagen dauern kann, noch erhalten, die Reaktion für CNP und MOG ist jedoch negativ. Diese weniger häufigen Myelinproteine werden innerhalb von 1-2 Tagen nach Myelinphagozytose abgebaut. Zugleich findet sich in diesen Läsionen nur noch der Aktivierungsmarker 27E10. 
Inaktive Läsionen wiederum zeigen eine vollständige Demyelinisierung sowie eine Infiltration mit T-Lymphozyten und Makrophagen, wobei letztere entweder leere Vakuolen oder PAS-positive Abbauprodukte enthalten.

In dem folgenden möglichen Stadium, der früh remyelinisierenden Läsion, bleibt das Zellbild bestehen. Einzelne Makrophagen mit Myelinabbauprodukten können noch vorhanden sein. Charakterisierend sind die Gruppen von Axonen, die von neugebildeten, sehr feinen Myelinscheiden umgeben sind.

Die spät remyelinisierenden Läsionen, auch shadow-plaques genannt, zeigen nur noch wenige Makrophagen, dafür eine ausgeprägte astrozytäre Gliose. Die Remyelinisierung ist vorangeschritten, weist jedoch im Vergleich zur umgebenden normalen weißen Substanz aufgrund der dünneren Myelinscheiden eine verminderte und unregelmäßige Dichte auf.

\subsubsection{Pathologie}

Makroskopisch zeigt die Multiple Sklerose zahlreiche, relativ scharf abgegrenzte Entmarkungsherde (Plaques) wechselnder Größe, die über das gesamte ZNS verteilt sein können. Prädilektionstellen betreffen den N.opticus, die periventrikuläre weiße Substanz, das C. callosum, das Zerebellum und das Zervikalmark. In der frühen Phase sind diese Herde weich und von grau-rötlicher Farbe. Im Verlauf werden sie durch Konsistenzzunahme aufgrund von Gliawucherung jedoch hart und grau. Im Herd finden sich zentral häufig ein kleines Gefäß sowie fingerähnliche Ausläufer der Entmarkung in die Peripherie, welche dem Verlauf der Gefäße folgen (Dawson 1916).

Mikroskopisch zeigen die Läsionen ein heterogenes Bild. Abhängig vom Alter dominieren perivaskuläre Infiltration von Entzündungszellen, Demyelinisierung oder reaktive Astrogliose das Bild. Anhand zahlreicher Untersuchungen von Läsionen konnte gezeigt werden, dass sich die Histopathologie von Patient zu Patient unterscheiden kann. Betrachtet man dagegen verschiedene Läsionen bei ein und demselben Fall, zeigen sich ähnliche pathologische Veränderungen. Basierend auf dieser Untersuchung ließen sich vier verschiedene 
Läsionsmuster bezüglich ihrer immunopathologischen Erscheinung charakterisieren (Lucchinetti et al. 2000).

Muster I ist assoziiert mit einer T-Lymphozyten- und Makrophagen-dominierten Entzündung. Die demyelinisierten Plaques sind scharf abgegrenzt und um kleine Venen oder Venulen zentriert. Der Oligodendrozytenverlust ist begrenzt auf die Demyelinisierung. Außerdem findet eine schnelle, ausgeprägte Remyelinisierung statt.

Muster II zeigt wie I zahlreiche T-Lymphozyten sowie Makrophagen. Der Unterschied liegt in der ansehnlichen Ablage von Immunglobulinen, überwiegend IgG, und Komplement-C9Neoantigen an Orten aktiven Myelinabbaus.

Auch Muster III enthält zahlreiche T-Lymphozyten, Makrophagen und aktivierte Mikroglia, jedoch fehlt die Ig- und Komplement-Ablagerung gänzlich. Ebenso auffällig ist ein häufig beobachteter Rand von Myelin, der die entzündete Vene innerhalb des demyelinisierten Areals umgibt. Die Grenzen der Läsion sind unscharf mit einer diffusen Ausbreitung in die umgebende normale weiße Substanz. Charakteristikum dieses Musters ist der vorrangige Verlust von MAG (Myelin-assoziiertes Glykoprotein) bei Erhalt der übrigen Myelinproteine wie MOG, MBP oder PLP. Es finden sich ein ausgeprägter Oligodendrozytenverlust, auch bezeichnet als distale Oligodendrogliopathie, an der Grenze zwischen aktiver Läsion und umgebender weißer Substanz sowie ein inaktives Zentrum, in dem kaum Oligodendrozyten vorhanden sind. Das Remyelinisierungspotenzial ist gering.

Muster IV ist gekennzeichnet durch einen Oligodendrozytenverlust in einem kleinen Streifen von periplaque white matter (PPWM), welcher an die Zone der aktiven Demyelinisierung angrenzt. Hierbei zeigen die Oligodendrozyten jedoch nicht, wie in Muster III, die typischen morphologischen Merkmale einer Apoptose. Die Läsion ist scharf begrenzt und zeigt eine fehlende Remyelinisierung

Diese histopathologische Heterogenität weist möglicherweise auf eine variable Pathogenese der Multiplen Sklerose hin. Es bleibt jedoch noch unklar, ob sich diese Muster während des Fortschreitens der Erkrankung konstant halten oder sich im Verlauf verändern. 


\subsubsection{Verlaufsformen}

Bezogen auf den zeitlichen Ablauf sowie die unterschiedliche Ausprägung kann die Multiple Sklerose in verschiedene Verlaufsformen unterteilt werden, welche von Lublin und Reingold (1996) beschrieben wurden. Bei über 80\% der Patienten findet sich zu Beginn der Krankheit ein schubförmiger Verlauf. Als Schub wird dabei generell ein erstes Anzeichen oder die Reaktivierung bzw. Verschlechterung von zuvor aufgetretenen Symptomen bezeichnet, die meist subakut auftreten und sich einige Zeit halten. Schließlich folgt eine teilweise oder komplette Erholung. Bedingungen dabei sind, dass die Gesamtdauer über 24 Stunden beträgt und das Intervall zu einem vorausgegangenen Schub $\geq 30$ Tage beträgt (McDonald et al. 2001). Abzugrenzen davon ist der Pseudoschub. Hierbei handelt es sich um die vorübergehende Verschlechterung neurologischer Symptome aufgrund der Erhöhung der Körpertemperatur (Uhthoff-Phänomen) durch Hitze, Fieber oder körperliche Anstrengung (Uhthoff 1890).

Häufigste Form ist somit die relapsing-remitting Multiple Sklerose (RR-MS), die durch klar definierte Schübe mit häufig vollständiger Remission gekennzeichnet ist. In der schubfreien Zeit findet sich kein Fortschreiten der Krankheit. Nach vielen Jahren geht diese Verlaufsform bei den meisten Patienten in die sekundär chronisch-progrediente Form (SP-MS) über. Nach dem vorerst schubförmigen Verlauf kommt es zur Krankheitsprogression mit oder ohne gelegentliche Schübe sowie leichten Remissionen und Plateaus. Die dritte Form stellt die primär chronisch-progrediente Multiple Sklerose (PP-MS) dar, welche eine Krankheitsprogression von Beginn an aufweist. Sie tritt bei rund 15\% der Patienten auf. Zeitweise kann es zu geringer Remission sowie Plateauphasen kommen. Als letztes findet sich in einigen Fällen die progredient-schubförmige MS (PR-MS). Sie ist gekennzeichnet durch ein von Beginn an chronisches Fortschreiten, welches durch akute Schübe ohne oder mit vollständiger Remission unterbrochen werden kann. 


\subsubsection{Klinik}

Gleich dem klinischen Verlauf der Multiplen Sklerose sind auch die Symptome nicht vorhersehbar und weisen individuelle Variabilität auf. Selbst auf einen einzelnen Patienten bezogen, können sich zu verschiedenen Zeiten, bedingt durch das Auftreten neuer Läsionen, unterschiedliche Symptomkomplexe zeigen.

Dabei ist, abhängig von der Lokalisation der Schädigung im zentralen Nervensystem, jede Art der neurologischen Störung möglich. Initial finden sich häufig motorische und sensible Störungen, welche sich unter anderem in Form von Schwäche in einem oder mehreren Gliedmaßen, Parästhesien, Schmerz, spastischem Muskeltonus, Reflexverlust, Diplopie oder einer retrobulbären Optikusneuritis äußern (McAlpine et al. 1972). Bei Befall des Kleinhirns kann es zu der bereits im 19. Jahrhundert von Charcot beschriebenen und einst als pathognomonisch geltenden typischen Trias von Nystagmus, Intentionstremor und skandierender Sprache kommen (Charcot 1868).

Ebenso augenfällig sind das Lhermitte-Zeichen, welches das Auftreten elektrisierender Missempfindungen entlang der Wirbelsäule und in die Arme bei kräftigem Beugen des Nackens aufgrund von Demyelinisierungsherden im Spinalmark bezeichnet (Lhermitte et al. 1924) sowie das bereits oben erwähnte Uhthoff-Phänomen, von dem mehr als $80 \%$ der Erkrankten betroffen sind (Guthrie und Nelson 1995).

Weitere, häufig auftretende Symptome sind Augenmotilitätsstörungen, vegetative Anzeichen wie Blasen- und Mastdarmstörungen und psychische Erscheinungen, wobei insbesondere die Kognition und der Affekt betroffen sind. Es konnte gezeigt werden, dass es in rund $45 \%$ der Fälle während der Krankheitsentwicklung zu einem teilweisen Verlust der intellektuellen Fähigkeit kommt (Rao et al. 1991). Zudem tritt bei $78 \%$ der Patienten im Verlauf das Fatigue-Syndrom auf, welches einen ausgeprägten allgemeinen Erschöpfungszustand beschreibt, der sich typischerweise über den Tag stetig verschlechtert (Iriarte et al. 2000).

Während bei etwa einem Drittel die benigne Form der Multiplen Sklerose vorliegt, die selbst nach Jahren nur mit minimalen Behinderungen, welche kaum den Lebensalltag einschränken, einhergeht (McAlpine 1964), sterben andere wiederum bereits nach 
kurzer Zeit nach Ausbruch der Krankheit, bedingt durch massive Demyelinisierung oder Befall der Medulla mit konsekutivem respiratorischen Versagen (Barnett und Prineas 2004).

Bleibt die genaue Entwicklung der Krankheit auch unvorhersehbar, so ist es dennoch möglich, das aktuelle Ausmaß und den Schweregrad der Behinderung anhand der von Kurtzke (1983) entwickelten Leistungsskala EDSS (expanded disability status scale) festzuhalten. Dabei müssen für die Ermittlung des EDSS die Beeinträchtigungen von sieben funktionellen Systemen (Pyramidenbahn, zerebelläre Funktion, Sensorik, Blasen-und Mastdarmfunktion, zerebrale Funktion, Funktion des visuellen Systems) dokumentiert werden.

\subsubsection{Diagnostik}

In den wenigsten Fällen reicht allein das klinische Bild des Patienten zur Diagnosesicherung von Multipler Sklerose aus. Vielmehr werden auf Basis der Klinik Überlegungen bezüglich der Art und des Spektrums weiterer Diagnostik gemacht. Dabei wird in den meisten Fällen auf die gängigen Untersuchungsmethoden wie Bildgebung, Aufzeichnung evozierter Potenziale und Liquoruntersuchung zurückgegriffen (McAlpine et al. 2005). Bei der Liquoruntersuchung können bei über 95 \% der Patienten in der isoelektrischen Fokussierung oligoklonale Banden nachgewiesen werden (Andersson et al. 1994). Eine zweite, weniger verwendete Methode ist der IgG-Index (Liquor-IgG: Serum-IgG/ Liquor-Albumin: Serum-Albumin), welcher bei Werten über 1,7 auf Multiple Sklerose hinweist (Link und Tibbling 1977). Für diese Untersuchungen konnte eine hohe Sensitivität und Spezifität gezeigt werden (Brasher et al. 1998). Ebenfalls finden sich bei einem Drittel aller Patienten, insbesondere jenen mit akutem Verlauf oder Exazerbationen, mittelgradige Pleozytosen von 10-20 Zellen/ $\mathrm{cm}^{3}$ (Adams und Tourtellotte 1983). Die Aufzeichnung evozierter Potenziale kann visuell, auditorisch oder (somato-)motorisch erfolgen (Halliday et al. 1973; Chiappa 1980; Trojaborg und Petersen 1979).

Die meistgenutzte Untersuchungsmethode ist jedoch das MRT, da es im Gegensatz zur Liquoruntersuchung und den evozierten Potenzialen gleich bei Erkrankungsbeginn Pathologien im Gehirn aufzeigen kann (Masuhr und Neumann 2007). 
Da kein einziges Laborprozedere, wenn es allein oder nur zu einer Zeit betrachtet wird, einen absolut zuverlässigen Beweis zur Diagnose der MS darstellt, wird diese mit Hilfe der Kriterien nach McDonald et al. (2001), revidiert nach Polman et al. (2011), gestellt. Für sie konnte sowohl eine hohe Sensitivität als auch Spezifität gezeigt werden (Swanton et al. 2006). Bei der folgenden Diagnosemitteilung an die Patienten ziehen diese meist eine frühe Krankheitsaufklärung und Diskussion der Diagnose vor, selbst wenn diese noch nicht gänzlich bestätigt worden ist (Heesen et al. 2003, Strasser-Fuchs et al. 1997). 


\begin{tabular}{|c|c|}
\hline Klinische Präsentation & $\begin{array}{l}\text { Weitere erforderliche Kriterien zur } \\
\text { Diagnoseerhebung }\end{array}$ \\
\hline $\begin{array}{l}\geq 2 \text { Schübe; objektivierbare klinische Evidenz } \\
\text { von } \geq 2 \text { Läsionen oder } 1 \text { Läsion mit } \\
\text { begründeter historischer Evidenz eines } \\
\text { früheren Schubs }\end{array}$ & Keine \\
\hline $\begin{array}{l}\geq 2 \text { Schübe; objektivierbare klinische Evidenz } \\
\text { einer Läsion }\end{array}$ & $\begin{array}{l}\text { Räumliche Dissemination(DIS) demonstriert durch: } \\
\geq 1 \text { T2-Läsion in mindestens } 2 \text { von } 4 \text { MS-typischen } \\
\text { Regionen des ZNS (periventrikulär, juxtakortikal, } \\
\text { infratentoriell oder RM) } \\
\text { oder } \\
\text { weiterer klinischer Schub ein anderes Gebiet des ZNS } \\
\text { einbeziehend }\end{array}$ \\
\hline $\begin{array}{l}1 \text { Schub; objektivierbare klinische Evidenz von } \\
\geq 2 \text { Läsionen }\end{array}$ & $\begin{array}{l}\text { Zeitliche Dissemination (DIT) demonstriert durch: } \\
\text { Gleichzeitiges Vorhandensein von asymptomatischen } \\
\text { Gadolinium-anreichernden und nicht anreichernden } \\
\text { Läsionen } \\
\text { oder } \\
\text { eine neue T2- und/oder Gadolinium-anreichernde } \\
\text { Läsion im Verlaufs-MRT, unabhängig von seinem } \\
\text { Zeitpunkt in Bezug auf das Baseline-MRT } \\
\text { oder } \\
\text { zweiter klinischer Schub }\end{array}$ \\
\hline $\begin{array}{l}\text { 1 Schub; objektivierbare klinische Evidenz } \\
\text { einer Läsion (CIS) }\end{array}$ & $\begin{array}{l}\text { Räumliche und zeitliche Dissemination demonstriert } \\
\text { durch: } \\
\text { DIS: Anforderungen s.o. } \\
\text { DIT: Anforderungen s.o. }\end{array}$ \\
\hline Verdachtsdiagnose PPMS & $\begin{array}{l}\text { Krankheitsprogression für } 1 \text { Jahr (retrospektiv oder } \\
\text { prospektiv festgelegt) plus } 2 \text { von } 3 \text { der folgenden } \\
\text { Kriterien: } \\
\text { 1. Evidenz für DIS im Gehirn basierend auf } \geq 1 \text { T2- } \\
\text { Läsion in MS-typischen Regionen } \\
\text { 2. Evidenz für DIS im Rückenmark basierend auf } \geq 2 \\
\text { Läsionen } \\
\text { 3. Positive CSF (Oligoklonale Banden und/oder } \\
\text { erhöhter IgG-Index) }\end{array}$ \\
\hline
\end{tabular}

Tabelle 2: McDonald-Kriterien zur Diagnose der Multiplen Sklerose (revidiert nach Polman et al. 2011), S. 297 


\subsubsection{Therapie}

Da die Ätiologie der Multiplen Sklerose nicht vollständig geklärt ist, gibt es zurzeit noch keine kausale Therapie. Die Behandlung erfolgt daher symptomatisch und krankheitsmodifizierend und lässt sich in eine Schubtherapie, immunmodulierende Langzeittherapie und Behandlung von körperlichen sowie psychischen Beschwerden unterteilen. Ziel dabei ist es, dem Patienten die bestmögliche Lebensqualität zu sichern und ihm seine Unabhängigkeit möglichst lange zu erhalten.

Im akuten Schub sollte sich der Patient, wenn möglich, wie bei allen akuten entzündlichen Krankheiten, ausruhen, bis sich die Symptome bessern. Es konnte gezeigt werden, dass körperliche Aktivität während des Bestehens einer akuten Entzündung zu irreversiblen axonalen Schädigungen führen kann (Smith et al. 2001).

Bei der Therapie des akuten Schubs ist die Gabe von hochdosierten, intravenös verabreichten Glukokortikoiden über 3 bis 5 Tage erste Wahl (Barnes et al. 1985; Ohno et al. 1987). Diese wirken antiinflammatorisch über die beschleunigte Eliminierung von Entzündungszellen durch Apoptosemechanismen, eine Reduzierung der T-Helferzellen-1Zytokinproduktion durch aktivierte T-Zellen (Leussink et al. 2001) und über eine Stabilisierung der Blut-Hirn-Schranke (Burnham et al. 1991; Rosenberg et al. 1996). Zudem konnte gezeigt werden, dass unter der Gabe von Methylprednisolon die Level von Stickoxiden im Serum und in der zerebrospinalen Flüssigkeit gesenkt werden und es zu einer reduzierten intrathekalen IgG-Synthese sowie herabgesetzten Produktion von Antimyelin-AK kommt (Durelli et al. 1986; Warren et al. 1986). Auch wenn Glukokortikoide im akuten Schub wirkungsvoll sind, konnte für sie kein Effekt auf den Langzeitverlauf der Krankheit gezeigt werden (Milligan et al. 1987). Vielmehr wiesen Martínez-Cáceres et al. (2002) nach, dass kortikoid-bedingte Veränderungen in der Lymphozytenpopulation, IFNY-Produktion, Chemokinexpression sowie weiteren immunologischen Funktionen sechs Monate nach Therapieende nicht mehr sichtbar und somit nur vorübergehend waren. Bei Versagen der Glukokortikoidtherapie oder schwierigen Fällen mit schwerer, lebensbedrohlicher Symptomatik kann eine Plasmapherese in Betracht gezogen werden, 
welche in etwa 40\% der Fälle Erfolg verzeichnen kann (Weinshenker et al. 1999, Keegan et al. 2002).

Bei der Schubprophylaxe und Langzeittherapie wird auf immunmodulatorische, aber auch immunsuppressiv-wirkende Substanzen, wie Mitoxantron, Azathioprin und Cyclophosphamid als Reservemittel, zurückgegriffen. Unter den immunmodulierenden Pharmaka haben sich insbesondere die $\beta$-Interferone (Jacobs et al. 2000) und Glatirameracetat (Wolinsky 2006) bewährt. Beta-Interferon, welches in Form von IFN $\beta 1 b$ (Betaferon) oder IFNß1a (Avonex bzw. Rebif) gegeben werden kann, behindert die Wirkung des proinflammatorischen IFN $\gamma$, hat einen antiproliferativen Effekt auf T- Zellen (Noronha et al. 1993) und reduziert die Expression von MHC-Klasse-II-Antigenen und Adhäsionsmolekülen (Jiang et al. 1995). Zudem konnte eine inhibierende Wirkung auf die IL1- bzw.IFNa-induzierte Produktion von Stickoxiden gezeigt werden (Hua et al. 1998). Darüber hinaus kommt es unter IFNß-Therapie zu einer herabgesetzten Migrationsfähigkeit der T-Zellen (Prat et al. 1999).

Für die Therapie der schubförmig verlaufenden Multiplen Sklerose haben sich diese Substanzen als wirkungsvoll erwiesen. Unter der Therapie mit Beta-Interferon oder Glatirameracetat konnte eine 30\%ige Reduktion der Schübe über die ersten zwei Jahre beobachtet werden (McAlpine et al. 2005). Bei der sekundär progredienten Multiplen Sklerose besteht weniger Einigkeit über die Wirkung dieser Behandlung. Während in einigen Studien ein Erfolg verzeichnet und die Schubfrequenz gesenkt werden konnte, wurde bei anderen keine positive Auswirkung beobachtet (Corboy et al. 2003, Cohen et al. 2002). Für die Therapie der primär progredienten Multiplen Sklerose konnte bisher noch kein Erfolg vermerkt werden (Leary et al. 2003).

Darüber hinaus wird symptomatisch therapiert, wobei der Patient als Ganzes gesehen werden muss und somit neben den physischen Problemen auch die psychischen betrachtet werden müssen. Für die Behandlung bieten sich dabei sowohl die Physiotherapie, Logopädie oder Ergotherapie zur Erhaltung und Maximierung verbleibender Funktionen, z.B. bei Sprech- und Schluckstörungen, als auch medikamentöse oder operative Maßnahmen an. Ebenfalls sollte eine psychologische Beratung angeboten werden und der Patient dazu motiviert werden, seinen täglichen Arbeiten und Aktivitäten, ggf. mit Hilfe und 
lebenspraktischen Übungen, weiter nachzugehen, um seine Selbstständigkeit zu fördern und seine Lebensqualität zu erhöhen.

\subsection{Remyelinisierung}

Remyelinisierung beschreibt ein Phänomen, von dem bereits in den frühen Jahren der Multiple-Sklerose-Forschung berichtet wurde (Marburg 1906). Sie ist gekennzeichnet durch eine herabgesetzte Myelindichte, dünne Markscheiden, reduzierte Axondichte und verkürzte Abstände zwischen den Internodien. Betrachtet man den Grad der Remyelinisierung, kann diese von gar nicht vorhanden, über inkomplett bis hin zu komplett sein. Die inkomplette Form findet sich dabei häufig am Läsionsrand und wird als „shadow plaque area" bezeichnet, während die komplette Remyelinisierung "shadow plaque" benannt wird (Prineas und Connell 1979). Diese Neubildung schützt die zuvor „nackten“ Axone wieder vor Angriffen, Transektionen und Zerstörung, und führt zur Wiederherstellung der axonalen Leitungsgeschwindigkeit.

Remyelinisierung tritt vielfach sehr schnell nach vorangegangener Demyelinisierung und bisweilen auch gleichzeitig mit noch vorangehendem Myelinabbau auf (Raine und Wu 1993). Findet man sie meist in einer frühen Phase der Erkrankung, ist sie doch, wie früher vermutet, nicht auf diese begrenzt, sondern zeigt sich auch in Patienten mit chronischer Multipler Sklerose (Patrikios et al. 2006).

In früh remyelinisierenden Läsionen findet sich noch eine große Anzahl von Makrophagen, die sich jedoch im Verlauf reduziert, sodass die Makrophagen in spät remyelinisierenden Läsionen kaum noch präsent sind (Brück et al. 1995). Auffällig ist zudem die starke Korrelation zwischen Remyelinisierung und dem Vorhandensein zahlreicher Oligodendrozyten, welche in ihrem Zytoplasma Myelinprotein oder Myelinprotein-mRNA exprimieren (Brück et al. 1994).

Warum einige Areale remyelinisieren und andere nicht, ist bis heute, trotz zahlreicher Theorien, ungeklärt. Prineas et al. (1993) verwiesen auf den Verlust und die Destruktion von 
Oligodendrozytenvorläuferzellen (OPC) innerhalb der Läsion, bedingt durch die wiederholten De- und Remyelinisierungen. Da jedoch auch Läsionen gefunden werden konnten, die zahlreiche Vorläuferzellen enthielten, aber in denen dennoch keine Remyelinisierung stattfand, schlugen andere eine fehlende Remyelinisierung aufgrund einer beeinträchtigten Axon-Oligodendrozyten-Interaktion (Charles et al. 2002) oder einer gestörten Reifung der Vorläuferzellen (John et al. 2002) vor. Eine weitere Hypothese geht von einer Behinderung der Remyelinisierung durch gliale Narben aus (Chang A et al. 2002). Auch ein genetischer Hintergrund wird diskutiert.

Ebenso scheint die Lokalisation der Läsion einen Einfluss auf die Remyelinisierung zu haben. Subkortikale sowie Läsionen weit in der weißen Substanz scheinen besser zu remyelinisieren als periventrikuläre. Die Ursache ist unbekannt (Patrikios et al. 2006).

Betrachtet man den Prozess der Remyelinisierung, trifft man unweigerlich auf das Schicksal der Oligodendrozyten in der Läsion, da man davon ausgeht, dass Demyelinisierung zum Teil von direkter Oligodendrozytendestruktion herrührt und das Ausmaß der Remyelinisierung vom Vorhandensein von Oligodendrozyten abhängig ist. Solange remyelinisierungsfähige Zellen in einer Läsion vorhanden sind, scheint diese auch spontan abzulaufen (Lucchinetti et al. 1999).

Bis heute bestehen kontroverse Meinungen darüber, ob die Oligodendrozyten das primäre Ziel der Immunreaktion sind oder sie mit dem Myelin zusammen während der aktiven Demyelinisierung zugrunde gehen. Die gleiche Unstimmigkeit besteht hinsichtlich der Quelle der remyelinisierenden Zellen. Die heute vorherrschenden Konzepte deuten daraufhin, dass nur Zellen aus einem undifferenzierten Pool, die noch dazu fähig sind, mehrere Zyklen von Zellteilung zu vollziehen, Remyelinisierung leisten können (Targett et al. 1996).

Prineas et al. (1993) beobachteten einen gewaltigen Oligodendrozytenverlust in aktiven Läsionen, der jedoch durch eine schnelle Rekrutierung von neuen remyelinisierenden Zellen aus einem Pool von Vorläuferzellen kompensiert wurde. Diese Beobachtung bestätigten Lucchinetti et al. (1999) in einer Studie, in der sie zwei verschiedene Muster in Bezug auf die Pathologie der Oligodendrozyten darlegen konnten. Das erste Muster wies eine variable Zerstörung der Oligodendrozyten mit folgendem Wiedererscheinen von Oligodendrozyten in inaktiven und remyelinisierenden Läsionen auf. Auffällig war hierbei die erhöhte Anzahl von 
PLP-exprimierenden Zellen im Vergleich zu MOG-positiven. Da MOG einen Marker für reife Oligodendrozyten darstellt, deutet dies auf einen Ursprung der neuen Zellen aus einem Pool von Vorläuferzellen hin. Da die Anzahl der Vorläuferzellen im Verlauf der Erkrankung und dem Alter der Läsion abnimmt, kann eine zeitlich bedingte Begrenzung der Remyelinisierungsfähigkeit vermutet werden. Das zweite Muster hingegen wies eine massive Zerstörung der Oligodendrozyten mit geringer oder fehlender konsekutiver Remyelinisierung auf. Als Gründe hierfür wurden die lokale Zerstörung der Vorläuferzellen zusammen mit den differenzierten Oligodendrozyten, eine fehlende Rekrutierung, der Tod der unreifen Zellen kurz nach ihrer Schaffung oder die fehlende Differenzierung der Vorläuferzellen diskutiert. Diese scheint dabei eine entscheidendere Rolle zu spielen als die fehlende Rekrutierung (Sim et al. 2002, Woodruff et al. 2004).

Da das Verständnis der OPC-Differenzierung somit grundlegend für die Erklärung einer fehlschlagenden Remyelinisierung ist, soll im Weiteren darauf eingegangen werden.

\subsubsection{OPC-Differenzierung}

Während der embryonalen Entwicklung des zentralen Nervensystems konnte auf eine Vielzahl von Ursprüngen der Vorläuferzellen verwiesen werden. So erfolgen Wellen der OPC-Produktion aus dem ventralen embryonalen Rückenmark, aus dem dorsalen Teil sowie weiteren Arealen im Gehirn (Kessaris et al. 2008, Vallstedt et al. 2005). Von diesen Zentren wandern die OPCs aus, um die verschiedensten Teile des sich entwickelnden zentralen Nervensystems zu bevölkern. In jeder Phase dieser Entwicklung erfolgt eine selektive Genregulierung mittels epigenetischer Regulationsmechanismen, die die Zugänglichkeit bestimmter Chromosomenabschnitte bestimmt. Diese Chromatinmodifikationen finden zum überwiegenden Teil auf Ebene der Nukleosomen statt, wo es durch die enzymatischen Aktivitäten der Histonmethyltransferase (HMT), der Histonazetyltransferase (HAT), der Histondeazetylase (HDAC) und weiteren zu Veränderungen in der Histonstruktur kommt (Copray et al. 2009). Die Histonazetylierung ist dabei mit einer Aktivierung der Transkription assoziiert, während die Histondeazetylasen die Azetylgruppen von Lysinresten der Histone entfernen und das Chromatin so in einen weniger zugänglichen Zustand versetzen (Bartova 
et al. 2008). Die verschiedenen HDAC-Klassen, deren Aufbau und genaue Aufgabe werden im nachfolgenden Kapitel erläutert.

Obwohl für die Differenzierung neuronaler Stammzellen und weiterer Abstammungslinien der große Einfluss sowie der kritische Part der Histonazetylase gezeigt werden konnte (Asklund et al. 2004, Song und Ghosh 2004), scheint die Histondeazetylase im Bezug auf die OPC-Differenzierung eine gewichtigere Rolle zu spielen.

So wird die Differenzierung zu Oligodendrozyten, im Gegensatz zu den anderen neuronalen Linien, durch eine allgemeine Histondeazetylierung getriggert (Marin-Husstege et al. 2002). Die Deazetylierung in dieser frühen Phase bewirkt dabei eine Unterdrückung der Entwicklung in eine andere Differenzierungsrichtung sowie die Hemmung der Expression von Myelin-spezifischen Geninhibitoren. Die Differenzierung in eine andere Richtung wird dadurch verhindert, dass HDAC die wichtigsten Transkriptionsfaktoren, insbesondere Sox2, der alternativen Linien blockiert. Experimentell konnte dieses in mehreren Studien mit HDAC-Inhibitoren nachgewiesen werden. In Anwesenheit der Inhibitoren sank nach der Stammzelldifferenzierung die Anzahl der Oligodendrozyten, während sich jene der Astrozyten und Neurone erhöhte (He et al. 2007a, Liu et al. 2007).

Die Unterdrückung der Expression von Myelin-spezifischen Gen-Inhibitoren wiederum kommt durch eine Wanderung der HDACs, insbesondere von HDAC1 und 2, zu den Promotorregionen dieser inhibitorischen Moleküle, wie Hes5, Sox 11 oder Tcf4, zustande (He et al. 2007a, Kondo und Raff 2004). In Bezug auf diesen Vorgang konnte auch ein Transkriptionsfaktor, als Yin Yang1 (YY1) bezeichnet, gefunden werden, der die Rekrutierung von HDAC1 an die Promotorregion erleichtert (He et al. 2007b).

Der Vollständigkeit wegen muss auch auf die Rolle der Histonmethyltransferase (HMTase) während der Oligodendrozytendifferenzierung eingegangen werden, auch wenn sie im weiteren Verlauf dieser Arbeit nicht mehr erwähnt werden wird. So konnte ebenfalls für einige HMTasen ein Einfluss auf die Differenzierung gezeigt werden. Ein erhöhtes Level an HMTasen schien dabei die OPC-Bildung und Proliferation zu erleichtern sowie die Differenzierung Richtung Neuronen und Astrozyten zu verhindern (Sher et al. 2008). Für die Histondemethylase konnte keiner dieser Effekte nachgewiesen werden. 
Auch in der weiteren Entwicklung der unreifen Oligodendrozyten, nach Festlegung der Differenzierungsrichtung, übernehmen die HDACs die Rolle als Repressoren der Transkriptionsinhibitoren (Shen et al. 2005). Generell scheinen demnach hohe HDAC-Level in OPCs für die Differenzierung in reife Oligodendrozyten notwendig zu sein.

Eben dieser Zustand der OPCs wird auch als erforderlich im Bezug auf die Remyelinisierung nach erfolgter Entmarkung im entwickelten Nervensystem erachtet und stellt eine mögliche Ursache für den unterschiedlichen Remyelinisierungsgrad zwischen verschiedenen Patienten sowie für die Abnahme der Remyelinisierung mit dem Alter dar. In einer Studie konnten Shen et al. (2008) mit ihrer Hypothese, dass die Remyelinisierung eine epigenetische Kontrolle der Genexpression beinhaltet, diese Aussage bestätigen. Nach einer Cuprizoninduzierten Demyelinisierung bei Mäusen konnte mit Einhalt der Gabe von Cuprizon eine spontane Remyelinisierung beobachtet werden, die durch erhöhte Level von HDAC, insbesondere der Klasse-I-HDACs, gekennzeichnet war. Im Gegensatz dazu waren die Level von Sox2, welches mit dem Erhalt der Multipotenz von Zellen assoziiert ist, sowie weitere Transkriptionsinhibitoren, wie Hes5, ein direkter Inhibitor der OPC-Differenzierung, reduziert. Um die genaue Beziehung zwischen Remyelinisierung und dem Vorhandensein von HDAC darzustellen, wurde zusätzlich zu dem Cuprizon Valproinsäure (VPA), ein HDACInhibitor, gegeben. Ergebnis war eine Zunahme von unreifen sowie eine Abnahme der reifen Oligodendrozyten in VPA-behandelten Mäusen. Die Remyelinisierung fiel mit dünneren und weniger zahlreichen Myelinfasern geringer aus. Dieses Bild der ineffizienten Reparatur glich demjenigen von älteren Mäusen auch ohne VPA-Behandlung. Bei der differenzierten Unterdrückung von Histondeazetylasen der Klasse I, die zuvor während der spontanen Remyelinisierung besonders beobachtet wurden, konnte gezeigt werden, dass nur die Inhibition von HDAC1 und 2 zu einer beeinträchtigten OPC-Differenzierung führten, während die Unterdrückung von HDAC3 und 8 keine Auswirkung hatte.

Diese Studie bestätigte somit einen direkten, altersabhängigen Bezug zwischen der Effizienz der Remyelinisierung und epigenetischen Modulatoren der Genexpression, speziell HDAC1 und 2, in Mäusen. Im Nervensystem älterer Mäuse nimmt der Remyelinisierungsgrad aufgrund der ineffizienteren HDAC-Rekrutierung und somit folgender Ansammlung von Transkriptionsinhibitoren der Myelin-spezifischen Gene ab. 
Ob nun generell das Ausmaß der Remyelinisierung bei der Multiplen Sklerose, das wie oben bereits beschrieben von Fall zu Fall von nicht vorhanden bis komplett variieren kann, von dem Vorhandensein von HDAC1 abhängig ist, bleibt zunächst ungewiss.

\subsubsection{Histondeazetylasen (HDACs)}

Bei den HDACs handelt es sich um eine Klasse von Enzymen, die eine wichtige Rolle in zahlreichen biologischen Prozessen spielt, überwiegend durch ihren repressiven Einfluss auf die Transkription. Diese ist dabei weitestgehend von der Chromatinarchitektur, d.h. wie die DNS verpackt ist, abhängig. Durch posttranslationale Modifikation der Histone kann die Architektur beeinflusst werden. HDACs wurden dabei nach ihrer Fähigkeit benannt die Azetylgruppen von azetyliertem Lysin am N-terminalen Ende von Histonen zu entfernen, wodurch dieses seine positive Ladung wiedererhält und die Affinität zwischen dem Histon und dem negativ geladenen Phosphatgerüst der DNS erhöht wird. Durch diese verstärkte Bindung kommt es zur Kondensation der DNS-Struktur, welche zu einer Unterbindung der Transkription führt (De Ruijter et al. 2003). HDACs arbeiten dabei jedoch selten allein, da ihnen die intrinsische DNS-Bindungsaktivität fehlt. Sie müssen durch ihre direkte Assoziation mit transkriptionellen Aktivatoren bzw. Repressoren oder durch ihre Eingliederung in große Multiproteinkomplexe rekrutiert werden. Dadurch ergibt sich eine Spezifität für HDACs in Bezug auf die Regulation bestimmter Genprogramme, die von der Zellidentität und dem mit ihr einhergehendem Spektrum an verfügbaren Partnerproteinen abhängig ist (Haberland et al. 2009). Die entgegengesetzte Aktion der Azetylierung von Histonen übernimmt dabei die Histonazetylase (HATs), welche für eine erhöhte transkriptionelle Aktivität sorgt (De Ruijter et al. 2003). HDACs wirken jedoch nicht nur repressiv, sondern können zusätzlich einige Gene aktivieren, sodass eine Deletion oder Inhibition von HDACs häufig zu einer Hoch- bzw. Herunterregulation von ungefähr derselben Anzahl von Genen führt (Haberland et al. 2009). Ebenfalls konnte für die HDACs gezeigt werden, dass sie auch die Aktivität von nichthistonischen Proteinen wie YY1 modulieren können (Yao et al. 2001). Die Histondeazetylasen werden in vier Klassen eingeteilt, welche sich in ihrer Struktur, Lokalisation, Funktion und ihrem Expressionsmuster unterscheiden. 


\subsubsection{Klasse-I-HDACs}

Zur Klasse I gehören $\operatorname{HDAC} 1,2,3$ und 8. Diese sind ubiquitär vorkommend, befinden sich jedoch überwiegend im Nukleus. Da HDAC 1 und 2, im Gegensatz z.B. zu HDAC 3, das „nuclear export signal“ (NES) fehlt, sind diese sogar ausschließlich im Nukleus lokalisiert (Johnstone 2002).

Sie besitzen eine verhältnismäßig einfache Struktur aus der Deazetylasedomäne mit einem kurzen Amino- sowie Carboxyende als Verlängerung (Haberland et al. 2009). HDAC 1 und 2 haben eine sehr ähnliche Struktur, die nahezu 82\% sequenzidentisch ist (De Ruijter et al. 2003). Die Expression von HDAC 1 wird durch Wachstumsfaktoren stimuliert, wobei die Kontrolle mittels negativen Feedbacks durch das eigene Produkt erfolgt (Bartl et al. 1997, Schüttengruber et al. 2003).

HDAC 1 gilt als die Hauptdeazetylase in embryonalen Stammzellen, welches dadurch gezeigt werden konnte, dass es im Rahmen einer Deletion von HDAC 1 zu Proliferationsdefekten und generellen Wachstumsstörungen mit konsekutiver früher embryonaler Sterblichkeit kam (Lagger et al. 2002). Es gilt jedoch zu beachten, dass einige Deletionen von HDAC 1 in bestimmten Geweben wie Gehirn, Herz oder Skelettmuskulatur toleriert werden, welches auf die Redundanz mit HDAC 2 in der späteren Entwicklung und im postnatalen Leben zurückgeführt werden kann (Montgomery et al. 2007).

HDAC 1 und 2 agieren häufig gemeinsam und bilden in einer Anzahl von Multiproteinkomplexen den katalytischen Kern. In Form dieser Komplexe wirken sie an den verschiedensten regulierenden Prozessen, wie der Zellzyklusprogression, Zellalterung oder Differenzierung, mit (Taplick et al. 2001).

Wie oben bereits beschrieben, ist das Vorhandensein von Klasse-I-HDACs, insbesondere von HDAC 1, für die oligodendrogliale Differenzierung und Entwicklung essentiell (Cunliffe und Casaccia-Bonnefil 2006). Eine Inhibition der HDACs führt dabei zu einer verminderten Oligodendrozytendifferenzierung und darauf folgend $z u$ einer ineffektiveren Remyelinisierung nach Cuprizon-induzierter Demyelinisierung. Als Erklärung hierfür wird die Funktion der HDACs angesehen, welche unter normalen Umständen an die Promotorregionen des Stammzellmarkers Sox2 sowie von Inhibitoren der Oligodendrozytendifferenzierung, z.B. Hes1, Hes5 oder Id4, binden, so deren Expression 
unterdrücken und für eine positive Regulation der Oligodendrozytendifferenzierung sorgen (Shen et al. 2008). Unter HDAC-Inhibition kommt es folglich zu einer ungehemmten Hochregulierung von Sox2 und Hes5 mit der daraus resultierenden verminderten Remyelinisierung.

Warum das Vorhandensein von HDAC 1 und 2 für die Differenzierungsrichtung in Oligodendrozyten kritisch ist, wurde auch von Ye et al. (2009) in einer Studie über den Wnt/ß-Catenin-Signalweg diskutiert. Die Aktivierung des Wnt-Signals, welches die Progression der Oligodendroglia-Differenzierung während der regulären Entwicklung negativ reguliert, führt zu einer Stabilisierung und nukleären Translokation des $\beta$-Catenins. In diesem Zustand kann das $\beta$-Catenin an TCF7L2, einen Transkriptionsfaktor, der als wichtiger Bestandteil eines Transkriptionskomplexes zur Regulation der Oligodendrozytenentwicklung dient, binden. Dieser $\beta$-Catenin/TCF7L2-Komplex wirkt dabei über die Expression von Differenzierungsinhibitoren, wie Id2 oder 4, sowie die Unterdrückung von Olig2 und MBP als Repressor der Oligodendrozytendifferenzierung. Ye et al. (2009) konnten dabei während ihrer Versuche ein Konkurrieren von $\beta$-Catenin und HDAC 1 und 2 um den Transkriptionsfaktor TCF7L2 beobachten. Auffällig war, dass das Verdrängen von $\beta$-Catenin und die Bindung von HDAC1/2 an TCF7L2 diesen zu einem Aktivator der Oligodendrozytendifferenzierung machte. Demnach kann festgestellt werden, dass ein regulierender Faktor der Oligodendrozytenentwicklung die Inhibition von auf die Differenzierung hemmend wirkenden $\beta$-Catenin/TCF7L2-Komplexen durch HDAC1/2 ist. Ein Gleichgewicht zwischen an TCF7L2 gebundenem $\beta$-Catenin und HDAC1/2 scheint die Differenzierung und Reifung zeitlich zu koordinieren.

In neuesten Studien konnte darüber hinaus dargelegt werden, dass HDAC 1 eine wichtige Rolle bei der neuronalen Schädigung während der Multiplen Sklerose spielt. Dabei findet ein nukleärer Export des ansonsten ausschließlich im Nukleus vorkommenden HDAC 1 ins Zytoplasma statt. Dort übt es eine toxische Wirkung auf den axonalen Transport aus, welcher sich durch verlangsamten mitochondrialen Transport äußert. Ursache ist die Bindung von HDAC 1 an Motorproteine und $\alpha$-Tubulin, wodurch deren Fähigkeit unterbunden wird mit anderen Beladungsproteinen, wie Dynamin, Komplexe zu bilden. 
HDAC 1 ist dabei die einzige Isoform, für welche dieses Phänomen beobachtet werden konnte (Kim et al. 2010).

Auch für HDAC 2 konnte eine zusätzliche Funktion gefunden werden. Sie fungiert, zusammen mit dem homodomain-only protein (HOP), als Regulator der Kardiomyozytenproliferation und -differenzierung (Kook et al. 2003). Darüber hinaus reguliert sie die Synapsenbildung, die synaptische Plastizität sowie die Gedächtnisbildung. Eine Überexpression von HDAC 2 führt dabei zu einer verringerten Dichte und Anzahl von dendritischen Fortsätzen und Synapsen und somit zu einer negativen Regulation von Gedächtnis und Lernen. Dieser Sachverhalt hat zur Forschung an HDAC2-selektiven Inhibitoren, die bei Erkrankungen mit Gedächtnisschädigung, beispielsweise infolge neurodegenerativer Prozesse, therapeutisch eingesetzt werden könnten, angeregt (Guan et al. 2009).

Für HDAC 3 konnte gezeigt werden, dass sie in engem Zusammenhang mit einer defekten Doppelstrangreparatur steht (Bhaskara et al. 2008). Die experimentelle Deletion oder Inhibition von HDAC 3 führte sowohl im Herzen als auch in der Leber zu gewaltigen Lipideinlagerungen und der Abnahme von Glykogenspeichern (Knutson et al. 2008, Montgomery et al. 2008).

Über HDAC 8, welches sich im Nukleus befindet und am ehesten der HDAC 3 gleicht, ist bis dato wenig bekannt (van den Wyngaert et al. 2000).

\subsubsection{Klasse-II-HDACs}

Bei der Klasse II wird zwischen Ila und IIb unterschieden. HDAC 4, 5, 7 und 9 gehören zur Klasse Ila, welche gegensätzlich $z u$ den anderen Gruppen ein eingeschränktes Expressionsmuster aufweist. Klasse-Ila-HDACs besitzen eine große $\mathrm{N}$-teminale Verlängerung mit Bindungsstellen für den Transkriptionsfaktor myocyte enhancer factor 2 (MEF2) und Chaperone. Durch Bindung an die Chaperone mittels Phosphorylierung durch Kinasen können die HDACs vom Nukleus ins Zytoplasma wandern (McKinsey et al. 2000, Lu et al. 2000). Die Phosphorylierung sorgt somit dafür, dass extrazelluläre Signale mit der Transkription verbunden werden und spielt dadurch während der Entwicklung, aber auch bei Erkrankungen in vielen Geweben eine große Rolle. 
HDAC 4 befindet sich vermehrt im Gehirn und in den Wachstumsfugen, wo sie eine zentrale Rolle bei der Skelettbildung spielt. Sie wird in den prähypertrophen Chondrozyten exprimiert, wodurch es bei Fehlen oder Inhibition der HDAC 4 zur exzessiven Knochenbildung sowie Chondrozytenhypertrophie kommt. Sie reguliert demnach die zeitliche Planung und das Ausmaß der enchondralen Ossifikation (Vega et al. 2004). HDAC 5 und 9 findet man überwiegend in Muskeln, Gehirn und Herz. Dort üben sie als Reaktion auf Stresssignale eine hemmende Funktion auf das kardiale Wachstum aus (Chang S et al. 2004).

HDAC 7 ist überwiegend in den Endothelzellen und Thymozyten lokalisiert. Fehlt sie, führt dieses zu einer Schädigung der Integrität der endothelialen Zellinteraktionen, und es kommt klinisch unter anderem zu einer Ruptur von Gefäßen (Chang S et al. 2006).

Zur Klasse Ilb gehören HDAC 6 und 10. Für HDAC 6 konnte gezeigt werden, dass sie die Hauptdeazetylase im Zytoplasma von Säugetierzellen ist (Zhang $Y$ et al. 2008). HDAC 6 unterscheidet sich dabei von den anderen HDACs dadurch, dass sie einen C-terminalen Zinkfinger und zwei Deazetylasedomänen besitzt, mit denen sie direkt zytoskelettale Proteine, wie $\alpha$ - Tubulin, transmembranäre Proteine, wie Interferon-Rezeptor IFN $\alpha$ R oder Chaperone deazetylieren kann (Tang X et al. 2007, Zhang X et al. 2007, Kovacs et al. 2005). Durch das Entfernen der Azetylgruppen vom $\alpha$-Tubulin verliert dieses seine Fähigkeit, die Motorproteine Kinesin 1 und Dynein zu den Mikrotubuli zu rekrutieren, wodurch der axonale Transport behindert wird (Hubbert et al. 2002).

Die Funktion von HDAC 10 hingegen ist bisher noch nicht bekannt. Es wird vermutet, dass es sich hierbei eher um einen Rekrutierer anderer HDACs handelt als um eine Deazetylase selbst. Diese Aussage wird dadurch begründet, dass HDAC 10 allein keine deazetylierende Wirkung zeigt, jedoch dazu fähig ist, mit vielen anderen HDACs zu assoziieren (Kao et al. 2002).

\subsubsection{Klasse-III-HDACs}

Unter die Klasse III fällt eine Familie von Enzymen, die NAD- abhängig sind. Aufgrund ihrer Ähnlichkeit zu der Hefe Sir2 werden sie auch als Sirtuine bezeichnet (Imai et al. 2000). Sie scheinen eine wichtige Rolle bei der Deazetylierung von H4 zu spielen (Vaquero et al. 2007). 


\subsubsection{Klasse-IV-HDACs}

Die Klasse IV besteht nur aus HDAC 11, welche in ihrer Struktur mit kurzen N-und Cterminalen Verlängerungen den Klasse I und II HDACs gleicht. Sie findet sich vermehrt in Herz, Gehirn, Muskeln, Niere und Hoden. Bis heute ist nur wenig über ihre Funktion bekannt (Gao et al. 2002). 


\subsection{Fragestellung}

Wie im vorangegangenen Kapitel beschrieben, gelten die Klasse-I-HDACs, insbesondere HDAC 1 und 2, als essentiell für die Differenzierung in Richtung oligodendrogliale Zellen und die darauffolgende Differenzierung in reife, myelinisierende Oligodendrozyten. So konnten Shen et al. (2008) bei Mäusen zeigen, dass eine Inhibition von HDAC1 zu einer ineffektiveren Remyelinisierung nach Cuprizon-induzierter Demyelinisierung führte. Basierend auf dieser Arbeit entwickelten wir die Fragestellung, ob diese Beobachtungen auch bei an Multiple-Sklerose-erkrankten Menschen zu sehen sind und somit einen Ansatz für eine Erklärung bieten können, warum das Ausmaß der Remyelinisierung nach erfolgter Demyelinisierung bei verschiedenen Patienten so unterschiedlich ausfällt. Ziel dieser Arbeit ist daher die Untersuchung der folgenden Fragestellung:

- Sind Unterschiede in der oligodendroglialen Expression von HDAC 1 bzw. 2 in MSBiopsien mit Remyelinisierung gegenüber solchen ohne Remyelinisierung nachweisbar?

Die Bearbeitung dieser Fragestellung setzt eine zuverlässige Einteilung der ausgesuchten Fälle in präzise Remyelinisierungsstadien voraus. Da bis dato eine detaillierte Klassifizierung fehlt, werden wir uns zudem auf Grundlage der Oligodendrozytenentwicklung mit den Fragen beschäftigen:

- Welches Stadium der Remyelinisierung ist mit welchem Expressionsmuster an Myelinproteinen sowohl im Myelin als auch in oligodendroglialen Zellen verbunden?

- Gibt es Myelinproteine, die als zentrale Marker eine Einteilung in verschiedene Remyelinisierungsstadien erlauben? 


\section{Material und Methoden}

\subsection{Material}

\subsubsection{Gewebe}

\begin{tabular}{|c|c|c|c|c|c|c|c|c|c|}
\hline $\begin{array}{l}\text { Pat.- } \\
\text { Nr. }\end{array}$ & $\begin{array}{l}\text { Fall- } \\
\text { Nr. }\end{array}$ & Geschl. & Alter & $\begin{array}{l}\text { DM- } \\
\text { Aktivität }\end{array}$ & $\begin{array}{l}\text { Imm.path. } \\
\text { Subtyp }\end{array}$ & $\begin{array}{l}\text { OL- } \\
\text { Muster }\end{array}$ & $\begin{array}{l}\text { Klin. } \\
\text { Verlauf }\end{array}$ & $\begin{array}{l}\text { KH- } \\
\text { Dauer }\end{array}$ & Block-Nr. \\
\hline 1 & 3658 & $f$ & 28 & LA & - & II & - & - & B04/10999 \\
\hline 2 & 3663 & $m$ & 45 & EA & 1 & - & $\mathrm{CIS}$ & 2 Wochen & B05/541 VI \\
\hline 3 & 3690 & $f$ & 67 & EA & II & - & $\mathrm{CIS}$ & 2,5 Jahre & B06/345 \\
\hline 4 & 3692 & $\mathrm{~m}$ & 68 & $\mathrm{LA}$ & - & - & $\mathrm{CIS}$ & 3 Monate & B06/414 \\
\hline 5 & 3700 & $f$ & 45 & IA & - & II & $\mathrm{CIS}$ & $\begin{array}{l}1,5 \\
\text { Monate }\end{array}$ & B06/682 \\
\hline 6 & 3701 & $f$ & 50 & $\mathrm{IA}$ & - & 1 & - & - & B06/639 \\
\hline 7 & 3702 & $f$ & 48 & IA & - & - & RRMS & 2 Jahre & B06/610 \\
\hline 8 & 3705 & $f$ & 50 & IA & - & - & RRMS & 9,5 Jahre & B06/598 I \\
\hline 9 & 3707 & $f$ & 33 & IA & - & - & RRMS & 5,5 Jahre & B06/603 \\
\hline 10 & 3710 & $f$ & 49 & EA & II & - & SPMS & 13 Jahre & B06/882 \\
\hline 11 & 3715 & $f$ & 59 & IA & - & - & $\mathrm{CIS}$ & $\begin{array}{l}1,5 \\
\text { Monate }\end{array}$ & B06/868 \\
\hline 12 & 3728 & $f$ & 30 & $\mathrm{LA}$ & - & II & $\mathrm{CIS}$ & 2,5 Jahre & B07/153 II \\
\hline 13 & 3732 & $f$ & 31 & LA & - & 1 & $\mathrm{CIS}$ & 1 Monat & B07/288 II \\
\hline 14 & 3737 & $f$ & 49 & $\mathrm{LA}$ & - & $I$ & $\mathrm{CIS}$ & 2 Monate & $\mathrm{B} 07 / 410 \mathrm{I}$ \\
\hline 15 & 3762 & $f$ & 33 & EA & II & 1 & $\mathrm{CIS}$ & $\begin{array}{l}1,5 \\
\text { Monate }\end{array}$ & B07/1230 VI \\
\hline 16 & 3770 & $\mathrm{~m}$ & 32 & IA & - & 1 & $\mathrm{CIS}$ & $1 \mathrm{Jahr}$ & B08/74 IV \\
\hline 17 & 3777 & $m$ & 31 & EA & II & 1 & SPMS & 10 Jahre & B08/410 IV \\
\hline
\end{tabular}

Tabelle 3: Klinische Daten der untersuchten Patienten; Fall-Nr.= Nummer der Biopsie im Archiv des Instituts für Neuropathologie Göttingen; $\mathrm{f}=$ weiblich; $\mathrm{m}=$ männlich; $\mathrm{LA}=$ late active (spät aktiv); $\mathrm{EA}=$ early active (früh aktiv); $\mathrm{IA}=$ inactive (inaktiv); $\mathrm{CIS}=$ clinically isolated syndrome; Dauer= Zeitspanne von Auftritt des ersten Symptoms bis zum letzten Update 


\subsubsection{Antikörper und Chemikalien}

\begin{tabular}{|l|l|l|l|l|l|}
\hline $\begin{array}{l}\text { Humanes } \\
\text { Antigen }\end{array}$ & Herkunftspezies & Klon & Ig-Typ & Kat.- Nr. & Hersteller \\
\hline HDAC 1 & Kaninchen & - & IgG & ab7028-50 & $\begin{array}{l}\text { Abcam, } \\
\text { Cambridge, } \\
\text { UK }\end{array}$ \\
\hline NOGO A & Maus & $11 C 7$ & IgG2 & - & $\begin{array}{l}\text { M. Schwab, } \\
\text { ETH Zürich, } \\
\text { Schweiz }\end{array}$ \\
\hline HDAC 2 & Maus & 62 & IgG2b & ab12169-100 & $\begin{array}{l}\text { Abcam, } \\
\text { Cambridge, } \\
\text { UK }\end{array}$ \\
\hline p25 & Kaninchen & - & IgG & & $\begin{array}{l}\text { Prof. } \\
\text { Jensen, } \\
\text { Aarhus, DK }\end{array}$ \\
\hline
\end{tabular}

Tabelle 4: Primärantikörper

\begin{tabular}{|l|l|l|l|l|}
\hline Bezeichnung & Konjugiert mit & Kat.- Nr. & Hersteller & Verdünnung \\
\hline $\begin{array}{l}\text { Ziege-anti- } \\
\text { Kaninchen-Ig }\end{array}$ & Biotin & $111-065-144$ & Dianova & $\begin{array}{l}1: 2 \\
\text { vorverdünnt, } \\
\text { final 1:500 in } \\
10 \% \text { FCS }\end{array}$ \\
\hline Extravidin® & Peroxidase & E2886 & $\begin{array}{l}\text { Sigma-Aldrich } \\
\text { Chemie GmbH, } \\
\text { Steinheim }\end{array}$ & $\begin{array}{l}1: 1000 \text { in } 10 \% \\
\text { FCS }\end{array}$ \\
\hline $\begin{array}{l}\text { Kaninchen- } \\
\text { anti-Maus-Ig }\end{array}$ & & Z0259 & Dako & $1: 50$ in 10\% FCS \\
\hline APAAP Maus & & D0651 & Dianova & $1: 50$ in 10\% FCS \\
\hline $\begin{array}{l}\text { Maus-anti- } \\
\text { Kaninchen-Ig }\end{array}$ & M0737 & Dako & $1: 50$ in 10\% FCS \\
\hline
\end{tabular}

Tabelle 5: Sekundärsysteme für die Immunhistochemie 
Material und Methoden

\begin{tabular}{|l|l|l|}
\hline Bezeichnung & Kat.- Nr. & Hersteller \\
\hline $\begin{array}{l}\text { Citronensäure- } \\
\text { Monohydrat }\end{array}$ & 1.00244 .0500 & Merck KGaA, Darmstadt \\
\hline DAB & D-5637 & $\begin{array}{l}\text { Sigma-Aldrich Chemie } \\
\text { GmbH, Steinheim }\end{array}$ \\
\hline Fast-Blue-Salz & F0250 & Sigma \\
\hline $\begin{array}{l}\text { Fetales Kälberserum } \\
\text { FCS) }\end{array}$ & S 0115 & Biochrom AG, Berlin \\
\hline $\begin{array}{l}\text { Levamisol } \\
\text { medizinisch reinst, } \\
\text { stabilisiert }\end{array}$ & L-9756 & $\begin{array}{l}\text { Sigma-Aldrich Chemie } \\
\text { GmbH, Steinheim }\end{array}$ \\
\hline $\begin{array}{l}\text { Mayers Hämalaunlösung } \\
\text { Phosphat }\end{array}$ & 1.09249 .0500 & $\begin{array}{l}\text { Merck KGaA, Darmstadt } \\
\text { 9,55 g/l w/o Ca }{ }^{2+}, \text { Mg }\end{array}$
\end{tabular}

Tabelle 6: Chromogene, Substrate und sonstige Chemikalien

\begin{tabular}{|l|l|}
\hline Citratpuffer (10mM) & $\begin{array}{l}\text { 2,1014 g Citronensäure-Monohydrat in } 1 \mathrm{l} \\
\text { A. bidest., pH auf } 6.0 \text { einstellen }\end{array}$ \\
\hline DAB-Entwicklerlösung (50 $\mathbf{~ m l )}$ & $1 \mathrm{ml}$ DAB in $49 \mathrm{ml} \mathrm{PBS}+20 \mu \mathrm{l} \mathrm{30 \%} \mathrm{H}_{2} \mathrm{O}_{2}$ \\
\hline Fast-Blue-Entwicklerlösung & $\begin{array}{l}25 \mathrm{mg} \text { Fast-Blue-Salz in } 49 \mathrm{ml} \text { TRIS pH 8,2 + } 1 \\
\mathrm{ml} \text { Naphthol-AS-Mix }+50 \mu \mathrm{ll} \text { Levamisol }\end{array}$ \\
\hline
\end{tabular}

Tabelle 7: Lösungen und Puffer 


\subsection{Methoden}

\subsubsection{Auswahl der Biopsien}

Zu Beginn der Arbeit befassten wir uns damit, aus den gesammelten Biopsien der Neuropathologie Göttingen die für unsere Studie geeigneten auszuwählen. Insgesamt gingen wir von 120 Biopsien aus, die wir genauer betrachteten, um zuletzt unsere 18 Fälle auszusuchen. Hauptkriterien dafür waren das Vorhandensein von ausreichend Gewebematerial sowie von demyelinisierten Läsionen mit und ohne Remyelinisierung bzw. mit und ohne Oligodendrozytenerhalt. Es wurden sowohl aktiv entmarkende als auch rezente, jedoch nicht mehr aktiv entmarkende Läsionen eingeschlossen. Hierzu betrachteten wir zunächst die LFB-PAS-Färbung, da hier Entmarkungsprozesse und insbesondere ein substantielles Ausmaß an Remyelinisierung am besten zu beobachten sind. Aufgrund der hohen Affinität des LFB zu Bestandteilen des Myelins werden die Markscheiden in dieser Färbung leuchtend blau angefärbt, während das übrige Gewebe blass rosa erscheint. Kerne und Nissl-Schollen erscheinen dunkelblau, Gliazellen hingegen hellblau. Durch die PASFärbung, welche Substanzen wie Glykogen, Cellulose, neutrale Mukopolysaccharide und Glykolipide anfärbt, erhalten zudem das Parenchym und weitere Strukturen, z.B. Bindegewebe oder Basalmembranen, ihre Farbe.

Demyelinisierte Areale lassen sich somit gut abgrenzen, da in diesen Gebieten ein Verlust der blauen Markscheiden zu beobachten ist. In bereits wieder remyelinisierten oder remyelinisierenden Arealen lassen sich die leuchtend blau gefärbten Markscheiden erneut beobachten. Der Unterschied zu gesunden myelinisierten Arealen liegt jedoch in der Qualität und Quantität der Fasern. Bei der Remyelinisierung lassen sich sehr viel feinere Fasern in niedrigerer Dichte beobachten. Im Falle einer sehr fortgeschrittenen Remyelinisierung kann die Unterscheidung zwischen regelrecht myelinisierten und remyelinisierten Arealen lichtmikroskopisch jedoch sehr schwer fallen. 

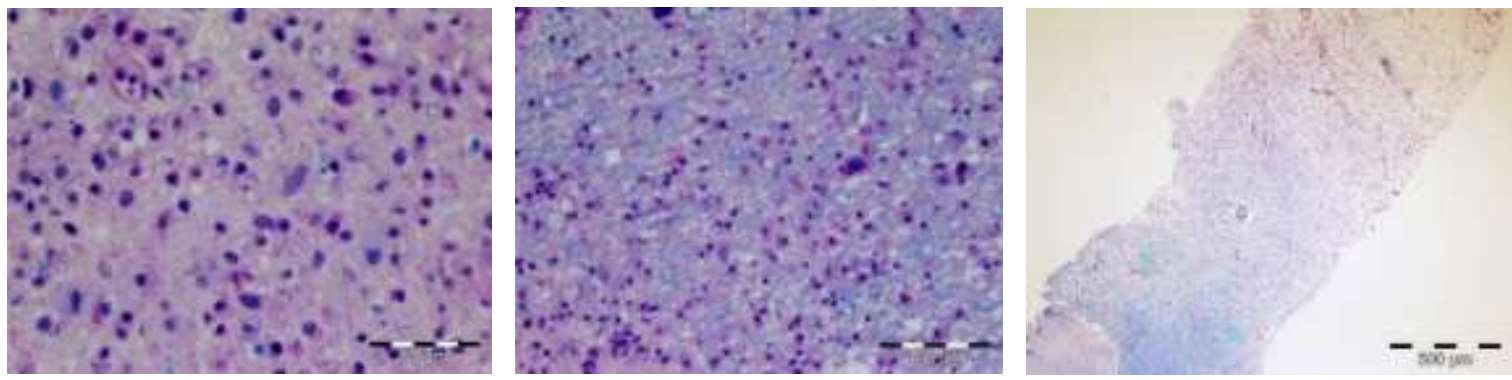

Abbildung 1: Darstellung der Remyelinisierung in der LFB-PAS-Färbung; Bild li.: keine Remyelinisierung; Bild Mitte: Remyelinisierung sichtbar durch feine blaue Markscheiden; Bild re.: Gradient der Remyelinisierung (von keiner RM zu ausgeprägter RM) von rechts-oben nach links-unten

Als besonders wertvoll zeigten sich bei der Auswahl der Fälle Läsionen, in denen ein Demyelinisierungs-Remyelinisierungs-Gradient zu erkennen war, da in diesen der Unterschied der HDAC1-Expression zwischen nicht-remyelinisiertem und remyelinisiertem Areal innerhalb eines einzelnen Falls beobachtet werden konnte. Gleiches betraf Biopsien, in denen mehrere Läsionen unterschiedlicher Entmarkungs- und Remyelinisierungsstadien zu finden waren.

Ein weiteres Auswahlkriterium war zudem die Qualität der bereits gefärbten Myelinproteine wie MBP (Myelin-basisches Protein) oder MOG (Myelin-Oligodendroglia-Glykoprotein), da diese Färbungen für die darauf folgende Stadieneinteilung der ausgewählten Biopsien notwendig sein würden. Fälle, bei denen die immunhistochemischen Färbungen der Myelinproteine durchgängig zu schwach oder mit zu viel Hintergrund belegt waren, wurden nicht weiter analysiert. Dies galt ebenfalls für physikalisch beschädigte, wie z.B. für die Schnellschnittdiagnostik eingefrorene und dann erst fixierte und eingebettete Fälle.

\subsubsection{Einteilung der MS-Biopsien in Stadien der Entmarkungsaktivität und der Remyelinisierung}

Die ausgewählten Fälle wurden daraufhin nach ihrer Entmarkungsaktivität sowie dem Remyelinisierungsgrad eingeteilt. Wir betrachteten hierfür insbesondere die Myelinfärbung 
mit LFB-PAS sowie die immunhistochemischen Färbungen für Myelin und Oligodendrozyten MBP, CNP, MAG, MOG, PLP und Nogo A. Zur Einschätzung der axonalen Schädigung bzw. des axonalen Verlust zogen wir die Versilberung nach Bielschowsky sowie die Immunreaktion für APP (Amyloid-Vorläuferprotein) hinzu.

Wie oben bereits beschrieben, betrachteten wir zunächst die LFP-PAS-Färbung zur Unterteilung in entmarkte Areale ohne oder mit Remyelinisierung. Zugleich diente diese Färbung der Herstellung von „lesionmaps“, d.h. Läsionskarten zur besseren Orientierung und Übersicht über die zu betrachtenden Areale. Fanden sich in einer Biopsie mehrere Areale, wurden diese nummeriert und separat analysiert.

Um die axonalen Strukturen und das Ausmaß der Axonschädigung genauer beurteilen zu können, wurden die Bielschowsky und APP-Färbung hinzugezogen. Bei der Versilberung nach Bielschowsky werden die Axone tiefbraun bis schwarz angefärbt, während sich das übrige Gewebe hellbraun abhebt.

Bei der APP-Färbung wird zur Einschätzung der (akuten) axonalen Schädigung das AmyloidVorläuferprotein dargestellt. APP, welches in den neuronalen Zellkörpern gebildet wird, wird gewöhnlich anterograd in den Axonen transportiert. Kommt es zu einer axonalen Verletzung oder gar Transektion, ist der Transport unterbrochen und APP akkumuliert vor allem in den proximal der Verletzung liegenden axonalen Enden. Dort entstehen folglich sogenannte APPpositive axonale Sphäroide, die für circa 30 Tage bestehen bleiben. Daher zeigen Antikörper, die gegen APP gerichtet sind, akute axonale Schädigungen an (Koo et al. 1990, Kuhlmann et al. 2002). Das Vorhandensein von axonalem Verlust in der Bielschowsky Färbung sowie APPAkkumulation kennzeichneten wir mit einem ",+

Neben der LFB-PAS-Färbung dienten auch die CNP- und MBP-Färbung zur genauen Definierung des Remyelinisierungsstatus. Remyelinisierung zeigte sich in diesen als feine, weniger strukturierte und organisierte, braun angefärbte Fasern. 


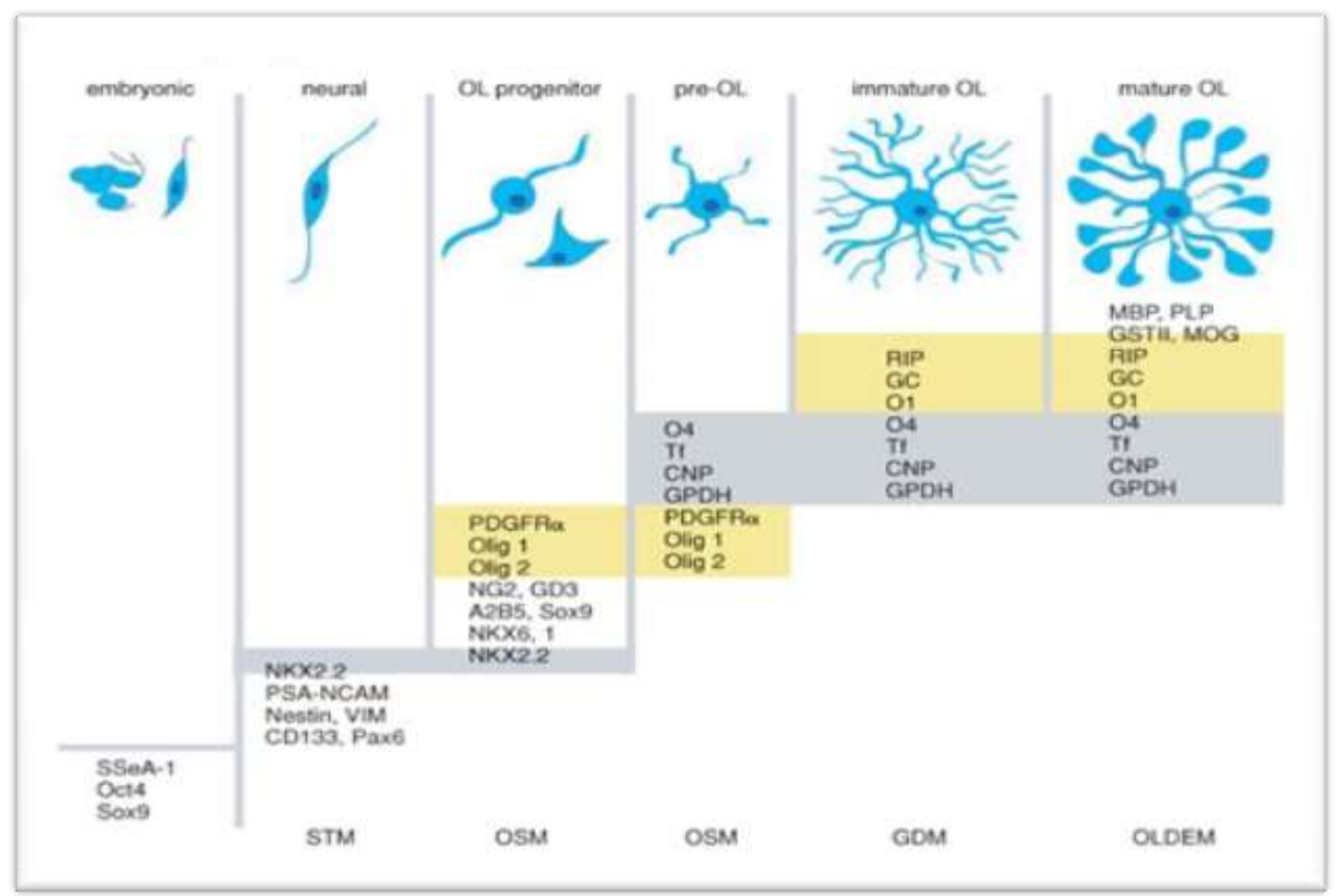

Abbildung 2: Darstellung der Oligodendrozytendifferenzierung mit den stadienabhängig vorkommenden Markern nach Espinosa-Jeffrey et al. (2009), S. 1

\section{$\underline{\mathrm{MBP}}$}

Das Myelin-basische Protein macht mit etwa $30 \%$ einen großen Anteil der Gesamtmyelinproteine aus und hat dem zufolge eine wesentliche Bedeutung für die Myelinscheiden (Zearfoss et al. 2008). Obwohl die genaue Funktion des MBPs nicht bekannt ist, wird, da es sich auf der zytoplasmatischen Seite der Myelinmembran befindet und eine Tendenz zur Selbstaggregation hat, vermutet, dass es an der Stabilisierung des Myelins mitwirkt, indem es die gegenüberliegenden zytoplasmatischen Oberfächen der Myelinscheiden verbindet. Eben diese Rolle scheint das MBP zudem während der Myelinogenese zur Unterstützung der Aneinanderlagerung der Myelinscheiden zu spielen (Kamholz et al. 1986, Pedraza et al. 1997). Zudem wird diskutiert, ob MBP bei der Übertragung von extrazellulären Signalen an das Zytoplasma beteiligt ist (Boggs 2006). Die MBP-Färbung gilt als empfindliches Verfahren für die Bewertung der Feinstruktur und Quantität der Myelinfasern abhängig von der Struktur und Farbintensität. 


\section{$\underline{\mathrm{CNP}}$}

Die 2‘3'-zyklische-Nukleotid-3'-Phosphodiesterase macht mit 4\% der Gesamtmyelinproteine nur einen kleinen Prozentsatz aus. CNP ist ausschließlich in zytoplasmatischen Bereichen des nicht-kompakten Myelins und der Paranodien lokalisiert (Trapp et al. 1988). Allein Oligodendrozyten sind dazu fähig, Genprodukte der CNP zu bilden. Es wird vermutet, dass CNP in der Aufrechterhaltung der paranodalen-axoglialen Strukturen von Relevanz ist und darüber hinaus mittels der Interaktion mit Tubulin auf das Wachstum von oligodendroglialen Fortsätzen Einfluss nimmt (Lee et al. 2005). Vor Beginn der Myelinbildung wird CNP in prämyelinisierenden Oligodendrozyten stark hochreguliert und gilt dabei als das Myelinprotein, welches während der Myelinogenese als erstes beobachtet werden kann (Reynolds und Wilkin 1988).

Da das Ziel der Auswahl Biopsien mit und ohne Oligodendrozytenerhalt waren, wurden, um den Oligodendrozytenstatus genauer zu definieren, neben der CNP- und der MBPImmunhistochemie folgende weitere Färbungen analysiert und die Anzahl positiver, braun angefärbter Zellkörper und Fasern anhand einer Skala von $\varnothing$ (keine) bis +++ (sehr viele) quantifiziert:

\section{$\underline{\text { PLP }}$}

Mit einem Anteil von circa 50\% des Gesamtmyelinproteins bildet PLP (Proteolipid-Protein) das Hauptmyelinprotein. Es besitzt eine intramembranöse Orientierung und soll, dem MBP ähnlich, eine Rolle beim Erhalt und der Stabilisierung der Myelischeiden und während der Oligodendrozytenentwicklung spielen (Klugmann et al. 1997).

$\underline{\text { MOG }}$

MOG befindet sich als Transmembranprotein spezifisch auf der Oberfläche von Oligodendrozyten und wird auf den Myelinscheiden exprimiert. Es besitzt am äußersten Rand der Markscheide eine extrazelluläre Ig-ähnliche Domäne (MOG-Igd). Diese hat direkten Kontakt zum Extrazellulärraum und bietet somit gute Kontaktmöglichkeiten für Antikörper, eine Beobachtung, die in der Pathogeneseforschung der multiplen Sklerose viel Beachtung gefunden hat. Es wird darüber hinaus davon ausgegangen, dass auch MOG an der Erhaltung der Integrität der Myelinscheiden als unverzichtbares Adhäsionsmolekül beteiligt ist. Im 
Unterschied zu den übrigen Myelinproteinen wird MOG jedoch eher später während der Myelinogenese exprimiert (della Gaspera et al. 1998, Pagany et al. 2003).

$\underline{\mathrm{MAG}}$

MAG (Myelin-assoziiertes Glykoprotein), das einen Anteil von $<1 \%$ der Gesamtmyelinproteine ausmacht, ist ein in periaxonalen Schwann Zellen (im peripheren Nervensystem) und oligodendroglialen Membranen der Myelinscheiden lokalisiertes Glykoprotein, welches dort als Ligand für Rezeptoren dient, welche für die Erhaltung der myelinisierten Axone und die Förderung der Differenzierung und das Überleben der Oligodendrozyten benötigt werden. Es ist zudem an der Verbesserung der axoglialen Stabilität beteiligt, hemmt jedoch auch die Regeneration von Axonen nach Verletzungen. Im Rahmen der Myelinogenese wird es sehr früh exprimiert (Keita et al. 2002, Quarles 2007)

\section{$\underline{\text { NOGO A }}$}

Nogo A, ein myelin-assoziiertes Transmembranprotein, ist bekannt als potenter (Oligodendrozyten-entstammender) Inhibitor axonalen Wachstums und Regeneration nach Verletzung des entwickelten, adulten zentralen Nervensystems und damit einhergehender limitierter neuronaler Plastizität. Es wird sehr früh im Verlauf der Oligodendrozytendifferenzierung exprimiert. Während OPCs nur die intrazelluläre Domäne des Nogo A ausbilden, besitzen reife Oligodendrozyten sowohl die intrazelluläre als auch eine zusätzliche extrazelluläre Domäne. Dieses könnte eine Ursache dafür sein, dass OPCs weniger stark inhibitorisch auf axonales Wachstum wirken als reife Oligodendrozyten (Ma et al. 2009, Pernet et al. 2008). Obgleich der hemmende Effekt des Nogo A reichlich untersucht worden ist, bleibt seine physiologische Rolle während der Entwicklung und auf gesunde Oligodendrozyten weiterhin unklar. Vermutet wird, dass das Vermögen neuronales Wachstum zu hemmen mit der Funktion als Modulator der neuronalen „Wegweisung" unter der Entwicklung einhergeht (Ng und Tang 2002). Aufgrund seiner selektiven Expression gilt Nogo A als zuverlässiger Marker für Oligodendrozyten-Zellkörper.

Nachdem die grobe Einteilung in Läsionen mit und ohne Remyelinisierung erfolgt war, unterteilten wir die Remyelinisierungsfälle präziser in eine früh- bzw. spät-remyelinisierte Gruppe. Hierbei ist anzumerken, dass unser als spät-remyelinisierendes eingeteiltes Stadium 
noch immer sehr früh ist. Weitaus früher als das Stadium, welches normalerweise als „late $R M^{\prime \prime}$ (shadow plaque) bezeichnet wird.

Bei der Einteilung richteten wir uns nach dem Vorhandensein der Myelinproteine CNP, MAG, MBP, MOG und PLP. Fälle, in denen LFB'-Fasern schon deutlich erkennbar waren, wurden als spät-remyelinisierend eingestuft, da dieses auf eine sehr fortgeschrittene (Re-) Myelinisierung hinweist.

Zur weiteren Einstufung benutzten wir bereits in publizierten Studien beschriebene Beobachtungen der Reihenfolge, in welcher Myelinproteine während der Myelinogenese bzw. der Remyelinisierung nach Entmarkung auftreten. Dass das zeitliche Expressionsmuster dieser beiden Prozesse, die Ausprägung der Myelinproteine assoziiert mit der Myelinogenese während der Remyelinisierung und der Myelinogenese unter der Entwicklung, einander entsprechen, konnte durch Woodruff und Franklin (1999) gezeigt werden. Darüber hinaus scheint die chronologische Ausbildung dieser Proteine von dauerhaften neuronalen Einflüssen nicht abhängig zu sein. In einem Versuch mit in vitro kultivierten Oligodendrozyten konnten Dubois-Dalcq et al. (1986) die gleiche Expressionsreihenfolge beobachten, obgleich die Oligodendrozyten sich in diesem Fall ja ohne Neuronen entwickelt hatten.

Das erste Myelinprotein, das in der frühen Phase der Remyelinisierung zu beobachten ist, ist das CNP. Es erscheint zu etwa derselben Zeit wie das Galaktocerebrosid (GC), ein Marker für Oligodendroglia, der eine Unterscheidung zu deren Vorläuferzellen sicherstellt, da diese GC nicht exprimieren (Reynolds und Wilkin 1988).

Einige Tage später lässt sich die erste Expression von MAG, MBP und PLP verzeichnen, auch wenn sie noch auf den Zellkörper begrenzt ist. MAG ist darauffolgend das erste dieser drei Myelinproteine, welches in den GC-positiven Prozessen nachgewiesen werden kann. Dass das Vorhandensein von MAG in manchen Fällen nicht oder später als die übrigen Myelinproteine beobachtet wird, kann auf den geringen Anteil des MAG am Gesamtmyelin und die damit verbundene schwierige Detektierbarkeit zurückgeführt werden (Baron et al. 2000, Dubois-Dalcq et al. 1986).

Auffällig ist, dass alle diese Myelinproteine beobachtet werden können, bevor eine signifikante Remyelinisierung im Elektronenmikroskop sichtbar ist (Lindner et al. 2008). 
Allein MOG fällt durch seine verzögerte Expression während der Remyelinisierung auf und kann somit als wegweisender Marker für das Stadium einer späten Remyelinisierung gesehen werden (della Gaspera et al. 1998, Lindner et al. 2008).

Nachdem die semiquantitative Einschätzung der Quantität und Qualität der Myelinproteine zur Bestimmung des Entmarkungsstatus, des Remyelinisierungsatus sowie des Oligodendrozytenbesatzes mit der folgenden Einteilung in die entsprechenden Stadien erfolgt war, wurde zur Bestätigung dessen die genaue Anzahl CNP- und MBP-positiver Fasern sowie CNP-, MAG-,MBP-, MOG- und NOGO-A- positiver Zellen mittels Auszählung unter dem Mikroskop ermittelt.

\subsubsection{Immunhistochemisches Protokoll}

\section{HDAC1/Nogo-A-Doppelmarkierungen}

Um die MS-Biopsien auf ihre Expression von HDAC1 in Oligodendrozyten zu untersuchen, verwendeten wir die immunhistochemische Methode der Doppelmarkierung. Dafür wurden von den Gewebeblöcken mit dem Mikrotom Schnitte von 3-5 $\mu \mathrm{m}$ Dicke hergestellt. Diese wurden nachfolgend immunhistochemisch für HDAC 1 und NOGO A angefärbt. Die zu detektierenden Strukturen waren Zellen, die sowohl für HDAC 1 (nukleär) als auch NOGO A (zytoplasmatisch) positiv waren.

Zunächst wurden die Schnitte - nach Trocknen bei $37^{\circ} \mathrm{C}$ über Nacht und 30 minütigem Abschmelzen bei $54^{\circ} \mathrm{C}$ - zur Entparaffinierung, nacheinander in folgende Lösungen gestellt:

- 4x 10 Minuten Xylol

- 5 Minuten Isoxylol

- 2x 5 Minuten $100 \%$ Isopropanol

- Jeweils 5 Minuten in eine Isopropylalkohol-Reihe absteigender Konzentration (90\%, $70 \%, 50 \%)$

und danach mit $A$. dest. rehydriert. 
Zur Antigenmaskierung erfolgte die Behandlung mit Citratpuffer $(10 \mathrm{mM}, \mathrm{pH} 6)$ für jeweils $5 \mathrm{x}$ 3 Minuten in einer Plastikküvette in einer Mikrowelle bei maximaler Leistung von 800 Watt. Die Küvette wurde dabei im Wechsel mit Puffer oder A. bidest. aufgefüllt. Im Anschluss kühlten die Schnitte für etwa 30 Minuten ab, um darauf 3x mit A. dest. gespült und in PBS gestellt zu werden.

Mittels 20-minütiger Inkubation mit $3 \% \mathrm{H}_{2} \mathrm{O}_{2}$ in PBS bei $4^{\circ} \mathrm{C}(50 \mathrm{ml}$ pro Küvette) und anschließendem 3-maligen Spülen mit PBS gelang die Blockierung der endogenen Peroxidase.

Die Blockierung unspezifischer Proteinbindungen, die sogenannte Vorinkubation, erfolgte mit $100 \mu \mathrm{l}$ 10\% FCS in PBS über circa 20 Minuten in einer feuchten Kammer.

Nach Dekantieren von FCS und Trockentupfen des Objektträgers wurde der erste Antikörper aufgetragen. HDAC1 wurde, 1:500 in 10\% FCS verdünnt, auf den Schnitt gegeben, luftblasenfrei mit einem Deckglas bedeckt und über Nacht in einer feuchten Kammer im Kühlschrank inkubiert.

Nach Entfernen der Deckgläser, 3x Spülen mit PBS sowie Trocknen der Schnitte folgte (für eine Stunde bei Raumtemperatur) die Inkubation mit dem sekundären, biotinylierten goatanti-rabbit-Antikörper, der, zuvor 1:2 vorverdünnt, in 10\% FCS letztlich auf 1:500 verdünnt wurde.

Die Schnitte wurden erneut mit PBS gespült, trocken getupft und dann nach der LABMethode (= labelled avidin-biotin technique) mit $100 \mu \mathrm{l}$ Peroxidase-konjugiertem Avidin (1:1000 in 10\% FCS) beschichtet und bei Raumtemperatur eine Stunde inkubiert. Nach Abschluss der Immunmarkierung folgte die Entwicklung der Schnitte, nach wiederholtem Spülen mit PBS, in einer Küvette mit DAB-Entwicklerlösung (49 ml PBS, $1 \mathrm{ml}$ DAB $+20 \mu \mathrm{l} 30 \% \mathrm{H}_{2} \mathrm{O}_{2}$ ). DAB wird durch die mittels Avidin an den sekundären Antikörper gebundene Peroxidase sowie $\mathrm{H}_{2} \mathrm{O}_{2}$ umgesetzt, wodurch es zu einem bräunlichen Farbniederschlag kommt.

Die Inkubation mit dem zweiten Primärantikörper, $100 \mu$ l NOGO A (1:15000 in 10\% FCS), verlief mit Spülen, Abschütteln, Auftragen des Antikörpers und Inkubation in einer feuchten Kammer analog zum HDAC1-Verfahren.

Im Anschluss folgte nach der sogenannten „APAAP-Methode“ die Inkubation mit dem 
sekundären AK sowie dem APAAP-Komplex (alkalische Phosphatase-anti-alkalischePhosphatase-Komplex). Der sekundäre Antikörper dient dabei als Brückenantikörper, der den Primärantikörper mit dem anti-Maus-Antikörper des Enzymkomplexes verbindet. Diese Methode hat den Vorteil, dass sie die Interaktion der Hydrophobie der Antikörper mit den hydrophoben Bereichen des fixierten Gewebes vermeidet und somit Störungen durch Anfärben des Hintergrundes reduziert. Außerdem wird durch den APAAP-Komplex die Sensitivität wesentlich erhöht.

Für jeweils eine Stunde wurden die Schnitte mit Rbb-anti-Maus-Antikörper in 10\% FCS und darauffolgend mit dem Enzym-Immunkomplex APAAP-Maus, ebenfalls in 10\% FCS, inkubiert. Zwischendurch wurde gründlich mit TBS gespült.

Zur Steigerung der Reaktionsstärke wurde diese Methode ein weiteres Mal für jeweils nun nur 30 Minuten wiederholt. Diese abermalige Applikation des Brückenantikörpers und APAAP-Komplexes führt zu einer Bindung zusätzlicher Enzymmoleküle an die AntigenBindungsstellen und bewirkt so eine gesteigerte Sensitivität der Methode.

Darauf wurden die Schnitte mit Fast-Blue-Entwicklerlösung $(49 \mathrm{ml}$ TRIS Ph 8,2, $1 \mathrm{ml}$ Naphthol-AS-Mix + $50 \mu$ l Levamisol + 25 mg Fast-Blue-Salz) 45-60 Minuten lichtgeschützt entwickelt.

Zuletzt wurde mit Hämalaun zur Kerndarstellung kurz gegengefärbt und mit IMMU Mount wässrig eingedeckelt.

\section{HDAC2/p25-Doppelmarkierungen}

Das Verfahren zur Doppelmarkierung mit HDAC2 und p25 entsprach der obengenannten Durchführung. Abweichend davon wurde $100 \mu \mathrm{l}$ HDAC2 1:2000 als primärer Antikörper verwendet. Auf die Inkubation mit HDAC2 folgte die Inkubation mit einem sekundären biotynilierten Maus-Antikörper (1:2 vorverdünnt, final 1:500 in 10\% FCS vorverdünnt) und die zu HDAC1 analoge Entwicklung mit DAB. Da es sich bei HDAC2 um einen MausAntikörper handelt, wurde im weiteren Verlauf anstelle von Nogo A p25 als Marker für reife Oligodendrozyten verwendet, um die Doppelmarkierung gut durchführen zu können. Ein zusätzlicher Unterschied fand sich in der Antikörper-Inkubation mit dem APAAPKomplex, bei welchem zunächst eine Inkubation mit Ms-anti-Rabbit 1:50 (in 10\% FCS) für 
eine Stunde erfolgte. Die weitere Reihenfolge entsprach dem oben beschriebenen Verfahren. Die lichtgeschützte Entwicklung mit Fast Blue fiel mit 60-120 Minuten wesentlich länger aus.

\subsubsection{Mikroskopie und Morphometrie}

Die darauffolgende Auswertung der Schnitte erfolgte mit einem Lichtmikroskop vom Modell BX 41 der Firma Olympus (OLYMPUS Deutschland GmbH, Hamburg), welches mit Objektiven von 2-, 4-, 10-, 20-, 40- und 100-facher Vergrößerung ausgestattet war. Zum Zählen der Zellen bzw. Myelinfasern verfügten wir über Okulare 10-facher Vergrößerung mit integriertem, standardisiertem Zellzählgitter respektive Axonzählgitter (beide OLYMPUS Deutschland GmbH, Hamburg). Ausgezählt wurden:

- $\quad$ NOGO-A+-Zellen

- $\mathrm{MOG}^{+}$-Fasern und -zellen

- $\mathrm{MAG}^{+}$-Fasern und -zellen

- $\mathrm{CNP}^{+}$-Fasern und -zellen

- $\mathrm{MBP}^{+}$-Fasern und -zellen

- $\quad \mathrm{PLP}^{+}$-Fasern und -zellen

- $\mathrm{HDAC}^{+} /$NOGO$^{+} \mathrm{A}^{+}$-Zellen

- $\mathrm{HDAC2}^{+} / \mathrm{p} 25^{+}$-Zellen.

Aufgrund der unterschiedlichen Ausmaße der Läsionen und ihrer zum Teil geringen Größe war es nicht möglich, eine einheitliche Anzahl an Gesichtsfeldern zu untersuchen. Nach der Auszählung folgte zunächst die Errechnung des Durchschnitts von Zellen auf ein Gesichtsfeld und daraufhin die Hochrechnung auf Zellen pro $\mathrm{mm}^{2}$ mittels der Gleichung:

- 1 Gesichtsfeld x $16=$ Zellen $/ \mathrm{mm}^{2}$ (nach Auszählung mit 400er Vergrößerung). 
In Bezug auf die Auswertung myelinisierter Fasern wurde, von einem 25-Punktegitter ausgehend, die Anzahl der Schnittpunkte der Fasern mit diesen Punkten als relative Anzahl $x / 25$ angegeben.

\subsubsection{Statistische Analyse}

Die Daten wurden mit Microsoft Office Excel 2007 und Word 2007 (Microsoft Deutschland $\mathrm{GmbH}$, Unterschleißheim) zusammengefasst und mit GraphPad PRISM ${ }^{\circledR} 5.01$ (GraphPad Software, San Diego, USA) statistisch ausgewertet. Dabei wurde zum Vergleich mehrerer Gruppen untereinander der nicht-parametrische One-way ANOVA Test mit „Tukey's"- Post Test angewendet. Als statistisch signifikant wurden $p$-Werte von 0,05 und kleiner gewertet. 


\section{Ergebnisse}

\subsection{Einteilungen in Stadien}

Um im weiteren Verlauf der Arbeit die HDAC1-Expression verschiedener Remyelinisierungsstadien vergleichen zu können, musste im Vorfeld eine präzise Einteilung der Fälle in Stadien erfolgen. Dafür wurden die Läsionen auf die Expression der oben genannten Myelinproteine untersucht. Zunächst erfolgte die semiquantitative mikroskopische Einschätzung der Faserund Zelldichte in den jeweiligen immunhistochemischen Färbungen. Die darauffolgende Stadieneinteilung basierte auf den Kenntnissen um die Reihenfolge der Expression von Myelinproteinen während der Myelinisierung bzw. Remyelinisierung.

\begin{tabular}{|c|c|c|c|c|c|c|c|c|c|c|c|c|}
\hline & \multicolumn{2}{|c|}{ CNP } & \multicolumn{2}{|c|}{ MAG } & \multicolumn{2}{|c|}{ MOG } & \multicolumn{2}{|c|}{ МBP } & \multicolumn{2}{|c|}{ PLP } & \multirow[t]{2}{*}{ LFB } & \multirow[t]{2}{*}{ Nogo A } \\
\hline & Fasern & Zellen & Fasern & Zellen & Fasern & Zellen & Fasern & Zellen & Fasern & Zellen & & \\
\hline $\begin{array}{c}\text { keine } \\
\text { RM }\end{array}$ & $\bar{\varnothing}$ & $\varnothing-+$ & $\varnothing$ & $\varnothing$ & $\varnothing$ & $\varnothing$ & $\varnothing$ & $\varnothing$ & $\varnothing$ & $\varnothing$ & $\varnothing$ & +-++ \\
\hline $\begin{array}{c}\text { frühe } \\
\text { RM }\end{array}$ & +-++ & $\begin{array}{l}++- \\
+++\end{array}$ & +-++ & +-++ & $\varnothing-+$ & $\varnothing-+$ & $\bar{\varnothing}$ & $\varnothing$ & $\varnothing-+/-$ & $\begin{array}{l}\phi- \\
+/-\end{array}$ & $\varnothing$ & ++-+++ \\
\hline $\begin{array}{c}\text { späte } \\
\text { RM }\end{array}$ & $\begin{array}{l}+- \\
+++\end{array}$ & $\begin{array}{l}+- \\
+++\end{array}$ & $\begin{array}{l}+- \\
+++\end{array}$ & $\begin{array}{l}+- \\
+++\end{array}$ & +-++ & +-++ & +-++ & +-++ & $+/--+$ & $\begin{array}{l}+/- \\
-+\end{array}$ & $\begin{array}{c}+/-- \\
++\end{array}$ & ++-+++ \\
\hline
\end{tabular}

Tabelle 8: Stadien der Remyelinisierung nach Kenntnissen um die zeitliche Abfolge der Expression von Myelinproteinen ( $\varnothing=$ keine Expression, $+/-=$ vereinzelt,$+=$ vorhanden, $++=$ zahlreich vorhanden, +++ = sehr starke Expression)

Insgesamt konnten wir zwei Fälle ohne Remyelinisierung, von denen einer keinen Oligodendrozytenerhalt, der andere einen guten Erhalt aufwies, neun Fälle im Stadium der frühen Remyelinisierung sowie sieben Fälle im späten Stadium identifizieren. Zwei Fälle zeigten mehr als eine Läsion. Während bei dem einen die unterschiedlichen Läsionen dem gleichen Stadium zugeordnet werden konnten, wies der zweite Fall ein Areal ohne 
Remyelinisierung und ohne Oligodendrozytenerhalt sowie ein Areal mit später Remyelinisierung auf.

Zudem fanden sich bei zwei Fällen große Läsionen mit Remyelinisierungsgradienten, jeweils von Arealen der frühen Remyelinisierung hin bis zur fortgeschritteneren Stadien reichend. Tabelle 14 und $15 \mathrm{im}$ Anhang zeigen die Ergebnisse im Überblick.

\subsubsection{CNP}

Die zelluläre Expression von CNP, einem der frühesten Marker der Myelinisierung bzw. Remyelinisierung, konnte in allen Fällen, bis auf jenen ohne Remyelinisierung mit schlechtem Oligodendrozytenerhalt, beobachtet werden.

Mit 14,4 Zellen/mm² lag auch der Wert des Falles ohne Remyelinisierung mit gutem Oligodendrozytenerhalt stark unter den Mittelwerten der Fälle mit Remyelinisierung. Die Mittelwerte der remyelinisierenden Fälle lagen dicht beieinander, wobei der Eindruck entstand, dass die Werte im späten Stadium eine weitere Amplitude aufwiesen und einer größeren Streuung unterlagen. Insgesamt ließ sich jedoch keine statistische Signifikanz bezüglich der Dichte von $\mathrm{CNP}^{+}$-Zellen zwischen frühen und späten Stadien der Remyelinisierung aufzeigen.

$\mathrm{CNP}^{+}$-Myelinfasern ließen sich in keinem der Fälle ohne Remyelinisierung nachweisen. In den übrigen Fällen des frühen und späten Stadiums fanden sich durchgehend, bis auf einen Fall, $\mathrm{CNP}^{+}$-Fasern. Die Anzahl positiver Fasern des späten Stadiums gegenüber jenem ohne Remyelinisierung mit schlechtem Oligodendrozytenerhalt war statistisch signifikant erhöht $(p=0,0195)$. Auch die Biopsie ohne Remyelinisierung mit gutem Oligodendrozytenerhalt zeigte keine $\mathrm{CNP}^{+}$-Fasern. Hier war eine statistische Auswertung jedoch nicht möglich, da nur ein Wert vorlag.

Die Werte der Stadien mit Remyelinisierung vergleichend, fiel eine annähernde Verdopplung der Anzahl positiver Fasern von 4,3 $\pm 3,1 / 25$ zu 7,6 $\pm 3,8 / 25$ vom frühen zum späten Stadium hin auf. Hierbei soll kurz noch einmal darauf hingewiesen werden, dass die Anzahl positiver Fasern dabei als Anzahl der Schnittpunkte der Fasern mit Punkten eines 25-Punktegitters, also $\mathrm{x} / 25$, angegeben wird. Die Steigerung der Anzahl $\mathrm{CNP}^{+}$-Myelinfasern war 
zwar deutlich zu beobachten, hingegen, am ehesten aufgrund der geringen Fallzahl, nicht statistisch signifikant.


Abbildung 3: Vergleich der CNP-Expression; Bild li.: keine CNP+-Fasern oder -zellen; Bild re.: zahlreiche bräunlich imponierende $\mathrm{CNP}^{+}$-Fasern und -zellen
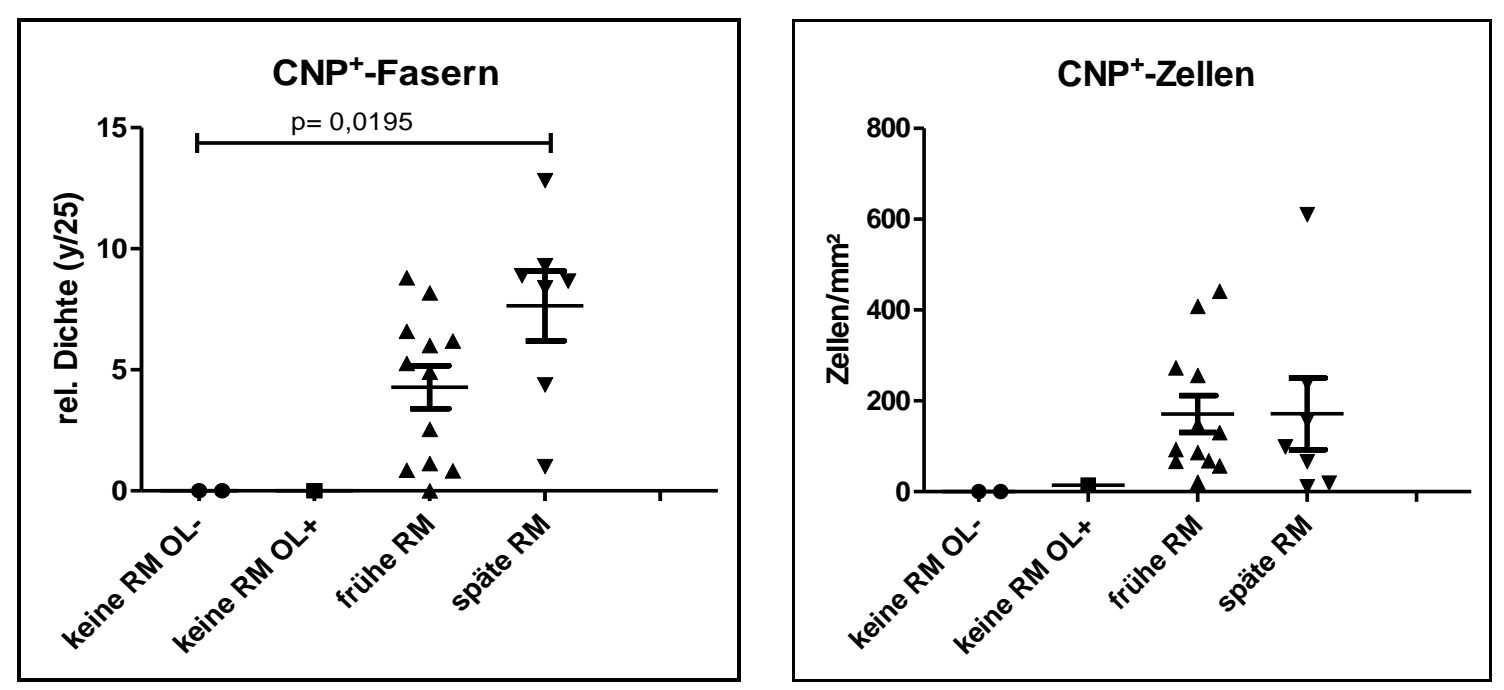

Abbildung 4: Dichte von $\mathrm{CNP}^{+}$-Fasern und -zellen in den jeweiligen Stadien der Remyelinisierung; Bild li.: statistisch signifikanter Unterschied in der Dichte der CNP+-Fasern zwischen dem Stadium ohne RM mit schlechtem Oligodendrozytenerhalt (OL-) und dem späten Stadium; Bild re.: deutlicher Unterschied in der Anzahl CNP+-Zellen zwischen den Stadien mit Remyelinisierung gegenüber jenen ohne Remyelinisierung. 


\subsubsection{MAG}

Weder in dem Fall ohne Remyelinisierung mit schlechtem Oligodendrozytenerhalt noch in jenem mit gutem Erhalt ließen sich $\mathrm{MAG}^{+}$-Zellen nachweisen. Auch unter den Fällen mit Remyelinisierung fanden sich Läsionen ohne zelluläre Expression von MAG. Überwiegend waren jedoch in diesen Fällen $\mathrm{MAG}^{+}$-Zellen in großer Anzahl vorhanden und quantifizierbar. Die Mittelwerte der Fälle mit früher und später Remyelinisierung lagen dabei eng beieinander.

Im Großen und Ganzen zeigte sich eine breite Streuung der Anzahl positiver Zellen zwischen den Läsionen, sodass sich folglich keine statistisch signifikanten Unterschiede beobachten ließen.

Wie im Fall der MAG ${ }^{+}$-Zellen war auch die $\mathrm{MAG}^{+}$-Fasern betreffend keine Expression in den Fällen ohne Remyelinisierung vorzuweisen. Die Werte des frühen und späten Remyelinisierungsstadiums lagen mit 2,6 \pm 1,7 Fasern/25 und $4 \pm 3,4$ Fasern/25 eng beieinander. Der Unterschied war statistisch nicht signifikant.
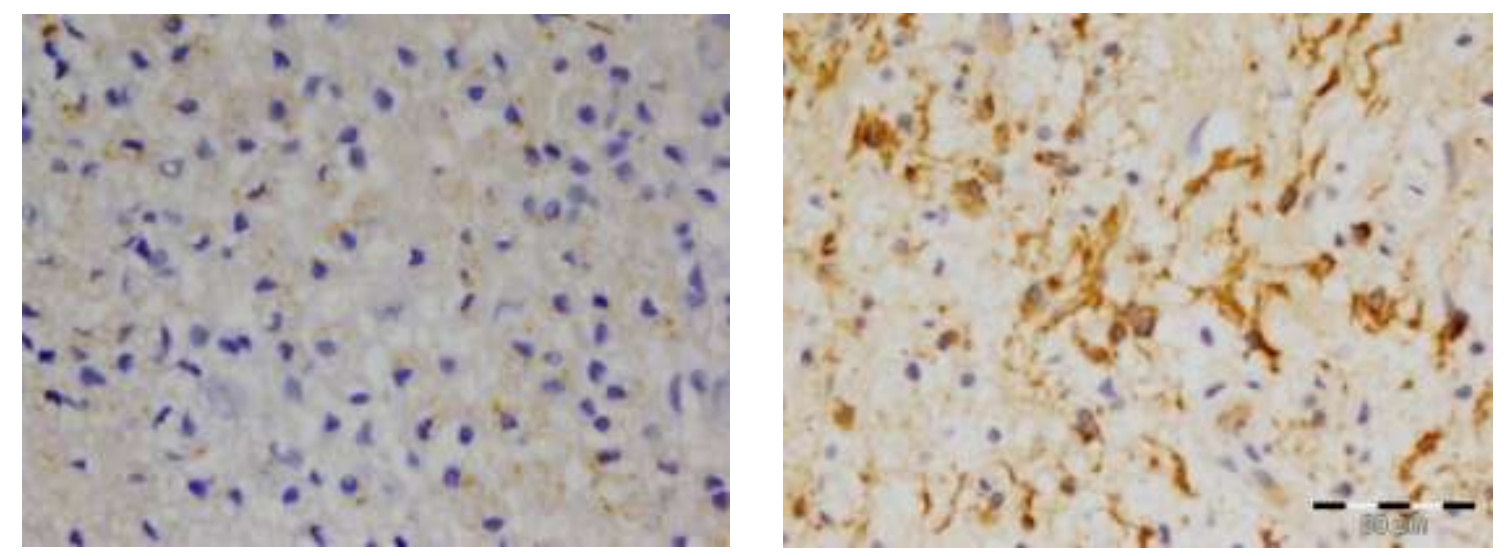

Abbildung 5: Dichte von MAG+-Fasern und -zellen; Bild li.: Darstellung des Stadiums ohne Remyelinisierung, charakterisiert durch Fehlen von $\mathrm{MAG}^{+}$-Fasern und -zellen; Bild re.: MAG+-Strukturen in einer Biopsie mit Zeichen der Remyelinisierung 

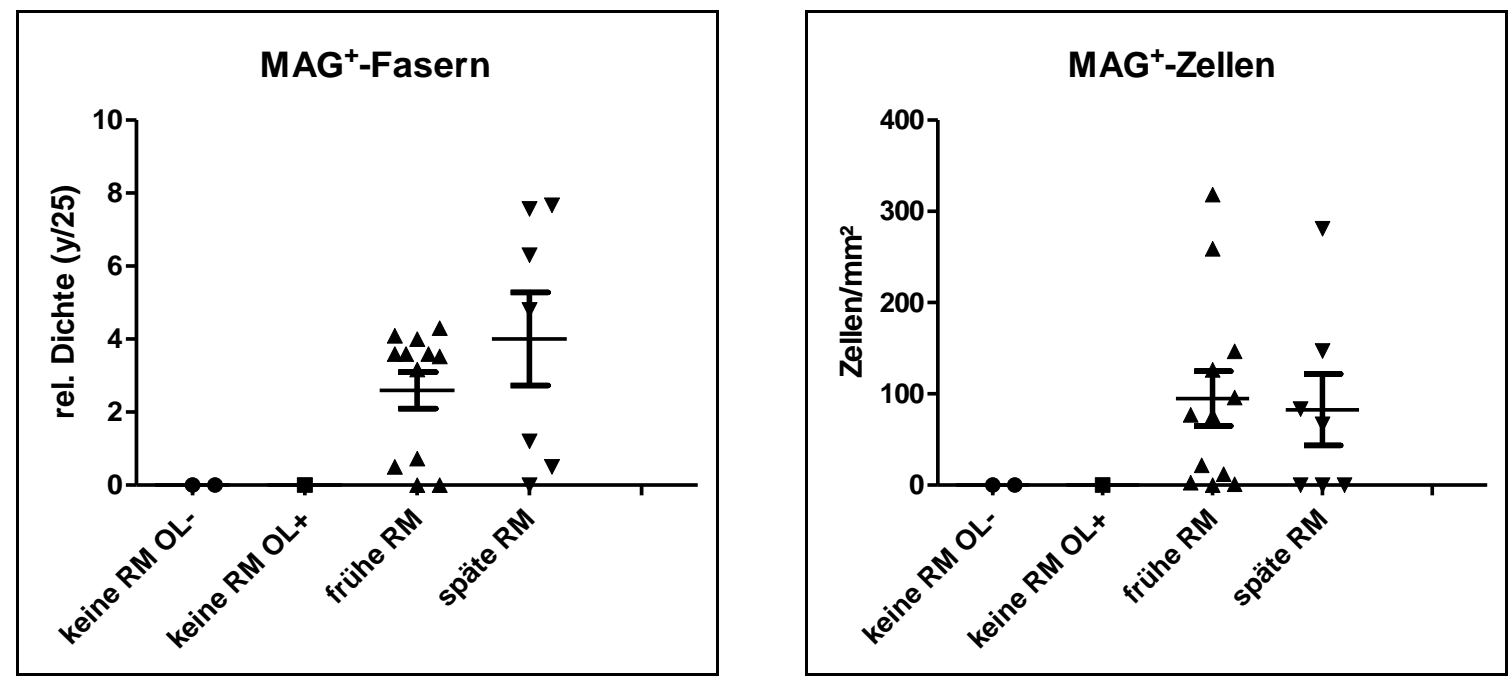

Abbildung 6: Dichte von $\mathrm{MAG}^{+}$-Fasern und $\mathrm{MAG}^{+}$-Zellen in den jeweiligen Stadien der Remyelinisierung; weder $\mathrm{MAG}^{+}$-Fasern noch -zellen in den Stadien ohne RM; breite Streuung der Anzahl positiver Strukturen in den Stadien mit Remyelinisierung

\subsubsection{MOG}

Unabhängig davon, ob $\mathrm{CNP}^{-}$- und Nogo- $\mathrm{A}^{+}$-Oligodendrozyten vorhanden waren, fanden sich in den Fällen ohne Remyelinisierung keine $\mathrm{MOG}^{+}$-Oligodendrozyten. Dahingegen konnten beim überwiegenden Teil der Fälle im frühen und späten Stadium zahlreiche $\mathrm{MOG}^{+}$-Zellen beobachtet werden, sodass Mittelwerte von 92,9 $\pm 122,2$ Zellen/ $/ \mathrm{mm}^{2}$, respektive $114,1 \pm$ 69,4 Zellen $/ \mathrm{mm}^{2}$ erreicht wurden.

Beim Vergleich des frühen zum späten Stadium zeigte sich eine leichte Erhöhung der Anzahl MOG $^{+}$-Zellen um circa $20 \%$. Diese Unterschiede waren zwar statistisch nicht signifikant, dennoch zeigten sich regelhaft mehr $\mathrm{MOG}^{+}$-Zellen im späten Stadium der Remyelinisierung. Im frühen Stadium war die Anzahl positiver Zellen breiter gestreut. Während einige Fälle noch keine $\mathrm{MOG}^{+}$-Zellen vorweisen konnten, fanden sich in anderen Läsionen dieses Stadium über 200 Zellen/mm². Demgegenüber konnten in ausnahmslos allen Fällen des späten Stadiums MOG+-Zellen gezählt werden.

Auch MOG+-Fasern, Marker der vorangeschrittenen Remyelinisierung, ließen sich in den Fällen ohne Remyelinisierung nicht identifizieren. Im frühen Stadium fanden sich in einigen Läsionen MOG-positive Fasern, größtenteils jedoch in sehr niedriger Dichte. Diese Streuung 
wurde wiederum in der Standardabweichung sichtbar (Abb. 8).

Demgegenüber zeigten Läsionen des späten Stadiums eine höhere Dichte MOG-positiver Fasern, die zudem homogener ausfiel. Der Unterschied von $2 \pm 2,9$ Fasern/25 zu 5,3 $\pm 3,4$ Fasern/25, der eine ungefähre Verdopplung der Faserdichte angibt, liegt mit $p=0,0502$ an der Grenze zur statistischen Signifikanz. Festlegen lässt sich dennoch, dass eine deutliche Zunahme der Expression von $\mathrm{MOG}^{+}$-Fasern zwischen frühem und spätem Stadium der Remyelinisierung vorhanden ist.

Anzumerken gibt es, dass ein Fall des späten Stadiums aufgrund von färbungs-technischen Problemen aus der Auswertung genommen werden musste.


Abbildung 7: Dichte von MOG+-Fasern und -zellen; Bild li.: keine MOG-Expression in Stadien ohne Remyelinisierung; Bild re.: MOG+-Fasern und -zellen in remyelinisierenden Stadien 



Abbildung 8: Dichte von $\mathrm{MOG}^{+}$-Fasern und $\mathrm{MOG}^{+}$-Zellen in den jeweiligen Stadien der Remyelinisierung; Bild li.: keine Fasern in den Stadien ohne RM, mit $p=0,0502$ Unterschied in der Faserdichte zwischen frühem und spätem Stadium an der Grenze zur stat. Signifikanz; Bild re.: keine $\mathrm{MOG}^{+}$-Zellen in den Stadien ohne RM, keine stat. signifikanten Unterschiede zwischen den Stadien, jedoch weisen im späten Stadium der Remyelinisierung im Gegensatz zu den anderen Stadien alle Fälle MOG+-Zellen auf.

\subsubsection{Nogo A}

Ausnahmslos zeigten alle untersuchten Fälle eine hohe Dichte von Nogo-A ${ }^{+}$-Zellen. Auch beim Vergleich der Mittelwerte konnten keine signifikanten Unterschiede zwischen den Stadien festgestellt werden. Aufgrund der fehlenden Färbung bei gleichzeitigem Fehlen des Blocks konnte auch hier ein Fall nicht in die Auswertung mit aufgenommen werden.

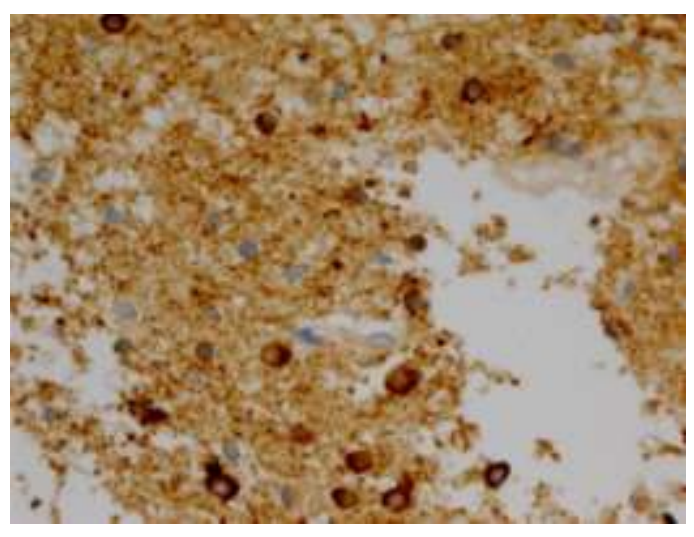

Abbildung 9: Stadienunabhängiges

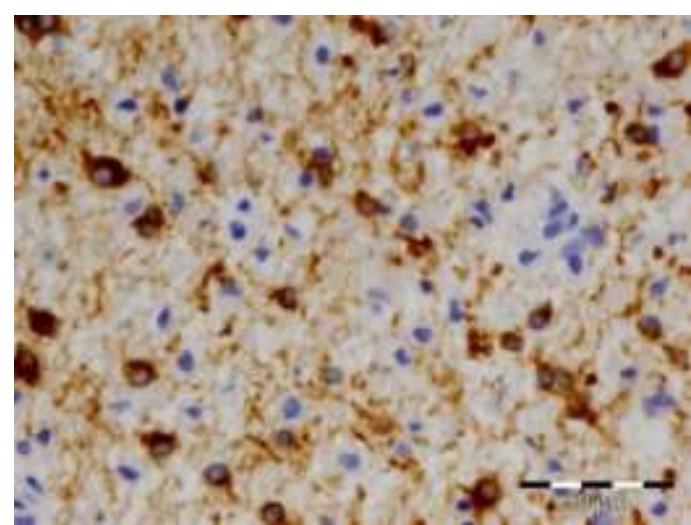

Vorhandensein von Nogo- $\mathrm{A}^{+}$-Oligodendrozyten: Vergleich eines Stadiums ohne Remyelinisierung (Bild li.) mit einem Stadium mit Remyelinisierung (Bild re.) 


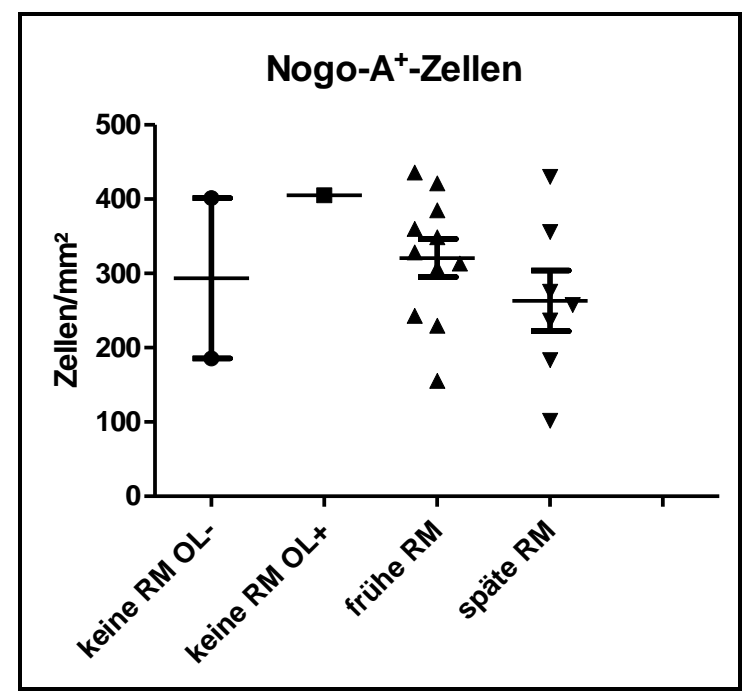

Abbildung 10: Dichte von Nogo- $\mathrm{A}^{+}-$ Zellen in den Stadien der Remyelinisierung; keine auffälligen Unterschiede zwischen den einzelnen Stadien

\subsubsection{MBP}

$\mathrm{MBP}^{+}$-Zellen konnten weder in den Stadien ohne Remyelinisierung noch im frühen Stadium der Remyelinisierung beobachtet werden. Allein in zwei Läsionen der späteren Phase waren positive Zellen nachzuweisen.

Das Bild der Faserexpression glich dem der Zellen. Auch hier fanden sich in den Fällen ohne Remyelinisierung keine MBP-positive Strukturen. Das frühe Stadium betrachtend, ließ sich nur eine Läsion mit MBP-positiven Fasern beschreiben, zudem in sehr geringer Dichte. Ein deutlicher Unterschied war im Bezug auf das späte Remyelinisierungsstadium zu beobachten, in welchem in allen Fällen $\mathrm{MBP}^{+}$-Fasern exprimiert waren. Mit $\mathrm{p}=0,0018$ zeigte sich eine statistisch signifikante Zunahme der Fasern vom Stadium ohne Remyelinisierung bzw. frühen zum späten Stadium (0,02 $\pm 0,07$ Faser/25 vs. 3,9 $\pm 3,4$ Fasern/25). 

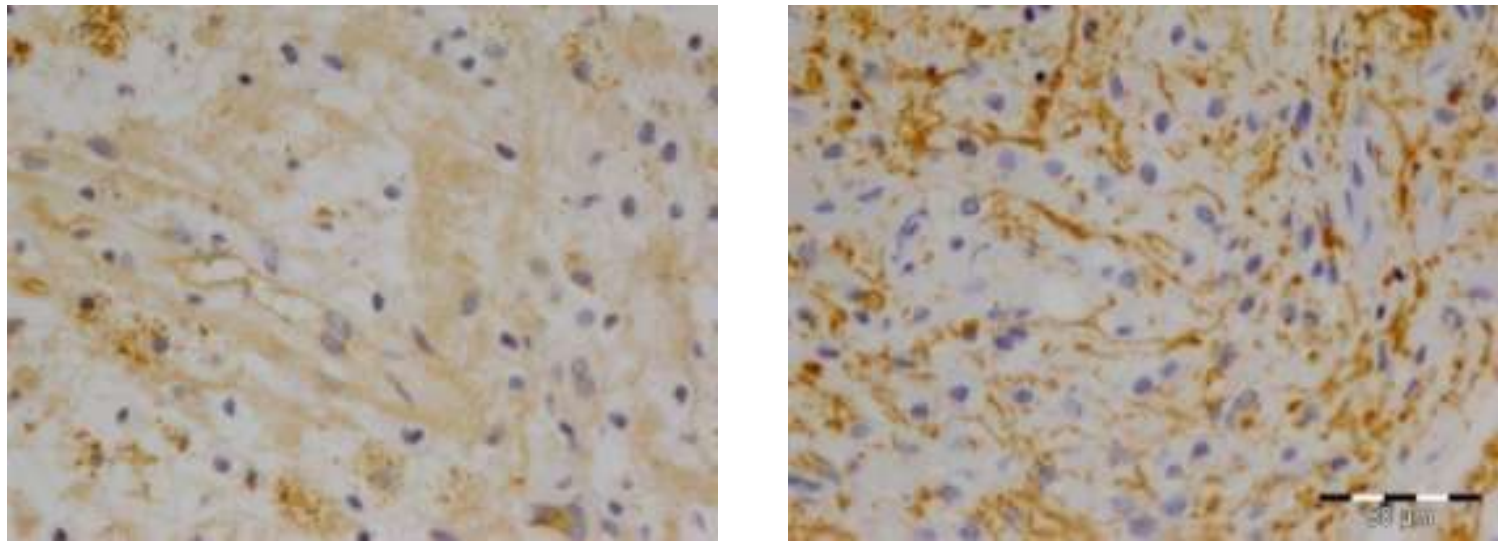

Abbildung 11: Dichte von $\mathrm{MBP}^{+}$-Fasern; Bild li.: keine positiven Fasern oder Zellen; Bild re.: spätes Stadium der Remyelinisierung mit zahlreichen $\mathrm{MBP}^{+}$-Fasern
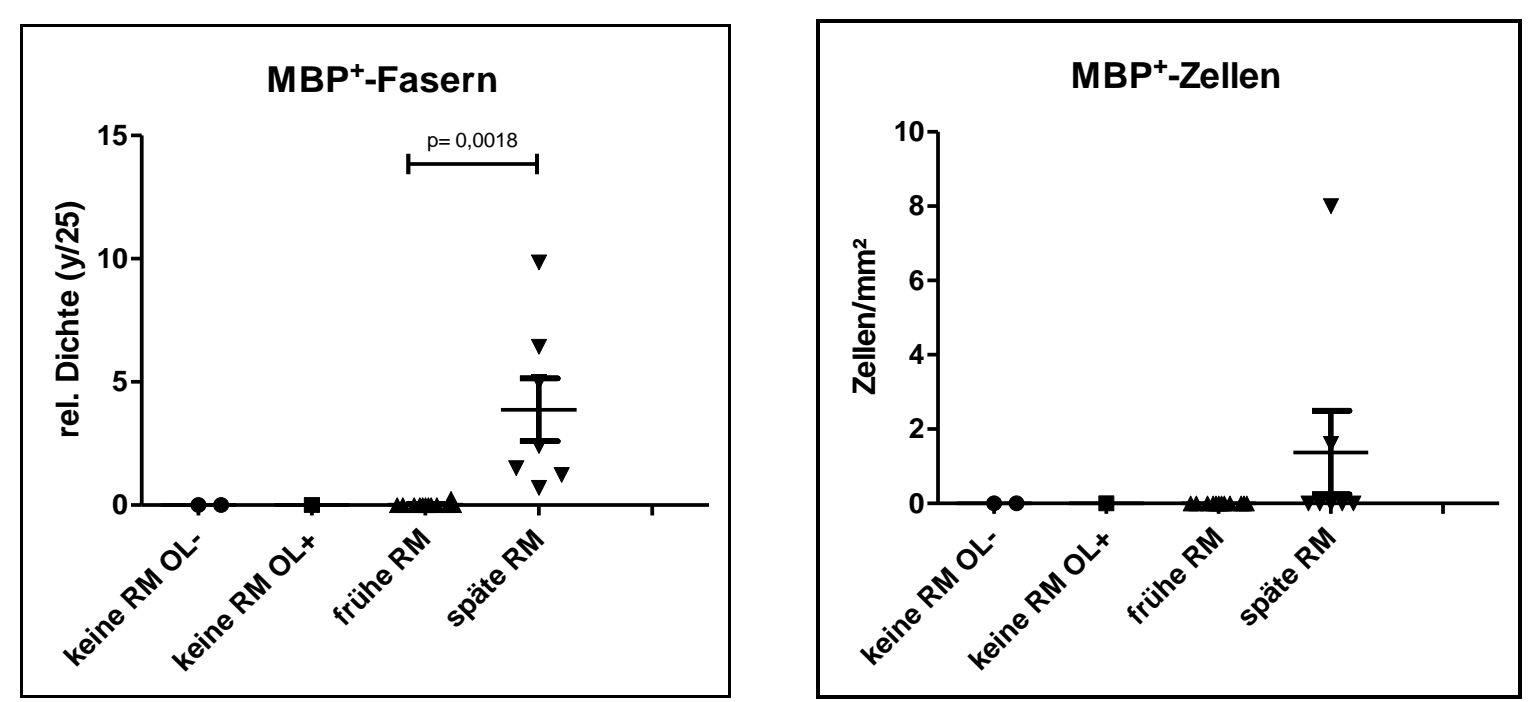

Abbildung 12: Dichte von $\mathrm{MBP}^{+}$-Fasern und $\mathrm{MBP}^{+}$-Zellen in den jeweiligen Stadien; Bild re.: $\mathrm{MBP}^{+}$-Fasern in ausnahmslos allen Fällen des späten Stadiums, stat. signifikanter Unterschied zum Stadium der frühen RM 


\subsubsection{Tabellarische Zusammenfassung der Dichte oligodendroglialer Zellen und Myelinfasern}

\begin{tabular}{|c|c|c|c|c|c|}
\hline & $\begin{array}{l}\text { Nogo-A- } \\
\text { Zellen } / \mathbf{m m}^{2}\end{array}$ & $\begin{array}{l}\text { CNP- } \\
\text { Zellen/mm }{ }^{2}\end{array}$ & $\begin{array}{l}\text { CNP- } \\
\text { Fasern/25 }\end{array}$ & $\begin{array}{l}\text { MBP- } \\
\text { Zellen/mm }{ }^{2}\end{array}$ & $\begin{array}{l}\text { MBP- } \\
\text { Fasern/25 }\end{array}$ \\
\hline $\begin{array}{l}\text { keine RM, } \\
\text { OL-Erhalt } \\
\text { schlecht }\end{array}$ & $\begin{array}{c}293,6 \\
\pm 152,7\end{array}$ & $\begin{array}{c}0 \\
\pm 0\end{array}$ & $\begin{array}{c}0 \\
\pm 0\end{array}$ & $\begin{array}{c}0 \\
\pm 0\end{array}$ & $\begin{array}{c}0 \\
\pm 0\end{array}$ \\
\hline $\begin{array}{l}\text { keine RM, OL- } \\
\text { Erhalt gut }\end{array}$ & 405,3 & 14,4 & 0 & 0 & 0 \\
\hline frühe RM & $\begin{array}{c}320 \\
\pm 84,7\end{array}$ & $\begin{array}{r}170,8 \\
\pm 141,2\end{array}$ & $\begin{array}{r}54,3 \\
\pm 3,1\end{array}$ & $\begin{array}{c}0 \\
\pm 0\end{array}$ & $\begin{array}{c}0,02 \\
\pm 0,07\end{array}$ \\
\hline späte RM & $\begin{array}{c}263,1 \\
\pm 107,8\end{array}$ & $\begin{array}{r}171,5 \\
\pm 209,3\end{array}$ & $\begin{array}{r}7,6 \\
\pm 3,8\end{array}$ & $\begin{array}{l}1,4 \\
\pm 3\end{array}$ & $\begin{array}{c}3,9 \\
\pm 3,4\end{array}$ \\
\hline
\end{tabular}

\begin{tabular}{|l|c|c|c|c|} 
& $\begin{array}{l}\text { MAG- } \\
\text { Zellen/mm }\end{array}$ & $\begin{array}{l}\text { MAG- } \\
\text { Fasern/25 }\end{array}$ & $\begin{array}{l}\text { MOG- } \\
\text { Zellen/mm }\end{array}$ & $\begin{array}{l}\text { MOG- } \\
\text { Fasern/25 }\end{array}$ \\
\hline $\begin{array}{l}\text { keine RM, } \\
\text { OL-Erhalt } \\
\text { schlecht }\end{array}$ & $\begin{array}{c}0 \\
\pm 0\end{array}$ & $\begin{array}{c}0 \\
\pm 0\end{array}$ & $\begin{array}{c}0 \\
\pm 0\end{array}$ \\
\hline $\begin{array}{l}\text { keine RM, } \\
\text { OL-Erhalt gut }\end{array}$ & 0 & 0 & 0 & 0 \\
\hline frühe RM & 94,8 & 2,6 & 92,9 & 2 \\
$\pm 104,4$ & $\pm 1,7$ & $\pm 122,2$ & $\pm 2,9$ \\
\hline späte RM & 82,6 & 4 & 114,1 & 5,3 \\
& $\pm 103,5$ & $\pm 3,4$ & $\pm 69,4$ & $\pm 3,4$ \\
\hline
\end{tabular}

Tabelle 9: Dichte oligodendroglialer Zellen und Myelinfasern 


\subsection{HDAC1-Expression in Oligodendrozyten}

Um die vorliegenden Fälle auf mögliche Unterschiede in der HDAC1-Expression von Oligodendrozyten zu untersuchen, wurde die immunhistochemische Methode der Doppelmarkierung mit HDAC1 und Nogo A an 15 der 17 Fälle durchgeführt. HDAC1 ist dabei im Gegensatz zu Nogo A nicht Oligodendrozyten-spezifisch, sondern wird von zahlreichen Zelltypen exprimiert.

Zwei Fälle entfielen aufgrund von nicht-vorhandenen Leerschnitten sowie fehlendem Paraffinblock oder der Unmöglichkeit der Auswertung hinsichtlich der geringen Größe. Es zeigten sich keine Unterschiede in der Expression von HDAC1 zwischen Fällen ohne Remyelinisierung gegenüber jenen mit Remyelinisierung. Das frühe und späte Stadium der Remyelinisierung betrachtend zeigte sich jedoch eine statistisch signifikante Steigerung der doppelmarkierten Zellen bei voranschreitender Remyelinisierung. Die Tabellen 16 und 17 des Anhangs fassen die Ergebnisse der Zählungen zusammen.

\subsubsection{HDAC1-Expression in Fällen ohne Remyelinisierung}

In Fällen, in denen sowohl keine Remyelinisierung hatte beobachtet werden können als auch die Oligodendrozyten schlecht erhalten waren, lag die absolute Anzahl HDAC1/Nogo-Adoppelmarkierter oligodendroglialer Zellen bei $119,7 \pm 38,1$ Zellen/ $\mathrm{mm}^{2}$. In dem Fall ohne Remyelinisierung bei gut erhaltenen Oligodendrozyten betrug die Anzahl 44,5 Zellen/mm². Aufgrund der geringen Fallzahlen konnte keine statistische Analyse bezüglich der Signifikanz der Unterschiedlichkeit der Ergebnisse durchgeführt werden. Doch auch ohne statistische Testung lässt sich rein von den Zahlenwerten her ein deutlicher Unterschied in der HDAC1Expression von Oligodendrozyten ausmachen.

Um die Fälle jedoch uneingeschränkt betrachten und bewerten zu können, wurde der prozentuale Anteil $\mathrm{HDAC1}^{+} / \operatorname{Nogo} \mathrm{A}^{+}$an den gesamten Nogo- $\mathrm{A}^{+}$-Zellen ermittelt. Absolute Werte lassen sich nur bedingt vergleichen, da die Dichte der Oligodendrozyten in den verschiedenen Fällen stark variiert. So würde ein Fall mit sehr vielen Oligodendrozyten, in dem nur einige doppelmarkiert sind, eine höhere Dichte HDAC1 ${ }^{+} /$Nogo- $\mathrm{A}^{+}$-Zellen aufweisen, 
als ein Fall, der kaum Oligodendrozyten vorweisen konnte, in welchem jetzt jedoch alle Oligodendrozyten doppelmarkiert sind. Diese absoluten Werte würden eine erhöhte Expression von HDAC1 im ersten Fall vortäuschen, obgleich die tatsächliche prozentuale Expression im zweiten Fall deutlich höher ist.
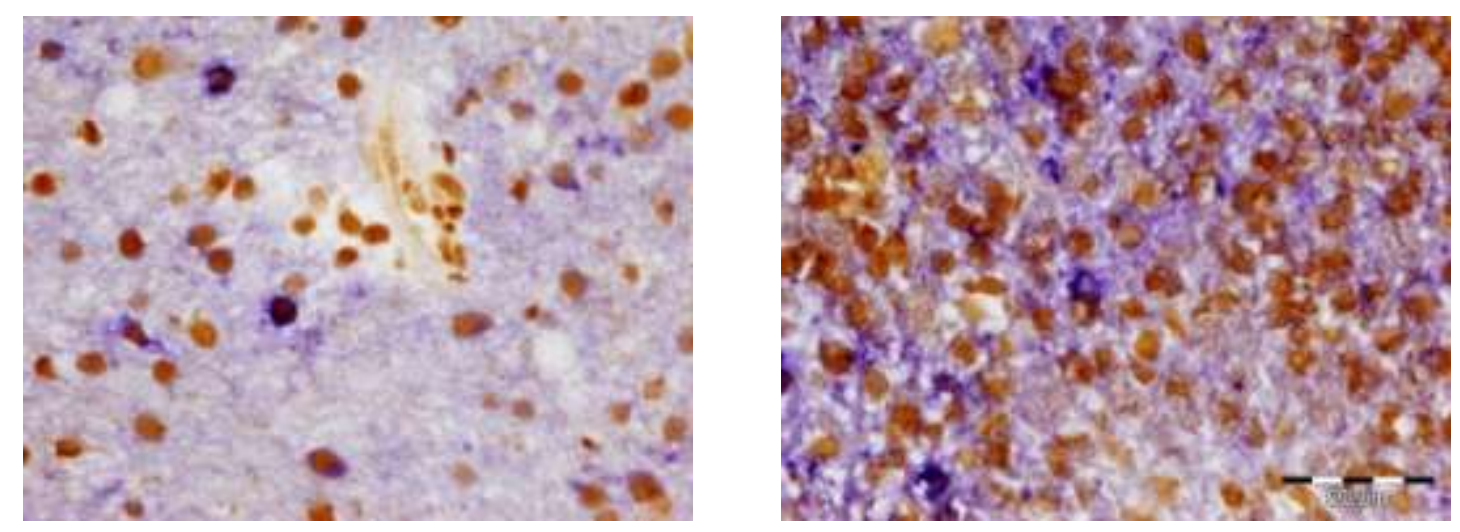

Abbildung 13: Expression von $\mathrm{HDAC}^{+} / \mathrm{Nogo}^{-} \mathrm{A}^{+}$Zellen in den Stadien ohne Remyelinisierung; Doppelmarkierung: brauner Kern: HDAC1 (auch viele andere Zellen sind HDAC1-positiv) + blaues Zytoplasma: Nogo A

Demnach musste für die Auswertung der Läsionen der prozentuale Anteil der doppelmarkierten Zellen an den gesamten Oligodendrozyten, d.h. allen Nogo- $\mathrm{A}^{+}$-Zellen (= $\mathrm{H}^{+} \mathrm{N}^{+}$und $\mathrm{H}^{-} \mathrm{N}^{+}$), verglichen werden. Anzumerken ist, dass im weiteren Text daher, aufgrund der beschränkten Aussagekraft der absoluten Werte, nur noch auf die relativen Werte eingegangen werden soll.

Es zeigte sich, dass $47,7 \pm 54,5 \%$ der Oligodendrozyten in Läsionen ohne Remyelinisierung mit schlechtem Oligodendrozytenerhalt und $61,5 \%$ in Läsionen ohne Remyelinisierung mit gutem Oligodendrozytenerhalt HDAC1 exprimieren. Auch diese Werte waren, wie bereits zuvor erwähnt aufgrund der geringen Fallzahl statistisch nicht zu vergleichen, liegen jedoch im Gegensatz zu den absoluten Werten nicht so deutlich auseinander.

Ausgewertet wurde darüber hinaus ebenfalls die Anzahl an $\mathrm{HDAC1}^{-} /$Nogo-A $^{+}$-Zellen. Dabei ergaben sich für die Fälle mit schlechtem Erhalt relative Werte von 52,4 $\pm 54,5 \%$. Der prozentuale Wert bei Fällen mit gutem Oligodendrozytenerhalt lag bei $38,5 \%$. 


\subsubsection{HDAC1-Expression in Fällen mit Remyelinisierung}

Betrachtet wurden hier Fälle im frühen Stadium der Remyelinisierung im Gegensatz zu Läsionen der späten Remyelinisierung, charakterisiert durch eine hohe Dichte von $\mathrm{MBP}^{+}-$ Myelinscheiden. Auch hier musste ein Fall aus der Wertung genommen werden, da das Areal nicht auszählbar war. Prozentual zeigte sich bei diesem Vergleich eine Zunahme von doppelmarkierten Zellen an der gesamten Nogo- $A^{+}$-Zellzahl von $70,8 \pm 16,5 \%$ im frühen Stadium der Remyelinisierung gegenüber $86,2 \pm 5,5 \%$ im späten Stadium, und somit eine signifikanter Unterschied in der HDAC1-Expression durch Oligodendrozyten $(p=0,0497)$.



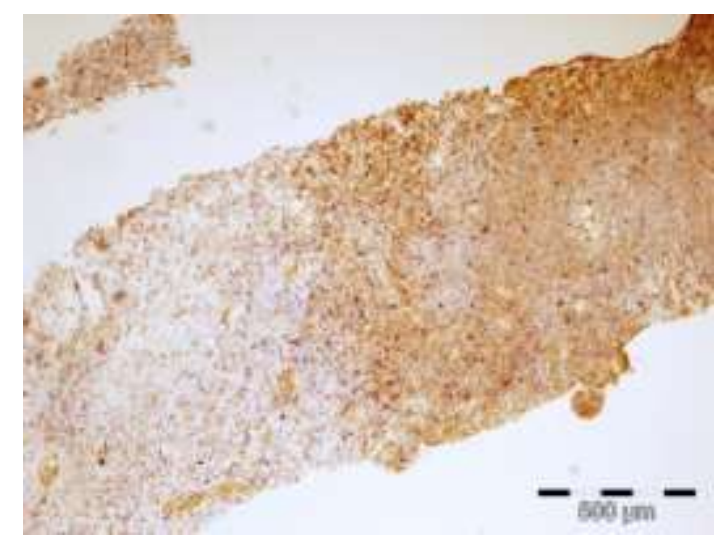

Abbildung 14: HDAC1/Nogo-A-Doppelmarkierung in remyelinisierten Läsionen; obere Reihe: frühes Stadium der Remyelinisierung mit einigen $\mathrm{HDAC1}^{+} /$Nogo-A+-Zellen; mittlere Reihe: spätes Stadium mit deutlicher Zunahme der HDAC1/Nogo-A-positiven Oligodendrozyten; untere Reihe: Biopsie mit Gradient der Remyelinisierung-Häufung der HDAC1/Nogo-A-doppelmarkierten Zellen im Bereich der stattfindenden Remyelinisierung

Eben dieses Bild zeigte sich auch in den Gradientenfällen, welche Läsionen vorweisen konnten, in denen sowohl ein frühes als auch ein spätes Stadium der Remyelinisierung vorzuweisen waren. In den Arealen mit früher Remyelinisierung waren 71,4\% bzw. 69,2 der Zellen $\mathrm{H}^{+} \mathrm{N}^{+}$. In den Arealen mit späterer Reymelinisierung zeigte sich eine Zunahme auf 87,6\% bzw. 84,7\%, eine Erhöhung um 15\%.

Bei der nachfolgenden Betrachtung der $\mathrm{HDAC1}^{-} /$Nogo- $\mathrm{A}^{+}$-markierten Zellen zeigte sich folglich mit 29,3 $\pm 16,5 \%$ (frühes Stadium) zu 13,9 \pm 5,5\% (spätes Stadium) das inverse Bild mit einer statistisch signifikanten Abnahme der zu zählenden Zellen Richtung späterem Stadium der Remyelinisierung.

\subsubsection{Vergleich der HDAC1-Expression aller Fälle}

Beim Vergleich der HDAC1-Expression aller Fälle zeigten sich keine statistisch signifikanten Unterschiede in der relativen Dichte doppelmarkierter Zellen zwischen den Stadien ohne Remyelinisierung gegenüber jenen mit Remyelinisierung. Auch hier ergaben sich Probleme mit der statistischen Analyse des Stadiums ohne Remyelinisierung mit gutem Oligodendrozytenerhalt, da dieses Stadium nur mit einem Fall vertreten war und sich somit keine statistischen Tests anwenden ließen.

Auffällig war der Vergleich vom Stadium ohne Remyelinisierung mit schlechtem 
Oligodendrozytenerhalt zum späten Stadium der Remyelinisierung, der mit $p=0,0841$ auf eine Tendenz bezüglich der statistischen Signifikanz hinweist.

Unter Zusammenfassung der Fälle ohne Remyelinisierung fiel auf, dass beim Vergleich des Stadiums ohne Remyelinisierung mit dem späten Stadium der Remyelinisierung eine deutliche Zunahme der Expression $\mathrm{H}^{+} \mathrm{N}^{+}$-Zellen von $52,3 \pm 39,4 \%$ zu 86,2 $\pm 5,5 \%$ mit $\mathrm{p}=$ 0,0615 zu erkennen war. Tabelle 10 und 11 sowie Abbildung 15 zeigen die Ergebnisse in tabellarischer und graphischer Übersicht.
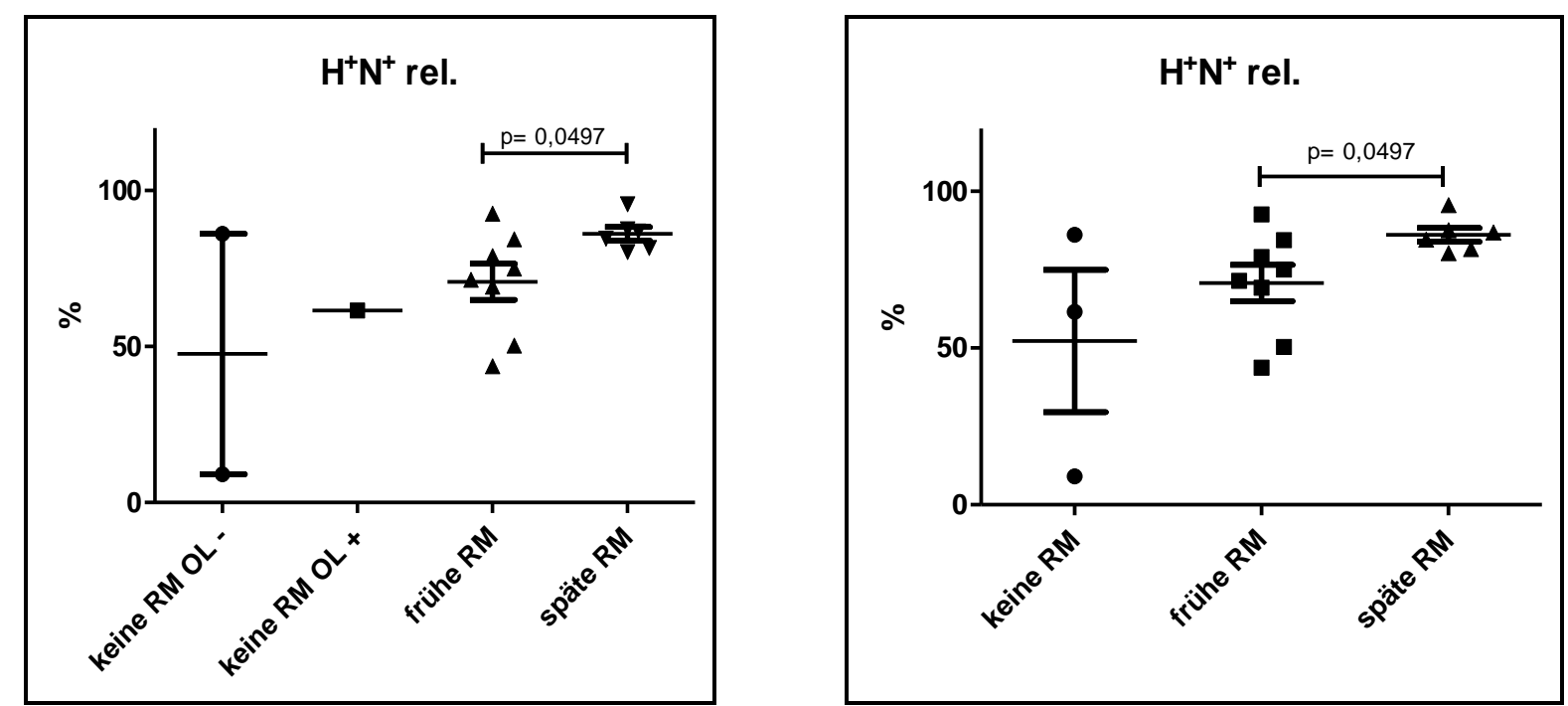

Abbildung 15: Doppelmarkierungen HDAC1/Nogo A; Graph rechts: graphische Darstellung der Ergebnisse der Doppelmarkierung unter Zusammenfassung der Fälle ohne Remyelinisierung; statistisch signifikante Zunahme der doppeltmarkierten Zellen vom frühen Stadium der Remyelinisierung zum späteren Stadium der Remyelinisierung hin

Für die relativen Werte der $\mathrm{HDAC1}^{-} /$Nogo- $\mathrm{A}^{+}$-markierten Zellen nach Auszählung ergab sich das gegenläufige Bild mit einer statistisch signifikanten Abnahme vom frühen zum späten Stadium der Remyelinisierung hin 

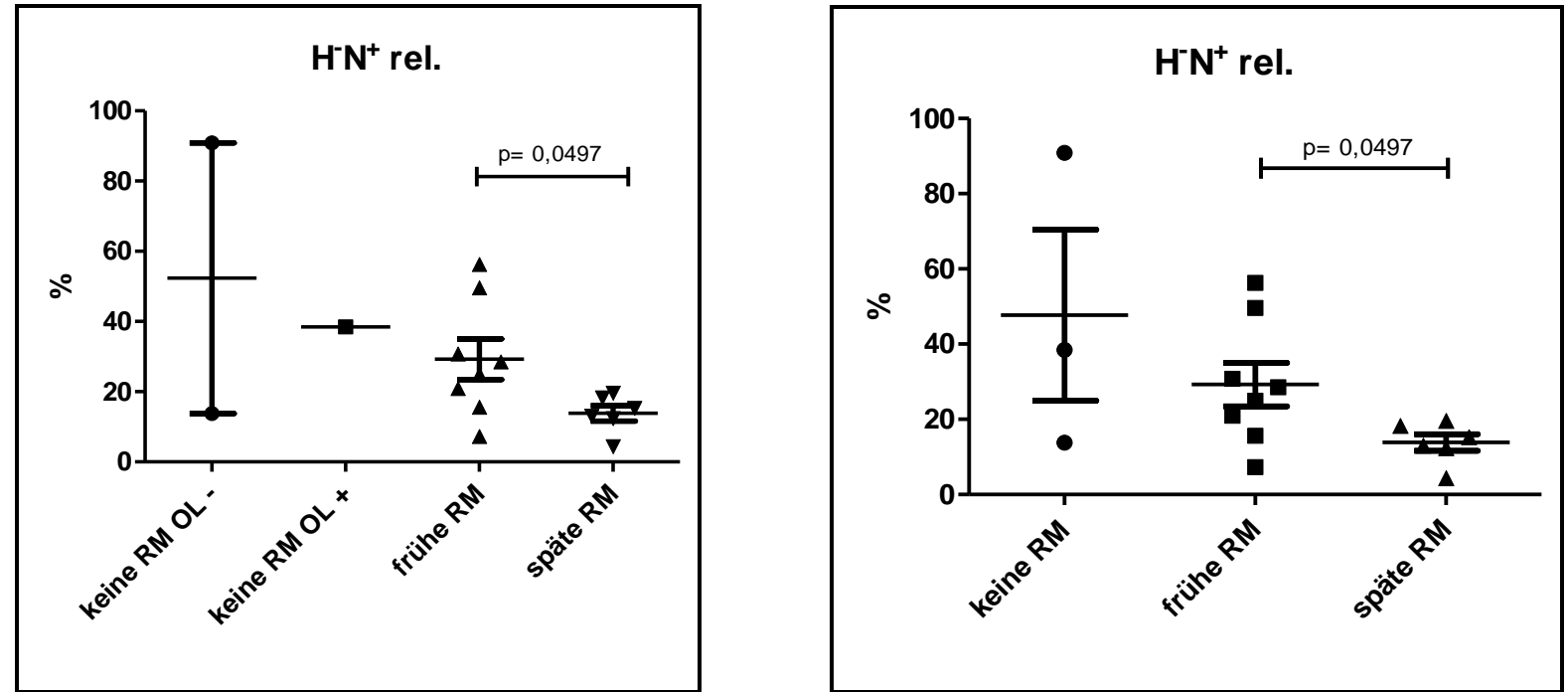

Abbildung 16: Prozentualer Anteil $\mathrm{HDAC1}^{-} /$Nogo- $\mathrm{A}^{+}$-Zellen an Gesamt-Nogo- $\mathrm{A}^{+}$-Zellen in den Läsionen; Graph rechts: Ergebnisse unter Zusammenfassung der Fälle ohne Remyelinisierung; statistisch signifikanter Unterschied zwischen frühem und späteren Stadium der Remyelinisierung

\begin{tabular}{|l|c|c|}
\hline & $\mathbf{H}^{+} \mathbf{N}^{+}$in \% & $\mathbf{H}^{-} \mathbf{N}^{+}$in \% \\
\hline $\begin{array}{l}\text { keine RM, } \\
\text { OL-Erhalt schlecht }\end{array}$ & $47,7 \pm 54,5$ & $52,4 \pm 54,5$ \\
\hline $\begin{array}{l}\text { keine RM, } \\
\text { OL-Erhalt gut }\end{array}$ & 61,5 & 38,5 \\
\hline frühe RM & $70,8 \pm 16,5$ & $29,3 \pm 16,5$ \\
\hline späte RM & $86,2 \pm 5,5$ & $13,9 \pm 5,5$ \\
\hline
\end{tabular}

Tabelle 10: HDAC1-Expression in den Läsionen

\begin{tabular}{|l|c|c|}
\hline & $\mathbf{H}^{+} \mathbf{N}^{+}$in \% & $\mathbf{H}^{-} \mathbf{N}^{+}$in $\%$ \\
\hline keine RM & $52,3 \pm 39,4$ & $47,7 \pm 39,4$ \\
\hline früh & $70,8 \pm 16,5$ & $29,3 \pm 16,5$ \\
\hline spät & $86,2 \pm 5,5$ & $13,9 \pm 5,5$ \\
& & \\
\hline
\end{tabular}

Tabelle 11: HDAC1-Expression in den Läsionen, Fälle ohne RM zusammengefasst 


\subsubsection{HDAC1-Expression im PPWM}

In 13 der 16 Fälle konnte neben der Läsion periläsionale weiße Substanz (peri plaque white matter= PPWM) beobachtet werden. Um mögliche Unterschiede bezüglich der HDAC1Expression zwischen den verschiedenen Stadien der Remyelinisierung in diesen Bereichen nicht zu übersehen, wurden auch hier die doppelmarkierten Zellen gezählt und ausgewertet.

Es zeigte sich hierbei, beim Vergleich der relativen HDAC1/Nogo-A-Expression des frühen gegenüber dem späten Stadium der Remyelinisierung, kein Unterschied von statistischer Signifikanz. Die Mittelwerte lagen mit 65,1 $\pm 34,1 \%$ (frühes Stadium) gegenüber $67,1 \pm 24,2 \%$ (spätes Stadium der Remyelinisierung) sehr dicht beieinander.

Diesem nahe kamen mit 68\% bzw. 60\% $\mathrm{HDAC1}^{+} /$Nogo- $\mathrm{A}^{+}$-Zellen an der Gesamtzahl Nogo- $\mathrm{A}^{+}-$ Zellen auch die Werte der Fälle ohne Remyelinisierung mit schlechtem bzw. gutem Oligodendrozytenerhalt. Bei der Betrachtung der $\mathrm{HDAC1}^{-} /$Nogo- $\mathrm{A}^{+}$-Zellen waren ebenfalls keine statistisch signifikanten Unterschiede sichtbar.

Auch bei der vereinfachten Darstellung mit Zusammenlegung der nicht-remyelinisierten Fälle konnten keine statistischen Auffälligkeiten und Differenzen zwischen den Stadien beobachtet werden. Tabelle 12 und 13 sowie Abbildung 18 und 19 zeigen die Ergebnisse im Überblick:

\begin{tabular}{|l|c|c|}
\hline & $\mathbf{H}^{+} \mathbf{N}^{+}$in \% & $\mathbf{H}^{-} \mathbf{N}^{+}$in \% \\
\hline $\begin{array}{l}\text { keine RM, } \\
\text { OL-Erhalt schlecht }\end{array}$ & 68 & 32 \\
\hline $\begin{array}{l}\text { keine RM, } \\
\text { OL-Erhalt gut }\end{array}$ & 60 & 40 \\
\hline frühe RM & $65,1 \pm 34,1$ & $34,9 \pm 34,1$ \\
\hline späte RM & $67,2 \pm 24,2$ & $32,8 \pm 24,2$ \\
\hline
\end{tabular}

Tabelle 12: HDAC1-Expression im PPWM 


\begin{tabular}{|l|c|c|}
\hline & $\mathbf{H}^{+} \mathbf{N}^{+}$in \% & $\mathbf{H}^{-} \mathbf{N}^{+}$in \% \\
\hline keine RM & $64 \pm 5,7$ & $36 \pm 5,7$ \\
\hline frühe RM & $65,1 \pm 34,1$ & $34,9 \pm 34,1$ \\
\hline späte RM & $67,2 \pm 24,2$ & $32,8 \pm 24,2$ \\
\hline
\end{tabular}

Tabelle 13: HDAC1-Expression im PPWM, Fälle ohne RM zusammengefasst
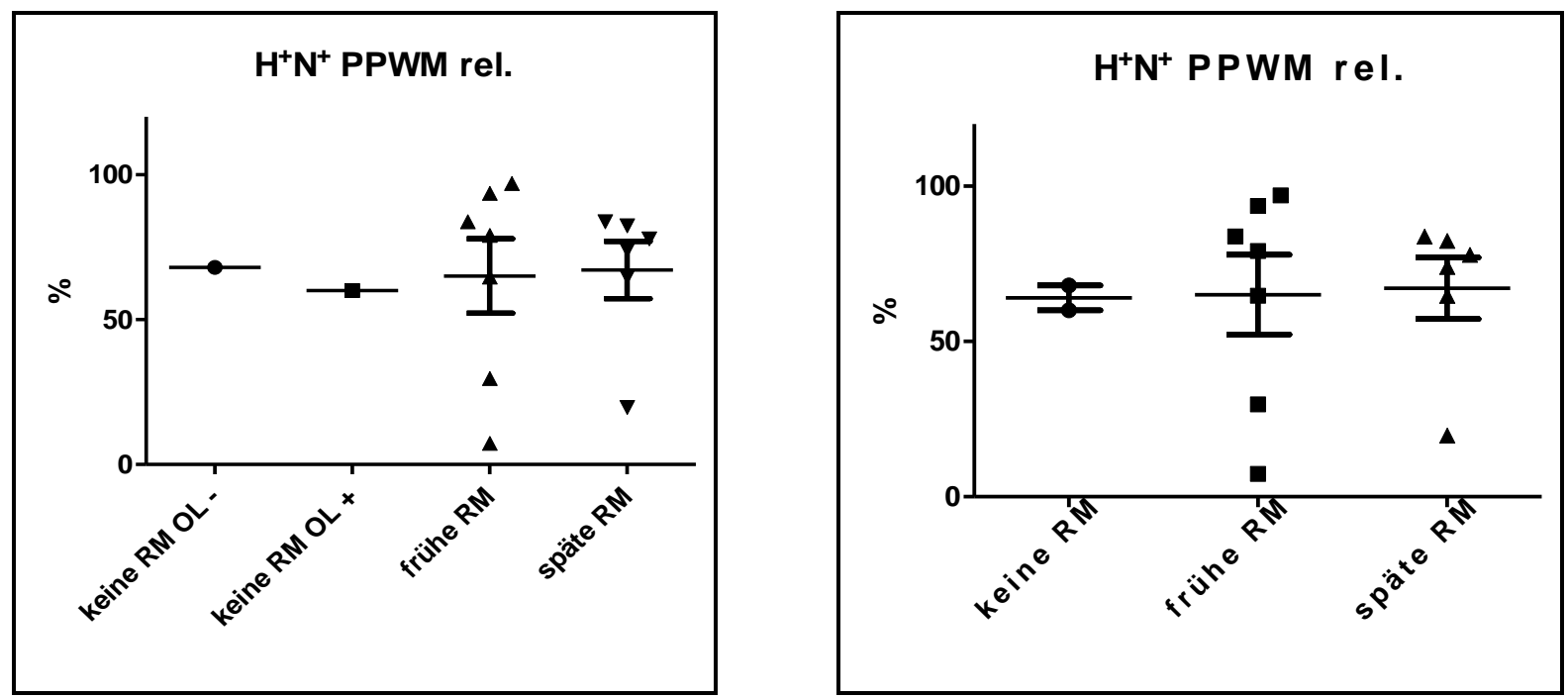

Abbildung 17: Graphische Darstellung der HDAC1-Expression im PPWM; keine statistisch signifikanten Unterschiede zwischen den einzelnen Stadien der Remyelinisierung; Graph rechts unter Zusammenfassung der Fälle ohne Remyelinisierung
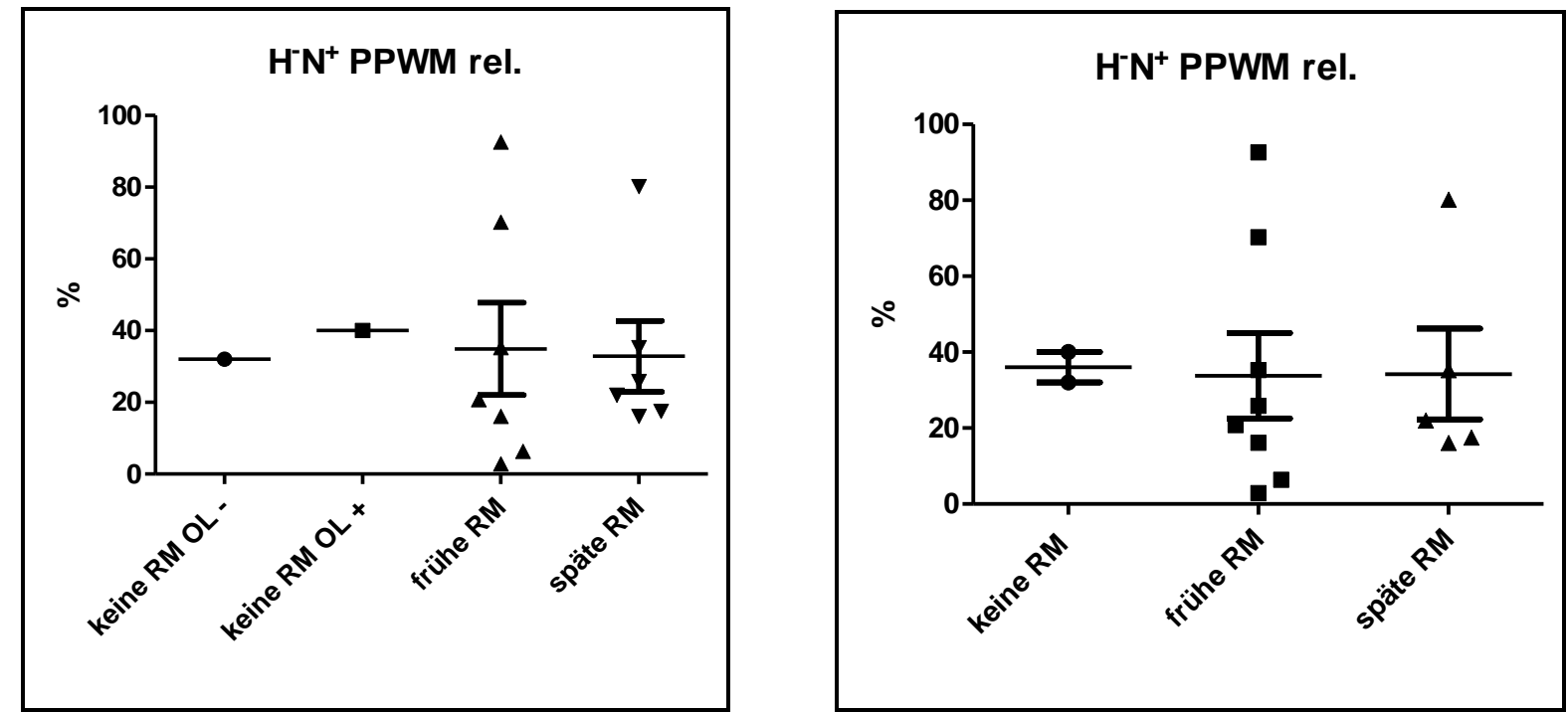

Abbildung 18: Graphische Darstellung der $\mathrm{H}^{-} \mathrm{N}^{+}$-Zellen im PPWM; Graph rechts unter Zusammenfassung der Fälle ohne Remyelinisierung 


\subsection{HDAC2 $^{+} /$p25 $^{+}$-Doppelmarkierung}

Im Falle der HDAC2/p25-Färbung zeigte sich, dass alle HDAC2-positiven Zellen sich auch positiv für den oligodendroglialen Marker p25 anfärbten. Von einer Auswertung wurde demnach abgesehen. p25 wurde hier als alternativer oligodendroglialer Marker verwendet, da der verfügbare Antikörper gegen HDAC2 aus der Maus stammte und daher eine Doppelmarkierung mit Nogo $A$ (ebenfalls aus der Maus) ungünstig war. 


\section{Diskussion}

\section{1 Überblick}

Die Multiple Sklerose gilt als eine autoimmune Erkrankung, die durch Markscheidenverlust gekennzeichnet ist. Bei manchen Patienten lässt sich auf die Demyelinisierung hin eine unterschiedlich stark ausgeprägte Remyelinisierung beobachten.

Viele Autoren haben sich bis heute mit der Frage beschäftigt, warum die Remyelinisierungseffizienz zwischen den einzelnen Patienten so stark divergiert. Basierend auf einer Theorie, die sich mit der verminderten Differenzierungsfähgkeit von OPCs aufgrund fehlender HDAC-Expression, insbesondere HDAC1 und 2, in alten Mäusen beschäftigt (Shen et al. 2008), entwickelten wir als Ziel dieser Arbeit die Fragestellung, ob sich unterschiedliche Prozentsätze $\mathrm{HDAC} 1 / 2^{+}$-Oligodendrozyten in Fällen mit und ohne Remyelinisierung beobachten lassen.

Methodisch erfolgte zunächst die Einteilung der Fälle, in diesem Fall von biopsierten entzündlich-entmarkenden Läsionen, in Remyelinisierungsstadien, wobei, da eine genaue Einteilung der frühen Remyelinisierung bis dato fehlt, zunächst ein detailliertes Klassifizierungssystem auf Grundlage der Oligodendrozytenentwicklung entwickelt werden musste. Dabei benutzten wir die in bereits publizierten Studien beschriebenen Beobachtungen über die Reihenfolge, in welcher Myelinproteine während der Myelinogenese bzw. Remyelinisierung auftreten.

Als schwierig erwies es sich hierbei, Fälle ohne Remyelinisierung, insbesondere jene mit schlechtem Oligodendrozytenerhalt zu finden, da in jener Phase, in welcher die meisten Biopsien entnommen werden, der Frühphase der Läsionsentwicklung, der überwiegende Teil der Läsionen noch gut remyelinisiert. Daher mussten wir eine geringe Datenlage von drei Fällen ohne Remyelinisierung akzeptieren. Daraufhin konnte die eigentliche Auswertung der HDAC1-Expression immunhistochemisch und quantitativ am Lichtmikroskop stadiengerecht erfolgen. 
Bezüglich der Stadieneinteilung zeigten sich statistisch signifikante Unterschiede in der $\mathrm{CNP}^{+}$- und $\mathrm{MBP}^{+}$-Faser-Expression einzelner Stadien sowie eine auffällige Zunahme der $\mathrm{MOG}^{+}$-Zellen hin zum späten Stadium, sodass es $\mathrm{zu}$ diskutieren ist, ob jene Myelinproteine generell zur detailierten Einteilung verwendet werden könnten.Auch die Ergebnisse der HDAC1-Expression zeigten einen statistisch signifikanten Unterschied zwischen dem frühen und späten Stadium der Remyelinisierung mit einer Zunahme HDAC1positiver Oligodendrozyten zum späten Stadium hin, waren demnach kongruent mit der vorangestellten These und spiegelten zum Teil die Beobachtungen anderer Arbeiten wider. Die Stadien ohne Remyelinisierung mit jenen mit Remyelinisierung vergleichend, konnte jedoch kein Unterschied festgestellt werden. Dieses lässt einen Diskurs über die Bedeutung von HDAC1 als ausschlaggebendem Faktor zur Remyelinisierung bzw. seine allgemeine Rolle bezüglich des Unvermögens zur Remyelinisierung zu. Auf dieses sowie die differenzierte Stadieneinteilung soll im Weiteren genauer eingegangen werden.

\subsection{Expression der Myelinproteine}

Im Rahmen dieser Arbeit kamen wir zu einem Punkt, an welchem die genaue Einteilung der ausgesuchten Fälle in Remyelinisierungsstadien notwendig war, um die Ergebnisse der HDAC1-Expression stadiengerecht beobachten und transferieren zu können. Dabei schien uns die bisherige Klassifikation in früh und spät remyelinisierende Läsionen zu weitmaschig. Dabei sind früh remyelinisierende Läsionen durch neugebildete LFB-PAS+-Myelinscheiden und noch vorhandene schaumzellige Makrophagen, spät remyelinisierende Läsionen durch sogenannte "shadow plaques" mit überwiegender Wiederherstellung der Myelinscheidendichte gekennzeichnet.

In vielen Fällen ist die Expression von bestimmten Myelinproteinen als Marker für eine frühe Remyelinisierung jedoch schon zu sehen, noch bevor anhand der LFB-PAS-Färbung positive Fasern zu erkennen sind (Lindner et al. 2008). Da zu diesem Zeitpunkt keine weitere detaillierte Einteilung vorlag, definierten wir in der vorliegenden Arbeit eine präzise Stadieneinteilung der Remyelinisierung in MS-Läsionen. 
Als Grundlage benutzten wir, wie zuvor erwähnt, die Reihenfolge der Myelinproteinexpression während der Oligodendrozytenentwicklung und der Myelinogenese. Dass das zeitliche Auftreten der Myelinproteine während der Remyelinisierung dem Muster der Myelinogenese gleicht, konnte vielfach, wie oben bereits beschrieben, beobachtet werden (Woodruff und Franklin 1999).

Die primäre Einteilung der Fälle erfolgte zunächst nach der rein optischen Einschätzung. Fälle, in denen LFB-PAS+-Fasern zu sehen waren, wurden automatisch dem späten Stadium der Remyelinisierung zugeordnet. Die weitere Einteilung erfolgte auf Basis des Wissens um die Expression von CNP, MAG, MBP und MOG während der Myelinogenese. Im weiteren Teil der Arbeit stellten wir uns der Frage, welches die zentralen Marker sind, die eine Einteilung der Läsionen in bestimmte Stadien der Remyelinisierung zulassen.

\subsubsection{Stadienabhängige Dichte von $\mathrm{CNP}^{+}$-Fasern und Zellen}

Unter den Myelinproteinen gilt CNP als dasjenige, dessen Expression als erstes zu beobachten ist (Reynolds und Wilkin 1988). Auffällig war, dass in unserer Arbeit alle Fälle bis auf zwei, die wir in das Stadium ohne Remyelinisierung mit schlechtem Oligodendrozytenerhalt eingeteilt hatten, $\mathrm{CNP}^{+}$-Zellen vorweisen konnten. Obwohl, aufgrund der kleinen Fallzahl, keine statistisch signifikanten Unterschiede bezüglich der Anzahl $\mathrm{CNP}^{+}$-Oligodendrozyten zwischen den Stadien ermittelt werden konnten, ist eine verminderte Dichte CNP-positiver Zellen in den Stadien ohne Remyelinisierung gegenüber jenem mit unübersehbar. Zu diskutieren gilt nun, ob eine Differenzierung zwischen dem Stadium ohne Remyelinisierung mit gutem Oligodendrozytenerhalt und dem frühen Stadium der Remyelinisierung bereits anhand der $\mathrm{CNP}^{+}$-Zellzahl möglich ist, ob also höhere $\mathrm{CNP}^{+}-$ Zellzahlen automatisch auf ein remyelinisierendes Stadium hinweisen oder ob dafür andere Markerproteine eingesetzt werden müssen. Wir wollen diese Frage zunächst offen lassen.

Interessant ist in diesem Rahmen auch die Expression von $\mathrm{CNP}^{+}$-Fasern, bei der sich in keinem Stadium ohne Remyelinisierung, unabhängig vom Oligodendrozytenstatus, Fasern zeigten. Konsequent stellt sich wieder die Frage, ob das Vorkommen $\mathrm{CNP}^{+}$-Fasern ein robuster Marker für funktionierende Remyelinisierung sein könnte. Da CNP das erste gebildete Myelinprotein während der Entwicklung, somit noch in unreifen Oligodendrozyten zu finden ist, könnte der Nachweis CNP-positiver Fasern, der 
regelgebunden erst verzögert auf die Expression von CNP in den Zellkörpern folgt, das erste Zeichen für eine effektive Remyelinisierung sein.

In dieser Arbeit konnten wir also die Divergenz in der $\mathrm{CNP}^{+}$-Faserexpression zwischen Stadien ohne Remyelinisierung und insbesondere dem Stadium der späten Remyelinisierung nachweisen. Bei der Überlegung einen Fall dem späten Stadium zuzuteilen, kann man somit hinweisend die $\mathrm{CNP}^{+}$-Faserzahl betrachten, wobei die eigentliche Einteilung in späte Stadien bisher eher anhand von Myelinproteinen wie MOG erfolgt ist.

\subsubsection{MOG - stadienspezifisches Expressionsmuster}

MOG ist ein weiteres Myelinprotein, das während der Myelinogenese hervorsticht. Es gilt als das Myelinprotein, welches im Gegensatz zu den anderen erst spät in der Entwicklung exprimiert wird (Pagany et al. 2003). Auf Grundlage dieses Wissens stellten wir uns die Frage, ob vielleicht die Expression von MOG zur schwierigen Unterscheidung zwischen dem frühen und dem späten Stadium der frühen Remyelinisierung unserer Klassifikation dienen könnte. Unsere Ergebnisse, zumindest jene der $\mathrm{MOG}^{+}$-Faser-Quantifizierung, legen eine solche Schlussfolgerung nahe.

Während kein signifikanter Unterschied in der Dichte von $\mathrm{MOG}^{+}$-Zellen zwischen den Stadien mit und ohne Remyelinisierung zu erkennen war, zeigte sich mit $p=0,0502$ eine deutliche Tendenz zu mehr $\mathrm{MOG}^{+}$-Fasern in Fällen mit fortgeschrittener Remyelinisierung. Auffällig bezüglich der Dichte $\mathrm{MOG}^{+}$-Zellen war dennoch, dass während im späten Stadium alle Fälle bereits positive Zellen vorweisen, dieses Bild im frühen Stadium weit inhomogener ist. Es finden sich hierbei Fälle, in denen schon zahlreiche MOG+-Oligodendrozyten zu erfassen sind neben anderen, in denen kein positiver Oligodendrozyt zu erkennen ist. Diese Unterschiede zeigen, dass das Stadium der frühen Remyelinisierung durch eine langsam beginnende MOG-Expression in den Oligodendrozytenzellkörpern gekennzeichnet ist, die sich in der späten Phase abschließt und die Bildung positiver Fasern nach sich zieht.

Man kann demnach schlussfolgern, dass eine entmarkte Läsion, die eine hohe Anzahl von $\mathrm{MOG}^{+}$-Fasern aufweist, sich bei der Einteilung in Remyelinisierungsstadien eher in Richtung eines späteren Stadiums einordnen lässt. Kritisch anzumerken ist jedoch, dass selbst wenn ein deutlicher Unterschied in der MOG-Faserexpression zwischen jenen Stadien besteht, es doch nicht möglich ist eine feste Trennlinie bezogen auf die Dichte zu ziehen, da eine 
gewisse Überlappung vorherrscht. Die Expression von $\mathrm{MOG}$, insbesondere von $\mathrm{MOG}^{+}-$ Fasern, in einem eher späten Stadium der Remyelinisierung ist zwar, wie Lindner et al. 2008 beschrieben haben, typisch, jedoch nicht zwingend, oder gar stadienbeweisend. So können im Rahmen der Stadieneinteilung MOG+-Fasern als hinweisendes Zeichen, nicht jedoch als absolute Marker des späten Stadiums der Remyelinisierung gesehen werden und müssen im Zusammenhang mit den übrigen Myelinproteinen betrachtet werden.

\subsubsection{Nogo-A- und MAG-positive Strukturen}

Im Verlauf beschäftigten wir uns mit der Expression von Nogo A und MAG. Da diese beiden Myelinproteine jedoch keine Auffälligkeiten zwischen den einzelnen Stadien zeigten und sie beide bereits sehr früh während der Myelinogenese exprimiert werden, erwiesen sie sich für die Klassifikation als zu unspezifisch. Interessant war aber die Beobachtung, dass einige Fälle unabhängig vom Stadium keine MAG-Expression vorweisen konnten, obwohl viele andere, weit spätere Myelinproteine bereits vorhanden waren. Wir führen dieses auf den Grund zurück, den auch Dubois-Dalcq et al. (1986) anführten, dass MAG mit $<1 \%$ einen sehr geringen Anteil am Myelin ausmacht und somit bei einem Teil der Fälle möglicherweise durch eine geringe Sensitivität der Methode die Detektion von MAG einschränkte.

\subsubsection{MBP - Marker der späten Remyelinisierung}

Das letzte Myelinprotein dessen Expression in der hier vorliegenden Arbeit genauer betrachtet wurde, ist MBP. MBP macht mit rund 30\% des Gesamtmyelins einen bedeutenden Anteil aus und wird, wie zahlreiche Studien zeigen konnten (Lindner et al. 2008, Reynolds und Wilkin 1988), früh nach kurzer Latenz zum CNP im Verlauf der Myelinogenese in den Zellkörpern exprimiert. Während dieses Expressionsmuster in vitro unter Versuchsbedingungen, unter denen zumeist Oligodendrozyten ohne Axone oder andere Zellen gezüchtet werden, gefunden wird, zeigen unsere Ergebnisse in MS-Läsionen ein anderes Bild.

So fanden sich bei der quantitativen Analyse lediglich zwei Fälle im späten Stadium der Remyelinisierung, in denen, zudem wenige, $\mathrm{MBP}^{+}$-Oligodendrozyten gezählt werden konnten. Da diese Ergebnisse sehr stark von jenen bekannter Publikationen divergieren, muss sich unweigerlich die Frage nach der Ursache hierfür stellen. Möglich wären die oben 
beschriebenen Unterschiede in den Versuchsbedingungen, unter denen Oligodendrozyten in vivo mit anderen Strukturen interagieren. $\mathrm{MBP}^{+}$-Zellkörper stellen so ein klares in vitroPhänomen dar.

War die Interpretation der Dichte von $\mathrm{MBP}^{+}$-Zellen somit eingeschränkt, erschien die Beobachtung der $\mathrm{MBP}^{+}$-Fasern umso interessanter. Wie in den Ergebnissen beschrieben, zeigte sich eine statistisch signifikante Zunahme der Faseranzahl vom frühen zum späten Stadium $(p=0,0018)$. Während im frühen Stadium nur ein Fall mit sehr geringer Faserexpression aufgezeigt werden konnte, exprimierten ausnahmslos alle späten Fälle $\mathrm{MBP}^{+}$-Fasern.

Dieser Sachverhalt lässt die Behauptung aufkommen, dass $\mathrm{MBP}^{+}$-Fasern ein Marker für die späte Remyelinisierung darstellen könnten. Wir gehen davon aus, dass die Ergebnisse und deren Signifikanz die These unterstützen, dass das Vorhandensein $\mathrm{MBP}^{+}$-Fasern als Marker für das späte Stadium zu sehen ist. Leider lassen sich in der Literatur keine genaueren Angaben oder Versuche explizit über die $\mathrm{MBP}^{+}$-Faserexpression während der Myelinogenese und ihrem zeitlichen Verhältnis zur Expression im Zellkörper finden, in deren Kontext unsere Ergebnisse diskutiert werden könnten.

\subsubsection{Zusammenfassung der Kriterien zur Einteilung der untersuchten Läsionen in Stadien der Remyelinisierung}

Zum Abschluss dieses Abschnitts sollen die Ergebnisse, die sich mit der Stadieneinteilung der Remyelinisierung in MS-Läsionen beschäftigen und der folgenden Interpretation der HDAC1Expression in Läsionen dienen, zusammengefasst werden.

Mit der Absicht ein detailliertes Klassifizierungssystem bezüglich des Remyelinisierungsstadiums zu entwickeln, untersuchten wir die Myelinproteinexpression in entmarkten Läsionen von biopsierten MS-Patienten mit dem Vorsatz stadienspezifische Expressionsmuster erkennen und entwickeln zu können. Gleichzeitig stellten wir uns die Frage, ob einige Myelinproteine als Marker zur definitiven Unterscheidung zwischen einzelnen Stadien dienen könnten.

So können $\mathrm{MOG}^{+}$-Fasern und -zellen sowie $\mathrm{MBP}^{+}$-Fasern als Unterteilungskriterien zur Differenzierung in frühere und spätere Phase der Remyelinisierung angeführt werden. 
Die in dieser Arbeit gewonnene Erkenntnis und vielfache Bestätigung der im laufenden Text genannten Versuchsergebnisse bereits publizierter Studien unterstreicht somit, dass die bewiesene vermehrte Expression von $\mathrm{MOG}^{+}$-Fasern und -zellen, wenn auch nicht als absolutes Kriterium, sowie die unserer Arbeit dem späten Stadium spezifische $\mathrm{MBP}^{+}-$ Faserexpression eine Einteilung von Fällen in Remyelinisierungsstadien ermöglicht und erleichtert.

\subsection{Unterschiede in der HDAC1-Expression zwischen verschiedenen Stadien der Remyelinisierung}

\subsubsection{Hintergrund und Durchführung}

Bis heute ungeklärt ist die Frage, warum in einigen Läsionen nach erfolgter Entmarkung Remyelinisierung beobachtet werden kann und in anderen nicht. Wie im Abschnitt 1.2 bereits ausführlich dargestellt, wurden dazu mehrere, z.T. auch widersprüchliche, Hypothesen aufgestellt.

Ein Theorem ist die Verbindung zwischen dem Vorhandensein von oligodendroglialen Zellen und dem Ausmaß der Remyelinisierung, welches davon ausgeht, dass Remyelinisierung solange natürlich abläuft wie zur Bildung von Markscheiden-fähige Zellen vorhanden sind (Lucchinetti et al. 1999).

Aufgrund der Tatsache jedoch, dass auch Läsionen mit großer Anzahl von oligodendroglialen Zellen gefunden werden konnten, in denen keine Remyelinisierung zu beobachten war, entwickelten andere die Ansicht, dass nicht die mangelnde Rekrutierung der Zellen, sondern die fehlende Differenzierung jener eine entscheidendere Rolle für das Remyelinisierungsausmaß spielt (Franklin 2002, Sim et al. 2002).

Ausgehend davon beobachtete man die Entwicklung der Oligodendrozyten und entdeckte, dass jene durch die Histondeazetylierung eingeleitet und gesteuert wird. Cunliffe und Casaccia-Bonnefil (2006) konnten zeigen, dass hohe Klasse-I-HDAC-Level, insbesondere HDAC1, in OPCs für die Differenzierung und Entwicklung in reife, myelinisierende 
Oligodendrozyten nötig sind.

Auch Shen et al. (2008) stellten sich in ihrer Arbeit der Frage, ob es einen direkten Bezug zwischen dem Vorhandensein epigenetischer Modulatoren der Genexpression, in diesem Fall HDAC1, und der Effizienz der Remyelinisierung gibt. Ausgehend von der Beobachtung einer altersabhängigen Abnahme der Remyelinisierung von jungen zu alten Mäusen und der Annahme, dass die fehlende Differenzierung von OPCs im Alter dafür verantwortlich ist, untersuchten sie die HDAC-Expression von Oligodendrozyten in alten und jungen Mäusen nach Cuprizon-induzierter Entmarkung. Ergebnis war eine Reduktion der HDAC1-Expression in Oligodendrozyten in alten Mäusen, die mit einer ineffizienteren Remyelinisierung einherging und zudem jenem Bild glich, das bei jungen Mäusen beobachtet werden konnte, die zuvor mit einem HDAC1-Inhibitor behandelt worden waren.

Sie zogen die Schlussfolgerung, dass die altersabhängige Abnahme der Remyelinisierungsfähigkeit in direktem Zusammenhang mit der HDAC1-Expression durch Oligodendrozyten steht.

Dass Klasse-I-HDACs, zu denen eben HDAC1 gehört, und deren Inhibition eine wichtige Rolle auch in der Pathogenese und Therapie weiterer neurologischer/neurodegenerativer Erkrankungen, wie z.B. Morbus Alzheimer spielen, ist bekannt. So konnte gezeigt werden, dass in diesem Fall die Inhibition von HDAC1 und 2 einen Einfluss auf die Stabilisierung sowie teilweise Wiederherstellung der Erinnerung hat (Fischer et al. 2010, Kilgore et al. 2010). Im peripheren Nervensystem ist das Vorhandensein von HDAC1 und 2 kritisch für die vorangehende Myelinisierung sowie das Bestehen von Schwann Zellen

Basierend auf der Arbeit von Shen et al. (2008) stellten wir uns die Frage, ob auch beim an MS erkrankten Menschen das unterschiedliche Ausmaß der Remyelinisierung in irgendeiner Weise mit der HDAC1- bzw. HDAC2-Expression korreliert und somit eine Erklärung für die beobachtete unterschiedliche Effizienz der Remyelinisierung sein könnte. Dafür stellten wir Läsionen von biopsierten MS-Patienten ohne Remyelinisierung Läsionen im Stadium der frühen sowie späteren Remyelinisierung gegenüber und untersuchten jene immunhistochemisch mittels HDAC1/Nogo-A-Doppelmarkierung bezüglich der Expression von HDAC1 und 2 in Oligodendrozyten. 


\subsubsection{Stadienabhängige HDAC1-Expression}

In unserer Studie konnten wir eine statistisch signifikante Zunahme der HDAC1-Expression in den Oligodendrozyten mit dem Verlauf der Remyelinisierung vom frühen Stadium hin zum späteren Stadium beobachten. In relativen Werten bedeutet dieses eine Zunahme um rund $16 \%$ von 70,8 $\pm 16,5 \%$ HDAC1 exprimierender Oligodendrozyten im frühen Stadium der Remyelinisierung auf 86,2 $\pm 5,5$ \% im späteren Stadium der Remyelinisierung. Auffällig war dabei zudem, dass im späten Stadium der Remyelinisierung in allen Fällen über 80\% HDAC1positive Oligodendrozyten vorzufinden waren. Demgegenüber war die HDAC1-Expression im frühen Stadium der Remyelinisierung viel inhomogener. Es zeigte sich mit Werten von 43,8\% bis $92,7 \%$ eine weitaus höhere Schwankungsbreite. Der Versuch, eine mögliche Korrelation zum Expressionsmuster bestimmter Myelinproteine zu zeigen, gelang jedoch nicht. Insbesondere die Dichte von $\mathrm{MOG}^{+}$-Zellen war dabei auffällig, da auch sie, wie in der vorangegangenen Arbeit beschrieben, eine breite Streuung innerhalb des frühen Stadiums der Remyelinisierung aufwies. Eine Beziehung zwischen der Dichte von MOG-positiven Zellen und $\mathrm{HDAC1}^{+}$-Oligodendrozyten konnte jedoch nicht gezeigt werden.

Im Gegensatz zu den Stadien mit Remyelinisierung war kein statistisch signifikanter Unterschied bezüglich des Prozentsatzes HDAC1-exprimierender Oligodendrozyten zwischen den beiden Stadien ohne Remyelinisierung noch zwischen den Stadien ohne Remyelinisierung (nach Zusammenfassung der Fälle) und den Stadien mit Remyelinisierung sichtbar. Mit $p=0,0841$ beim Vergleich des Stadiums ohne Remyelinisierung mit schlechtem Oligodendrozytenerhalt zum späten Stadium und $p=0,0615$ bei der Gegenüberstellung der zusammengefassten Fälle ohne Remyelinisierung zum späten Stadium der Remyelinisierung, zeigte sich doch eine tendenziell erhöhte HDAC1-Expression in den späten Läsionen.

Diese Ergebnisse entsprechen somit nur zum Teil den oben beschriebenen Ergebnissen von Shen et al. (2008) und unterstützen, zumindest das frühe und spätere Remyelinisierungsstadium betreffend, die Beobachtung des Zusammenhanges zwischen der HDAC1-Expression und der Remyelinisierungseffizienz. Je fortgeschrittener und weitreichender die Remyelinisierung in unseren Fällen war, desto ausgeprägter die HDAC1-Expression. Wir konnten somit zeigen, dass nicht nur im Rahmen des Alterungsprozesses bei 
Mäusen die Abnahme der Remyelinisierung bedingt durch den Verlust der Differenzierungsfähigkeit von OPCs von der HDAC1-Expression abhängig ist, sondern auch in menschlichen Biopsien von MS-Läsionen der zu beobachtende unterschiedliche Remyelinisierungsgrad mit einer ungleichen HDAC1-Expression einhergeht. Diese Tatsache kann als Hinweis dafür gewertet werden, dass HDAC1 essentiell für die Fähigkeit zur Remyelinisierung ist, und dass ein Grund für das Unvermögen einiger Areale zur Remyelinisierung in einer fehlenden HDAC1-Ausprägung liegen könnte.

Interessant ist darüber hinaus die Beobachtung, dass der Unterschied der HDAC1-Expression nicht nur zwischen den Fällen verschiedener Remyelinisierungsstadien besteht, sondern selbst in Fällen mit Gradienten der Remyelinisierung zu sehen ist. Es handelt sich dabei um zwei Fälle, innerhalb derer eine Zunahme der Remyelinisierung vom Läsionszentrum zum Läsionsrand zu beobachten ist. Bei der Auswertung der doppelmarkierten Zellen zeigte sich dabei für beide Fälle eine entsprechende Erhöhung der HDAC1-Expression mit fortschreitender Remyelinisierung von $69,2 \%$ bzw. 71,4\% auf $84,7 \%$ bzw. 87,6\% der Nogo-Apositiven Zellen.

Diese Fälle liefern zudem einen weiteren Beitrag zur Diskussion über den Grund des Unvermögens zur Remyelinisierung einiger Areale nach erfolgter Entmarkung, die von zahlreichen Autoren geführt wird.

So steigt in den Arealen mit später Remyelinisierung nicht nur die Expression von HDAC1 in den Oligodendrozyten gegenüber dem frühen Stadium der Remyelinisierung, auch lässt sich in den späteren Arealen gleichzeitig eine generelle Zunahme der Oligodendrozyten beobachten. Zusammengefasst zeigen diese Fälle also eine Zunahme der Remyelinisierung, die mit einer prozentualen Steigerung der HDAC1-positiven Oligodendrozyten sowie einer absoluten Zunahme der Dichte von Oligodendrozyten einhergeht. Es gibt mehr Oligodendrozyten, die zudem prozentual mehr HDAC1 exprimieren. Durch diese Ergebnisse können wir mit dieser Arbeit somit beide Hypothesen unterstützen, die von einer mangelnden bis fehlenden Differenzierung der OPCs und einer eingeschränkten Rekrutierung und Existenz von oligodendroglialen Zellen in den Läsionen als Grund für die unterschiedliche Remyelinisierungsfähigkeit ausgehen. Welche These von beiden die ausschlaggebende ist, bleibt offen. 
Auch die Frage, warum keine statistisch signifikanten Unterschiede zwischen den Stadien ohne Remyelinisierung und jenen mit Remyelinisierung $\mathrm{zu}$ beobachten sind, bleibt unbeantwortet. Möglich wären unnatürlich hohe Werte der HDAC1/Nogo-A-positiven Zellen durch eine generell geringe Anzahl an Nogo-A-positiven Zellen. Auch das Faktum der geringen Datenlage bezogen auf das Stadium ohne Remyelinisierung ist kritisch anzumerken.

\subsubsection{Dichte HDAC1/Nogo-A-positiver Oligodendrozyten im PPWM}

Bei der Betrachtung der HDAC1-Expression in der periläsionalen weißen Substanz konnten, wie oben beschrieben, keine statistisch signifikanten Unterschiede zwischen den Stadien der Remyelinisierung entdeckt werden. Die prozentualen Mittelwerte der HDAC1/Nogo-Apositiven Oligodendrozyten der einzelnen Remyelinisierungsstadien lagen alle rund um 60\%. Die Expression von HDAC1 in Oligodendrozyten im PPWM rund um die Läsion scheint somit unbeeinflusst vom Ausmaß der HDAC1-Expression in der Läsion zu sein.

Diese These wird durch eine Beobachtung unterstützt, die Pedre et al. (2011) machten. In ihrer Arbeit betrachteten sie die Verschiebung der Histonazetylierung von Oligodendrozyten im PPWM des Frontalhirns bei älteren Tieren sowie bei Patienten mit chronischer MS. Obwohl die Level von Histon-H3-Azetylierung im PPWM bei MS-Patienten im Vergleich mit Kontrollfällen erhöht waren, zeigte sich doch keine statistisch signifikante Abnahme der Transkriptionslevel von HDAC1 und 2. Die vermehrte Histonazetylierung muss daher anderswo herrühren. Die oben beschriebenen Beobachtungen entsprechen somit unseren Ergebnissen im PPWM.

\subsubsection{Ausblick}

In unserer Arbeit betrachteten wir vor allem Fälle von MS-Patienten, die im frühen Stadium der Erkrankung biopsiert worden waren. Unsere Ergebnisse spiegeln also die Remyelinisierungsfähigkeit der frühen Multiplen Sklerose wider, einer Phase, in der die Remyelinisierung meistens noch gut funktioniert. Interessant wäre daher die zukünftige Beschäftigung mit der Frage, ob Unterschiede in der HDAC1-Expression zwischen frühen und späten MS-Läsionen zu beobachten sind, da mit fortschreitender Multipler Sklerose die 
Remyelinisierungsfähigkeit, wie im Einführungsteil beschrieben und auch bei Pedre et al. (2011) nochmals beobachtet, größtenteils abnimmt.

Ein weiterer Punkt, der in Zukunft betrachtet werden sollte, ist die Expression von Klasse-IHDACs in Oligodendrozytenvorläuferzellen, da sich die Versuche unserer Arbeit ausschließlich mit reifen Oligodendrozyten beschäftigten.

Gerade die Differenzierung von OPCs in reife Oligodendrozyten, die an das Vorhandensein von Histondeazetylasen gebunden ist, ist jedoch essentiell für die Remyelinisierung. Es wäre daher interessant zu sehen, ob auch in diesem Entwicklungsstadium Unterschiede, insbesondere in der HDAC1-Expression, zwischen den einzelnen Stadien der Remyelinisierung zu entdecken sind. Vielleicht fänden sich darüber hinaus sogar Unterschiede zwischen Stadien der Remyelinisierung, wie z.B. zwischen dem Stadium ohne Remyelinisierung und dem frühen Stadium der Remyelinisierung, die in unserer Arbeit nicht hatten beobachtet werden können. 


\section{Zusammenfassung}

Bei der Multiplen Sklerose handelt es sich um eine Erkrankung, die durch einen Verlust an Myelinscheiden charakterisiert ist. In einigen Fällen kann auf diese Demyelinisierung eine Remyelinisierung erfolgen, die jedoch von Patient zu Patient unterschiedlich ausfällt. Bei der Beschäftigung mit der Ursache für diese Variabilität der Remyelinisierungsfähigkeit wurde das Vorhandensein von HDAC1 als möglicher Faktor diskutiert, da dessen Anwesenheit unabdingbar für die Differenzierung in Richtung oligodendrogliale Zellen und die Differenzierung in reife, zur Remyelinisierung-fähige Oligodendrozyten ist. Da eine Beziehung zwischen der HDAC1-Expression und dem Remyelinisierungsgrad in Mäusen zu sehen war, stellten wir uns in dieser Arbeit die Frage, ob dieses Verhältnis auch in MSPatienten zu beobachten ist. Um zwischen einzelnen Remyelinisierungsstadien und deren HDAC1-Expression unterscheiden zu können, stellten wir uns zunächst der Herausforderung der Entwicklung eines präzisen Klassifizierungssystems, da bis heute keine detaillierte Stadieneinteilung in Remyelinisierungsstadien für frühe Entmarkungsläsionen existierte. Unser neu entwickeltes Klassifizierungssystem basiert dabei auf der stadienabhängigen Expression von Myelinproteinen in (re-)myelinisierten Fasern und oligodendroglialen Zellen.

Die Auswertung der Expressionsmuster der Myelinproteine zeigte, dass insbesondere $\mathrm{MOG}^{+}-$ Fasern und --zellen sowie $\mathrm{MBP}^{+}$-Fasern eine Differenzierung zwischen unserem frühen und späten Stadium der Remyelinisierung erleichtern und erlauben. MOG ${ }^{+}$-Fasern und -zellen fanden sich vornehmlich im späten Stadium, während $\mathrm{MBP}^{+}$-Fasern sogar ausschließlich in diesem Stadium beobachtet werden konnten, statistisch signifikante Unterschiede zu den anderen Stadien der Remyelinisierung aufweisen und somit als relativ stadienspezifisch gelten können.

Nach erfolgter Stadieneinteilung konnte eine Zunahme der HDAC1-Expression bei voranschreitender Remyelinisierung zwischen dem frühen und späteren Stadium der Remyelinisierung gezeigt werden. Zwischen den übrigen Stadien ließen sich keine signifikanten Unterschiede erkennen.

Beim Vergleich des Stadiums ohne Remyelinisierung mit schlechtem Oligodendrozytenerhalt 
zum späten Stadium sowie letzterem mit den zusammengefassten Stadien ohne Remyelinisierung konnte lediglich eine Tendenz der Zunahme HDAC1/Nogo-A-positiver Oligodendrozyten zum späten Stadium hin belegt werden.

Darüber hinaus ließ sich in unserer Arbeit zeigen, dass in der periläsionalen weißen Substanz keine Unterschiede in der Expression von HDAC1 in Oligodendrozyten zwischen den einzelnen Stadien der Remyelinisierung bestehen und somit kein Zusammenhang zwischen der HDAC1-Expression im PPWM und dem Remyelinisierungsstadium festzustellen ist. 


\section{Anhang}

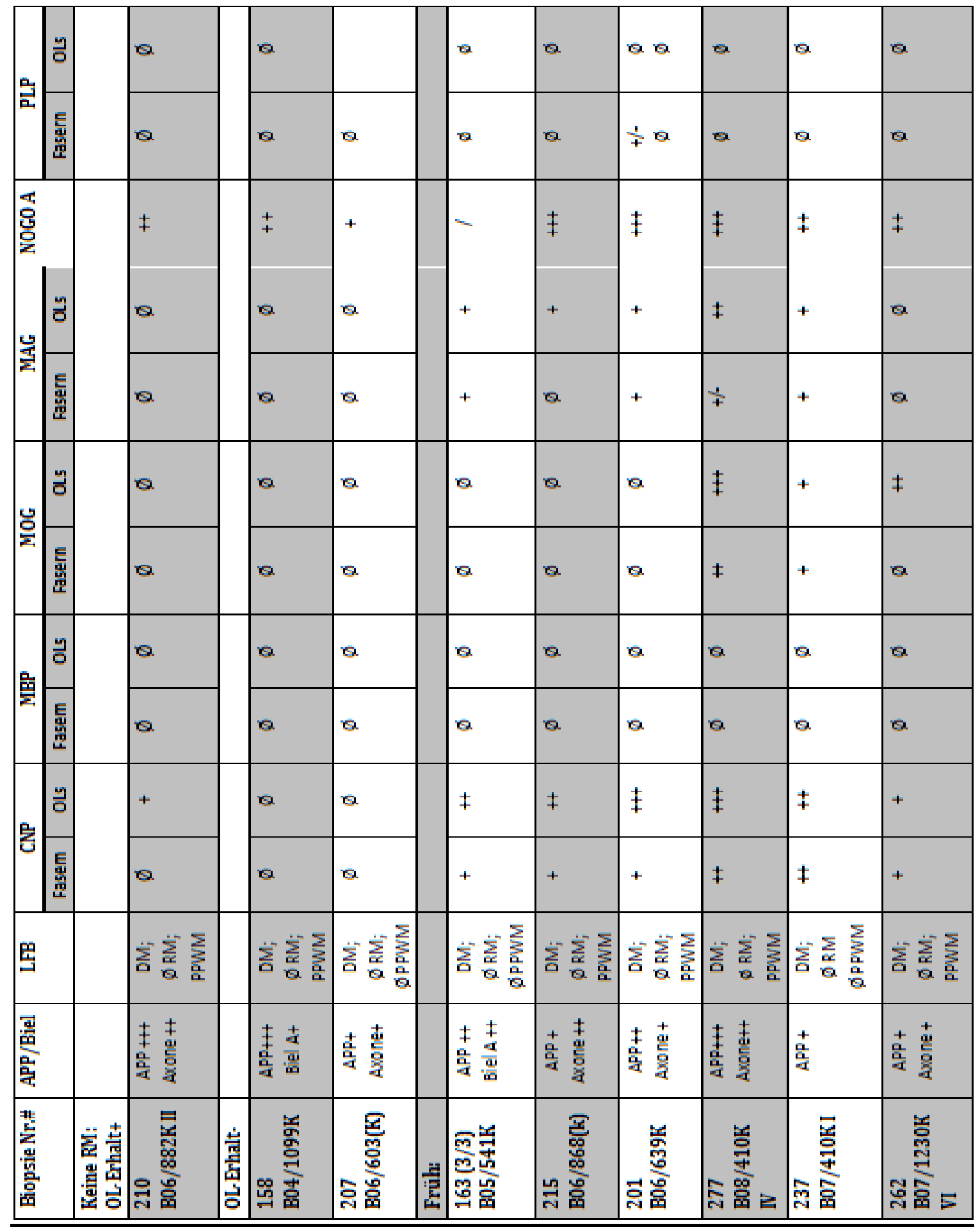




\begin{tabular}{|c|c|c|c|c|c|c|c|c|c|c|c|}
\hline \multirow{2}{*}{ 变 } & 筥 & $\stackrel{1}{\ddagger}$ & $a$ & $a$ & $a$ & a & $a$ & $\frac{1}{\mp}$ & $a$ & $a$ & a \\
\hline & 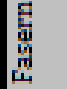 & $\stackrel{1}{+}$ & $\frac{1}{+}$ & + & + & $\frac{1}{+}$ & $\ddagger$ & + & 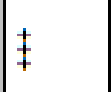 & a & $a$ \\
\hline 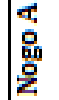 & 簽 & 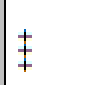 & $\ddagger$ & $\ddagger$ & $\ddagger$ & $\ddagger$ & $\neq$ & $\ddagger$ & $\ddagger$ & $\ddagger$ & 䒠 \\
\hline & 哭 & + & + & + & $a$ & $a$ & $\ddagger$ & + & $a$ & 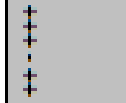 & 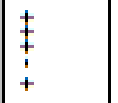 \\
\hline 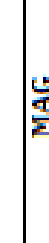 & 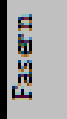 & + & + & $\neq$ & + & a & + & $\ddagger$ & + & $\begin{array}{l}\ddagger \\
\ddagger \\
\vdots\end{array}$ & $\begin{array}{l}\ddagger \\
\vdots \\
\vdots \\
\vdots\end{array}$ \\
\hline \multirow{2}{*}{  } & 总 & $\ddagger$ & $\ddagger$ & + & + & + & $\neq$ & $\neq$ & $\neq$ & $\ddagger$ & $\begin{array}{l}\ddagger \\
\vdots \\
\vdots\end{array}$ \\
\hline & 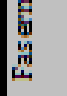 & 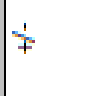 & + & $\neq$ & + & a & $\ddagger$ & $\frac{1}{f}$ & $\neq$ & $\begin{array}{l}\ddagger \\
\dot{a}\end{array}$ & + \\
\hline \multirow{2}{*}{ 道 } & 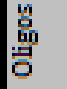 & a & $a$ & $\alpha$ & $a$ & a & $a$ & $\frac{1}{f}$ & a & $\dot{\dot{a}}$ & a \\
\hline & 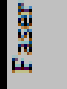 & $a$ & $a$ & + & $\ddagger$ & + & 市 & + & $\ddagger$ & $\mid \begin{array}{l}+ \\
\dot{a}\end{array}$ & $\begin{array}{l}f \\
a \\
Q\end{array}$ \\
\hline \multirow{2}{*}{ 选 } & 哭 & $\ddagger$ & $\ddagger$ & $\neq$ & $\ddagger$ & + & + & 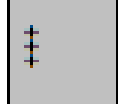 & $\neq$ & $\neq$ & $\begin{array}{l}\ddagger \\
\vdots \\
\vdots\end{array}$ \\
\hline & $\begin{array}{l}\text { 离 } \\
\text { 首 }\end{array}$ & + & + & $\ddagger$ & $\ddagger$ & + & $\ddagger$ & 市 & $\ddagger$ & $\begin{array}{l}\ddagger \\
t\end{array}$ & 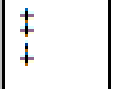 \\
\hline 茪 & & 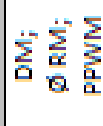 & $\sum_{0} \sum_{\alpha} \sum_{a} \sum_{a}$ & $\sum_{0} \sum_{\frac{\alpha}{a}} \sum_{a}^{\sum}$ & 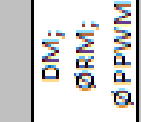 & 学竞产 & 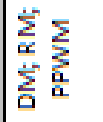 & $\sum_{\Delta} \sum_{\alpha} \sum_{\frac{a}{a}}^{\sum}$ & $\sum_{\Delta} \sum_{\frac{\alpha}{\alpha}} \sum_{a}^{\Sigma}$ & 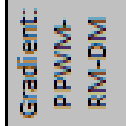 & 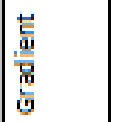 \\
\hline 迹 & & 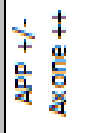 & 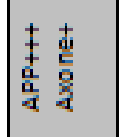 & 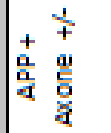 & 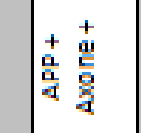 &  &  & 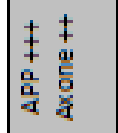 & 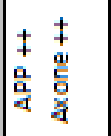 & $\begin{array}{l}\ddagger \\
\vdots \\
\dot{\alpha} \\
\frac{a}{a} \\
\alpha\end{array}$ & $\begin{array}{l}\frac{1}{f} \\
\text { 尊市 }\end{array}$ \\
\hline 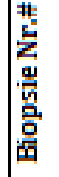 & & 学 & 売 & 胥 & 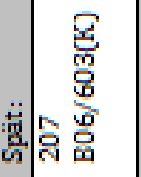 & 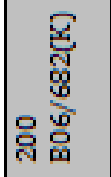 & 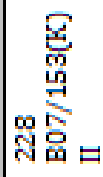 & 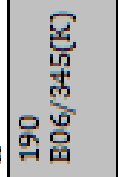 & 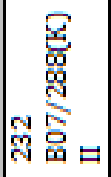 & 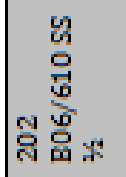 & 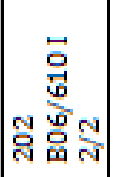 \\
\hline
\end{tabular}

Tabelle 14: Tabellarische Aufstellung aller untersuchter Biopsien 




Tabelle 15: Quantifizierung der Myelinproteine 


\begin{tabular}{|c|c|c|c|}
\hline & Läsion & Läsion & Läsion \\
\hline & $\mathrm{HDAC}+\mathrm{NOGO}+$ & HDAC- NOGO + & HDAC+ NOGO- \\
\hline \multicolumn{4}{|l|}{ Keine RM: } \\
\hline \multicolumn{4}{|l|}{ OL-Erhalt gut } \\
\hline 210 & 27,36 & 17,12 & 1604,8 \\
\hline \multicolumn{4}{|l|}{ OL-Erhalt schlecht } \\
\hline 158 & 80 & 12,8 & 576 \\
\hline 2071 & 13,33 & 133,33 & 1472 \\
\hline \multicolumn{4}{|l|}{ RM: } \\
\hline \multicolumn{4}{|l|}{ Früh } \\
\hline 163 & 1 & 1 & I \\
\hline 215 & 120,89 & 119 & 460,8 \\
\hline 277 & I & I & / \\
\hline 237 & 108,32 & 36 & 939,36 \\
\hline 262 & 86,4 & 16 & 1110,4 \\
\hline 192 & 140 & 11,04 & 1872 \\
\hline 270 & 133,33 & 35,36 & 423,36 \\
\hline 205 & 56 & 72 & 386,72 \\
\hline 202 2/2 DM Areal & 96 & 38,4 & 436,8 \\
\hline $2021 / 2$ DM Areal & 60,8 & 27,04 & 649 \\
\hline 201 & I & I & I \\
\hline \multicolumn{4}{|l|}{ Spät: } \\
\hline 200 & 209,33 & 9,6 & 1293,33 \\
\hline 228 & 72 & 16,16 & 464 \\
\hline 207 II & I & I & I \\
\hline 190 & 180 & 44 & 902,4 \\
\hline $202 \frac{1}{2}$ RM Areal & 161,78 & 29,28 & 758,4 \\
\hline 202 2/2 RM Areal & 189,3 & 26,72 & 464 \\
\hline 232 & 160 & 24 & 98,46 \\
\hline
\end{tabular}

Tabelle 16: HDAC1-Expression in der Läsion (Rohdaten) 


\begin{tabular}{|c|c|c|c|}
\hline & $\begin{array}{c}\mathrm{H}^{+} \mathrm{N}^{+}+\mathrm{H}^{-} \mathrm{N}^{+} \text {in } \\
\text { Zellen/mm } / \mathrm{mm}^{2}\end{array}$ & $\begin{array}{c}\mathrm{H}^{+} \mathrm{N}^{+} \text {an } \\
\left(\mathrm{H}^{+} \mathrm{N}^{+}+\mathrm{H}^{-} \mathrm{N}^{+}\right) \\
\text {in } \%\end{array}$ & $\begin{array}{c}\mathrm{H}-\mathrm{N}+\text { an } \\
\left(\mathrm{H}^{+} \mathrm{N}^{+}+\mathrm{H}^{-} \mathrm{N}^{+}\right) \\
\text {in \% }\end{array}$ \\
\hline \multicolumn{4}{|l|}{ Keine RM: } \\
\hline \multicolumn{4}{|l|}{ OL-Erhalt gut } \\
\hline 210 & 44,48 & 61,51 & 38,49 \\
\hline \multicolumn{4}{|l|}{ OL-Erhalt schlecht } \\
\hline 158 & 92,8 & 86,2 & 13,8 \\
\hline 207 I & 146,66 & 9,09 & 90,91 \\
\hline \multicolumn{4}{|l|}{ RM: } \\
\hline \multicolumn{4}{|l|}{ Früh: } \\
\hline 163 & / & I & I \\
\hline 201 & / & / & / \\
\hline $201 \mathrm{II}$ & I & I & I \\
\hline 215 & 239,89 & 50,39 & 49,61 \\
\hline 277 & I & I & I \\
\hline 237 & 144,32 & 75,06 & 24,94 \\
\hline 262 & 102,4 & 84,4 & 15,6 \\
\hline 192 & 151,04 & 92,69 & 7,31 \\
\hline 270 & 168,69 & 79,04 & 20,96 \\
\hline 205 & 128 & 43,75 & 56,25 \\
\hline 202 2/2 DM Areal & 134,4 & 71,43 & 28,57 \\
\hline $2021 / 2$ DM Areal & 87,84 & 69,22 & 30,78 \\
\hline \multicolumn{4}{|l|}{ Spät: } \\
\hline 200 & 218,93 & 95,62 & 4,38 \\
\hline 228 & 88,16 & 81,67 & 18,33 \\
\hline 207 II & I & 1 & I \\
\hline 190 & 224 & 80,36 & 19,64 \\
\hline 202 1/2 RM Areal & 191,06 & 84,68 & 15,32 \\
\hline 202 2/2 RM Areal & 216,02 & 87,63 & 12,37 \\
\hline 232 & 184 & 86,96 & 13,04 \\
\hline
\end{tabular}

Tabelle 17: HDAC1-positive Oligodendrozyten in der Läsion 


\begin{tabular}{|c|c|c|c|}
\hline & PPWM & PPWM & PPWM \\
\hline & HDAC+ Nogo A- & HDAC- Nogo A+ & HDAC+ Nogo A- \\
\hline \multicolumn{4}{|l|}{ Keine RM: } \\
\hline \multicolumn{4}{|l|}{ OL-Erhalt gut } \\
\hline 210 & 12 & 8 & 1068 \\
\hline \multicolumn{4}{|l|}{ OL-Erhalt schlecht } \\
\hline 158 & 156,8 & 73,6 & 590,4 \\
\hline \multicolumn{4}{|l|}{207 Areal I } \\
\hline \multicolumn{4}{|l|}{ RM: } \\
\hline \multicolumn{4}{|l|}{ Früh: } \\
\hline 163 & I & I & I \\
\hline 215 & 13,09 & 164,36 & 65,46 \\
\hline 277 & I & I & I \\
\hline 237 & I & I & I \\
\hline 262 & 213,6 & 6,4 & 208 \\
\hline 192 & 141,76 & 37,28 & 644 \\
\hline 270 & 236 & 16 & 610,67 \\
\hline 205 & 78,24 & 184,96 & 133,28 \\
\hline 202 2/2 DM Areal & 83,2 & 16 & 33,28 \\
\hline $202 \frac{1}{2}$ DM Areal & 35,2 & 19,2 & 128 \\
\hline 201 & I & I & I \\
\hline \multicolumn{4}{|l|}{ Spät: } \\
\hline 200 & 22,88 & 80 & 459,69 \\
\hline 228 & 10,67 & 45,33 & 1 \\
\hline 207 II & / & I & I \\
\hline 190 & 118,88 & 25,28 & 340,64 \\
\hline $202 \frac{1}{2}$ RM Areal & 35,2 & 19,2 & 128 \\
\hline 202 2/2 RM Areal & 83,2 & 16 & 33,28 \\
\hline 232 & 73,12 & 20,64 & / \\
\hline
\end{tabular}

Tabelle 18: HDAC1-Expression im PPWM (Rohdaten) 


\begin{tabular}{|c|c|c|c|}
\hline & $\begin{array}{c}\mathrm{H}^{+} \mathrm{N}^{+}+\mathrm{H}^{-} \mathrm{N}^{+} \text {in } \\
\text { Zellen } / \mathrm{mm}^{2}\end{array}$ & $\begin{array}{c}\mathrm{H}^{+} \mathrm{N}^{+} \text {an } \\
\left(\mathrm{H}^{+} \mathrm{N}^{+}+\mathrm{H}^{-} \mathrm{N}^{+}\right) \\
\text {in } \%\end{array}$ & $\begin{array}{c}\mathrm{H}^{-} \mathrm{N}^{+} \text {an } \\
\left(\mathrm{H}^{+} \mathrm{N}^{+}+\mathrm{H}^{-} \mathrm{N}^{+}\right) \\
\text {in \% }\end{array}$ \\
\hline \multicolumn{4}{|l|}{ Keine RM: } \\
\hline \multicolumn{4}{|l|}{ OL-Erhalt gut } \\
\hline 210 & 20 & 60 & 40 \\
\hline \multicolumn{4}{|l|}{ OL-Erhalt schlecht } \\
\hline 158 & 230,4 & 68 & 32 \\
\hline $207 I$ & I & I & / \\
\hline \multicolumn{4}{|l|}{ RM: } \\
\hline \multicolumn{4}{|l|}{ Früh: } \\
\hline 163 & I & I & I \\
\hline 215 & 177,45 & 7,38 & 92,62 \\
\hline 277 & I & I & / \\
\hline 237 & / & / & / \\
\hline 262 & 220 & 97,09 & 2,91 \\
\hline 192 & 179,04 & 79,18 & 20,82 \\
\hline 270 & 252 & 93,65 & 6,35 \\
\hline 205 & 263,2 & 29,73 & 70,27 \\
\hline 202 2/2 DM Areal & 99,2 & 83,87 & 16,13 \\
\hline 202 1/2 DM Areal & 54,4 & 64,71 & 35,29 \\
\hline 201 & I & I & I \\
\hline \multicolumn{4}{|l|}{ Spät: } \\
\hline 200 & 308,8 & 74,09 & 25,91 \\
\hline 228 & 54 & 19,76 & 80,24 \\
\hline 207 II & I & I & 1 \\
\hline 190 & 144,16 & 82,46 & 17,54 \\
\hline $2021 / 2$ RM Areal & 54,4 & 64,71 & 35,29 \\
\hline 202 2/2 RM Areal & 99,2 & 83,87 & 16,13 \\
\hline 232 & 93,76 & 77,99 & 22,01 \\
\hline
\end{tabular}

Tabelle 19: HDAC1-positive Oligodendrozyten im PPWM 


\section{Literaturverzeichnis}

Adams CWM, Tourtellotte EWW: Multiple Sclerosis: Pathology, diagnosis and management; William and Wilkins, Baltimore 1983

Andersson M, Alvarez-Cermeño J, Bernardi G, Cogato I, Fredman P, Frederiksen J, Fredrikson S, Gallo P, Grimaldi LM, Grønning M, et al. (1994): Cerebrospinal fluid in the diagnosis of multiple sclerosis: a consensus report. J Neurol Neurosurg Psychiatry $\underline{57}, 897-$ 902

Asklund T, Appelskog IB, Ammerpohl O, Ekstrom TJ, Almqvist PM (2004): Histone deacetylase inhibitor 4-phenylbutyrate modulates glial fibrillary acidic protein and connexin 43 expression, and enhances gap-junction communication, in human glioblastoma cells. Eur J Cancer 느, 1073-1081

Babbe H, Roers A, Waisman A, Lassmann H, Goebels N, Hohlfeld R, Friese M, Schröder R, Deckert M, Schmidt S, et al. (2000): Clonal expansion of CD8+ T cells dominate the T cell infiltrate in active multiple sclerosis lesions as shown by micromanipulation and single cell polymerase chain reaction. J Exp Med 192, 393-404

Barkhof F, Filippi M, Miller DH, Scheltens P, Campi A, Polman CH, Comi G, Adèr HJ, Losseff $\mathrm{N}$, Valk J (1997): Comparison of MR imaging criteria at first presentation to predict conversion to clinically definite multiple sclerosis. Brain $\underline{120}, 2059-2069$

Barnes MP, Bateman DE, Cleland PG, Dick DJ, Walls TJ, Newman PK, Saunders M, Tilley PJB (1985): Intravenous methylprednisolone for multiple sclerosis in relapse. J Neurol Neurosurg Psychiatry $\underline{48}, 157-159$

Barnett MH, Prineas JW (2004): Relapsing and remitting multiple sclerosis: pathology of the newly forming lesion. Ann Neurol $\underline{55}, 458-468$

Barnett MH, Henderson AP, Prineas JW (2006): The macrophage in MS: just a scavenger after all? Pathology and pathogenesis of the acute MS lesion. Mult Scler $\underline{12}, 121-132$

Baron W, de Jonge JC, de Vries H, Hoekstra D (2000): Perturbation of myelination by activation of distinct signaling pathways: an in vitro study in a myelinating culture derived from fetal rat brain. J Neurosci Res $\underline{59}$, 74-85

Bartl S, Taplick J, Lagger G, Khier H, Kuchler K, Seiser C (1997): Identification of mouse histone deacetylase 1 as a growth factor-inducible gene. Mol Cell Biol 17, 5033-43

Bartova E, Krejci J, Harnicarova A, Galiova G, Kozubek S (2008): Histone modifications and nuclear architecture: a review. J Histochem Cytochem $\underline{56}, 711-721$ 
Bhaskara S, Chyla BJ, Amann JM, Knutson SK, Cortez D, Sun ZW, Hiebert SW (2008): Deletion of histone deacetylase 3 reveals critical roles in $S$ phase progression and DNA damage control. Mol Cell $\underline{30}, 61-72$

Boggs JM (2006): Myelin basic protein: a multifunctional protein. Cell Mol Life Sci $\underline{63}$, 19451961

Brasher GW, Follender AB, Spiekerman AM (1998): The clinical value of commonly used spinal fluid diagnostic studies in the evaluation of patients with suspected multiple sclerosis. Am J Manag Care 4, 1119- 1121

Brück W, Schmied M, Suchanek G, Brück Y, Breitschopf H, Poser S, Piddlesden S, Lassmann $\mathrm{H}$ (1994): Oligodendrocytes in the early course of multiple sclerosis. Ann Neurol $\underline{35}, 65-73$

Brück W, Porada P, Poser S, Rieckmann P, Hanefeld F, Kretzschmar HA, Lassmann H (1995): Monocyte/macrophage differentiation in early multiple sclerosis lesions. Ann Neurol $\underline{38}, 788-796$

Burnham JA, Wright RP, Driesbach J, Murray RS (1991): The effect of high-dose steroids on MRI gandolinium enhancement in acute demyelinating lesions. Neurology 41, 1349-1354

Carton H, Vlietinck R, Debruyne J, De Keyser J, D'Hooghe MB, Loos R, Medaer R, Truyen L, Yee IM, Sadovnick AD (1997): Recurrence risks of multiple sclerosis in relatives of patients in Flanders, Belgium. J Neurol Neurosurg Psychiatry 62, 329-333

Cepok S, Zhou D, Srivastava R, Nessler S, Stei S, Büssow W, Sommer N, Hemmer B (2005): Identification of Epstein-Barr virus proteins as putative targets of the immune response in multiple sclerosis. J Clin Invest $\underline{115}, 1352-1360$

Chang A, Tourtellote WW, Rudick R, Trapp BD (2002): Premyelinating oligodendrocytes in chronic lesions of multiple sclerosis. N Engl J Med $\underline{346}, 165-173$

Chang S, McKinsey TA, Zhang CL, Richardson JA, Hill JA, Olson EN (2004): Histone deacetylases 5 and 9 govern responsiveness of the heart to a subset of stress signals and play redundant roles in heart development. Mol Cell Biol $\underline{24}$, 8467-8476

Chang S, Young BD, Li S, Qi X, Richardson JA, Olson EN (2006): Histone deacetylase 7 maintains vascular integrity by repressing matri metalloproteinase 10. Cell $\underline{126}, 321-334$

Charcot JM (1868): Histologie de la sclérose en plaques. Gaz Hop 141, 554-558

Charles P, Reynolds R, Seilhean D, Rougon G, Aigrot MS, Niezgoda A, Zalc B, Lubetzki C (2002): Re-expression of PSA-NCAM by demyelinated axons: an inhibitor of remyelination in multiple sclerosis? Brain $\underline{125}, 1972-1979$

Chiappa KH (1980): Pattern shift visual, brainstem auditory, and short latency somatosensory evoked potentials in multiple sclerosis. Neurology $\underline{30}, 110-123$

Clark D (2004): Human herpesvirus type 6 and multiple sclerosis. Herpes 11 , 112-119 
Cohen JA, Cutter GR, Fischer JS, Goodman AD, Heidenreich FR, Kooijmans MF, Sandrock AW, Rudick RA, Simon JH, Simonian NA, et al. (2002): Benefit of interferon beta-1a on MSFC progression in secondary progressive MS. Neurology $\underline{59}, 679-687$

Copray S, Huynh JL, Sher F, Boddeke E, Casaccia-Bonnefil P (2009): Epigenetic mechanisms in oligodendrocyte development, maturation and aging. Glia $\underline{57}, 1579-1587$

Corboy JR, Goodin DS, Frohman EM (2003): Disease-modifying therapies for multiple sclerosis. Curr Treat Options Neurol $\underline{5}, 35-54$

Cunliffe VT, Casaccia-Bonnefil $P$ (2006): Histone deacetylase 1 is essential for oligodendrocyte specification in the zebrafish CNS. Mech Dev $\underline{123}, 24-30$

Dawson J (1916): The histology of disseminated sclerosis. Trans R Soc Edinb $\underline{50}$, 517-740

Dean G (1967): Annual incidence, prevalence, and mortality of multiple sclerosis in white South African-born and in white immigrants to South Africa. BMJ 1967, 2, 724-730

della Gaspera B, Pham-Dinh D, Roussel G, Nussbaum JL, Dautigny A (1998): Membrane topology of the myelin/oligodendrocyte glycoprotein. Eur J Biochem $\underline{258}$, 478-484

De Ruijter AJM, van Gennip AH, Caron HN, Kemp S, van Kuilenburg ABP (2003): Histone deacetylases (HDACs): characterization of the classical HDAC family. Biochem $\mathrm{J} \underline{370}, 737-$ 749

De Stefano N, Narayanan S, Francis GS, Arnaoutelis R, Tartaglia MC, Antel JP, Matthews PM, Arnold DL (2001): Evidence of axonal damage in the early stages of multiple sclerosis and its relevance to disability. Arch Neurol $\underline{58}, 65-70$

Dubois-Dalcq M, Behar T, Hudson L, Lazzarini RA (1986): Emergence of three myelin proteins in oligodendrocytes cultured without neurons. J Cell Biol $\underline{102}, 384-392$

Durelli L, Cocito D, Riccio A, Barile C, Bergamasco B, Baggio GF, Perla F, Delsedime M, Gusmaroli G, Bergamin L (1986): High-dose intravenous methylprednisolone in the treatment of multiple sclerosis: clinical-immunological correlations. Neurology $\underline{36}, 238-243$

Espinosa-Jeffrey A, Wakeman DR, Kim SU, Snyder EY, de Vellis J (2009): Culture system for rodent and human oligodendrocyte specification, lineage progression, and maturation. Curr Protoc Stem Cell Biol 10, 1-26

Fischer A, Sananbenesi F, Mungenast A, Tsai LH (2010): Targeting the correct HDAC(s) to treat cognitive disorders. Trends Pharmacol Sci 31, 605-617. Epub 2010

Franklin RJ (2002): Why does remyelination fail in multiple sclerosis? Nat Rev Neurosci. $\underline{3}$, 705-714

Gao L, Cueto MA, Asselbergs F, Atadja P (2002): Cloning and functional characterization of HDAC11, a novel member of the human histone deacetylase family. J Biol Chem $\underline{277}$, 25748-25755 
Guan JS, Haggarty SJ, Giacometti E, Dannenberg JH, Joseph N, Gao J, Nieland TJ, Zhou Y, Wang X, Mazitschek R, et al. (2009): HDAC2 negatively regulates memory formation and synaptic plasticity. Nature $\underline{459}, 55-60$.

Guthrie TC, Nelson DA (1995): Influence of temperature changes on multiple sclerosis: critical review of mechanisms and research potential. J Neurol Sci 129: 1-8

Haberland M, Montgomery RL, Olson EN (2009): The Many Roles of Histone Deacetylases in Development and Physiology: Implications for Disease and Therapy. Nat Rev Genet 10, $32-42$

Halliday AM, McDonald WI, Mushin J (1973): Visual evoked response in diagnosis of multiple sclerosis. BMJ 1973, 4, 661-664

Hartung HP, Kieseier BC (2000): The role of matrix metalloproteinases in autoimmune damage to the central nervous system. J Neuroimmunol 107, 140-147

He Y, Dupree J, Wang J, Sandoval J, Li J, Liu H, Shi Y, Nave KA, Casaccia-Bonnefil P (2007a): The transcription factor Yin Yang 1 is essential for oligodendrocyte progenitor differentiation. Neuron $\underline{55}, 217-230$

He Y, Sandoval J, Casaccia-Bonnefil P (2007b): Events at the transition between cell cycle exit and oligodendrocyte progenitor differentiation: the role of HDAC and YY1. Neuron Glia Biol $\underline{3}, 221-231$

Heckl RW: Multiple Sklerose: Klinik, Differentialdiagnose, Behandlung; Thieme Verlag, Stuttgart 1994

Heesen C, Kolbeck J, Gold SM, Schulz H, Schulz KH (2003): Delivering the diagnosis of MSresults of a survey among patients and neurologists. Acta Neurol Scand 107, 363-368

Hein T, Hopfenmüller W (2000): Hochrechnung der Zahl an Multiple Sklerose erkrankten Patienten in Deutschland. Nervenarzt $\underline{71}, 288-294$

Henderon AP, Barnett MH, Parratt JD, Prineas JW (2009): Multiple Sclerosis: distribution of inflammatory cells in newly forming lesions. Ann Neurol $\underline{66}, 739-753$

Hua LL, Liu JSH, Brosnan CF, Lee SC (1998): Selective inhibition of human glial inducible nitric oxide synthase by interferon-beta: implications for multiple sclerosis. Ann Neurol $\underline{43}$, 384-387

Hubbert C, Guardiola A, Shao R, Kawaguchi Y, Ito A, Nixon A, Yoshida M, Wang XF, Yao TP (2002): HDAC6 is a microtubule-associated deacetylase. Nature $\underline{417}, 455-458$

Imai S, Armstrong CM, Kaeberlein M, Guarente L (2000): Transcriptional silencing and longevity protein Sir2 is an NAD-dependent histone deacetylase. Nature $\underline{403}, 795-800$

Iriarte J, Subira ML, Castro P (2000): Modalities of fatigue in multiple sclerosis: correlation with clinical and biological factors. Mult Scler $\underline{6}, 124-130$ 
Issazadeh S, Navikas V, Schaub M, Sayegh M, Khoury S (1998): Kinetics of expression of costimulatory molecules and their ligands in murine relapsing experimental autoimmune encephalomyelitis in vivo. J Immunol 161, 1104-1112

Jacobs LD, Beck RW, Simon JH, Kinkel RP, Brownscheidle CM, Murray TJ, Simonian NA, Slasor PJ, Sandrock AW (2000): Intramuscular interferon beta-1a therapy initiated during a first demyelinating event in multiple sclerosis. N Engl J Med $\underline{343}, 898-904$

Jiang $H$, Milo R, Swoveland $P$, Johnson KP, Panitch H, Dhib-Jalbut S (1995): Interferon $\beta-1 b$ reduces interferon $Y$-induced antigen-presenting capacity of human glial and $B$ cells. $J$ Neuroimmunol $\underline{61}, 17-25$

John GR, Shankar SL, Shafit-Zagardo B, Massimi A, Lee SC, Raine CS, Brosnan CF (2002): Multiple sclerosis: re-expression of a developmental pathway that restricts oligodenrocyte maturation. Nature Med $\underline{8}, 1115-1121$

Johnstone RW (2002): Histone-deacetylase inhibitors: novel drugs for the treatment of cancer. Nat Rev Drug Discov 1, 287-99

Kamholz J, de Ferra F, Puckett C, Lazzarini R (1986): Identification of three forms of human myelin basic protein by cDNA cloning. Proc Natl Acad Sci USA $\underline{83}$, 4962-4966

Kao HY, Lee CH, Komarov A, Han CC, Evans RM (2002): Isolation and characterization of mammalian HDAC10, a novel histone deacetylase. J Biol Chem 277, 187-193

Keegan M, Pineda AA, McClelland RL, Darby CH, Rodriguez M, Weinshenker BG (2002): Plasma exchange for severe attacks of CNS demyelination: predictors of response. Neurology $\underline{58}, 143-146$

Keita M, Magy L, Heape A, Richard L, Piaser M, Vallat JM (2002): Immunocytological studies of L-MAG expression regulation during myelination of embryonic brain cell cocultures. Dev Neurosci 24, 495-503

Kessaris N, Pringle N, Richardson WD (2008): Specification of CNS glia from neural stem cells in the embryonic neuroepithelium. Philos Trans R Soc Lond B Biol Sci $\underline{363}, 71-85$

Kilgore M, Miller CA, Fass DM, Hennig KM, Haggarty SJ, Sweatt JD, Rumbaugh G (2010): Inhibitors of class 1 histone deacetylases reverse contextual memory deficits in a mouse model of Alzheimer's disease. Neuropsychopharmacology 35, 870-880. Epub 2009 Dec 9.

Kim JY, Shen S, Dietz K, He Y, Howell O, Reynolds R, Casaccia P (2010): HDAC1 nuclear export induced by pathological conditions is essential for the onset of axonal damage. Nat Neurosci $\underline{13}, 180-189$

Klugmann M, Schwab MH, Pühlhofer A, Schneider A, Zimmermann F, Griffiths IR, Nave KA (1997): Assembly of CNS myelin in the absence of proteolipid protein. Neuron $\underline{18}, 59-70$

Knutson SK, Chyla BJ, Amann JM, Bhaskara S, Huppert SS, Hiebert SW (2008): Liverspecific deletion of histone deacetylase 3 disrupts metabolic transcriptional networks. EMBO J $\underline{27}, 1017-1028$ 
Kondo T, Raff M (2004): Chromatin remodeling and histone modification in the conversion of oligodendrocyte precursors to neural stem cells. Genes Dev 18, 2963-2972

Koo EH, Sisodia SS, Archer DR, Martin LJ, Weidemann A, Beyreuther K, Fischer P, Masters C, Price DL (1990): Precursor of amyloid protein in Alzheimer disease undergoes fast anterograde axonal transport. Proc Nati Acad Sci USA 구, 1561-1565

Kook H, Lepore JJ, Gitler AD, Lu MM, Wing-Man Yung W, Mackay J, Zhou R, Ferrari V, Gruber P, Epstein JA (2003): Cardiac hypertrophy and histone deacetylase-dependent transcriptional repression mediated by the atypical homeodomain protein Hop $\mathrm{J}$ Clin Invest $\underline{112}, 863-871$

Kovacs JJ, Murphy PJ, Gaillard S, Zhao X, Wu JT, Nicchitta CV, Yoshida M, Toft DO, Pratt WB, Yao TP (2005): HDAC6 regulates Hsp90 acetylation and chaperone-dependent activation of glucocorticoid receptor. Mol Cell $\underline{18}, 601-607$

Kuhlmann T, Lingfeld G, Bitsch A, Schuchardt J, Brück W (2002): Acute axonal damage in multiple sclerosis is most extensive in early disease stages and decreases over time. Brain $\underline{125}, 2202-2212$

Kurtzke JF (1983): Rating neurologic impairment in multiple sclerosis: an expanded disability status scale (EDSS). Neurology $\underline{33}, 1444-1452$

Lagger G, O'Carroll D, Rembold M, Khier H, Tischler J, Weitzer G, Schuettengruber B, Hauser C, Brunmeir R, Jenuwein T, et al. (2002): Essential function of histone deacetylase 1 in proliferation control and CDK inhibitor repression. EMBO J 21, 2672-2681

Leary SM, Miller DH, Stevenson VL, Brex PA, Chard DT, Thompson AJ (2003): Interferon beta-1a in primary progressive MS: an exploratory, randomized, controlled trial. Neurology $\underline{60}, 44-51$

Lee J, Gravel M, Zhang R, Thibault P, Braun PE (2005): Process outgrowth in oligodendrocytes is mediated by CNP, a novel microtubule assembly myelin protein. $\mathrm{J}$ Cell Biol $\underline{170}, 661-673$

Leussink VI, Jung S, Merschdorf U, Toyka KV, Gold R (2001): High-dose methylprednisolone therapy in multiple sclerosis induces apoptosis in peripheral blood leukocytes. Arch Neurol $\underline{58}, 91-97$

Lhermitte J, Bollak, Nicholas M (1924): Les douleurs à type de décharge électrique consecutives à la flexion céphalique dans la slérose en plaques. Rev Neurol $\underline{42}, 56-62$

Lindert RB, Haase CG, Brehm U, Linington C, Wekerle H, Hohlfeld R (1999): Multiple sclerosis: B- and T-cell responses to the extracellular domain of the myelin oligodendrocyte glycoprotein. Brain 122, 2089-2099

Lindner M, Heine S, Haastert K, Garde N, Fokuhl J, Linsmeier F, Grothe C, Baumgärtner W, Stangel M (2008): Sequential myelin protein expression during remyelination reveals fast and efficient repair after central nervous system demyelination. Neuropathol Appl Neurobiol $\underline{34}$, 105-114 
Link H, Tibbling G (1977): Principles of albumin and IgG analyses in neurological disorders. III. Evaluation of IgG synthesis within the central nervous system in multiple sclerosis. Scand J Clin Lab Invest $\underline{37}$, 397-401

Liu A, Han YR, Li J, Sun D, Ouyang M, Plummer MR, Casaccia-Bonnefil P (2007): The glial or neuronal fate choice of oligodendrocyte progenitors is modulated by their ability to acquire an epigenetic memory. J Neurosci 27, 7339-7343

Lu J, McKinsey TA, Nicol RL, Olson EN (2000): Signal-dependent activation of the MEF2 transcription factor by dissociation from histone deacetylases. Proc Natl Acad Sci USA 97, 4070-4075

Lublin FD, Reingold SC (1996): Defining the clinical course of multiple sclerosis: results of an international survey. National Multiple Sclerosis Society (USA) Advisory Committee on Clinical Trials of New Agents in Multiple Sclerosis. Neurology $\underline{46}, 907-911$

Lucchinetti C, Brück W, Rodriguez M, Lassmann H (1996): Distinct patterns of multiple sclerosis pathology indicates heterogeneity in pathogenesis. Brain Pathol $\underline{6}, 259-274$

Lucchinetti C, Brück W, Parisi J, Scheithauer B, Rodriguez M, Lassmann H (1999): A quantitative analysis of oligodendrocytes in multiple sclerosis lesions. Brain 122, 2279-2295

Lucchinetti C, Brück W, Parisi J, Scheithauer B, Rodriguez M, Lassmann H (2000): Heterogeneity of multiple sclerosis lesions: implications for the pathogenesis of demyelination. Ann Neurol $\underline{47}, 707-717$

Ma Z, Cao Q, Zhang L, Hu J, Howard RM, Lu P, Whittemore SR, Xu XM (2009): Oligodendrocyte precursor cells differentially expressing Nogo-A but not MAG are more permissive to neurite outgrowth than mature oligodendrocytes. Exp Neurol 217, 184-196

Marburg O (1906): Die sogenannte 'akute multiple sklerose'. Jahrb Psychiatr Neurol 27, 211312

Marin-Husstege M, Muggironi M, Liu A, Casaccia-Bonnefil P (2002): Histone deacetylase activity is necessary for oligodendrocyte lineage progression. J Neurosci $\underline{22}, 10333-10345$

Martinez-Caceres EM, Barrau MA, Brieva L, Espejo C, Barbera N, Montalban X (2002): Treatment with methylprednisolone in relapses of multiple sclerosis patients: immunological evidence of immediate and short-term but not long-lasting effects. Clin Exp Immunol 127, 165-171

Masuhr KF, Neumann M: Duale Reihe Neurologie, 6. Auflage; Thieme Verlag, Stuttgart 2007

McAlpine D (1964): The benign form of multiple sclerosis: results of a long-term follow up. BMJ 1964, 2, 1029-1032

McAlpine D, Lumsden CE, Acheson ED: Multiple Sclerosis: A Reappraisal, 2nd edn.; Churchill Livingstone, Edinburgh 1972

McAlpine D, Compston A, Confavreux C, Lassmann H: Multiple Sclerosis; Churchill Livingstone, Edinburgh 2005 
McDonald WI, Compston A, Edan G, Goodkin D, Hartung HP, Lublin FD, McFarland HF, Paty DW, Polman CH, Reingold SC, Sandberg-Wollheim M, et al. (2001): Recommended diagnostic criteria for multiple sclerosis: guidelines from the International Panel on the diagnosis of multiple sclerosis. Ann Neurol $\underline{50}, 121-127$

McKinsey TA, Zhang CL, Lu J, Olson EN (2000): Signal-dependent nuclear export of a histone deacetylase regulates muscle differentiation. Nature $\underline{408}, 106-111$

Milligan NM, Newcombe R, Compston DAS (1987): A double blind controlled trial of high dose methylprednisolone in patients with multiple sclerosis. I. Clinical effects. J Neurol Neurosurg Psychiatry $\underline{50}, 551-516$

Montgomery RL, Davis CA, Potthoff MJ, Haberland M, Fielitz J, Qi X, Hill JA, Richardson JA, Olson EN (2007): Histone deacetylases 1 and 2 redundantly regulate cardiac morphogenesis, growth, and contractility. Genes Dev 211, 1790-1802

Montgomery RL, Potthoff MJ, Haberland M, Qi X, Matsuzaki S, Humphries KM, Richardson JA, Bassel-Duby R, Olson EN (2008): Maintenance of cardiac enery metabolism by histone deacetylase 3 in mice. J Clin Invest $\underline{118}$, 3588-3597

Ng CE, Tang BL (2002): Nogos and the Nogo-66 receptor: factors inhibiting CNS neuron regeneration. J Neurosci Res $\underline{67}, 559-565$

Noronha A, Toscas A, Jensen MA (1993): Interferon beta-1b decreases T cell activation and interferon $y$ production in multiple sclerosis. Neurology $\underline{43}, 655-661$

Ohno R, Hamaguchi K, Sowa K, Tanaka H, Watanabe Y (1987): High-dose intravenous corticosteroids in the treatment of multiple sclerosis. Jpn J Med $\underline{26}, 212-216$

Olerup O, Hillert J (1991): HLA class II-associated genetic susceptibility in multiple sclerosis: A critical evaluation. Tissue Antigens $\underline{38}, 1-15$

Pagany M, Jagodic M, Bourquin C, Olsson T, Linington C (2003): Genetic variation in myelin oligodendrocyte glycoprotein expression and susceptibility to experimental autoimmune encephalomyelitis. J Neuroimmunol $\underline{139}, 1-8$

Patrikios P, Stadelmann C, Kutzelnigg A, Rauschka $H$, Schmidbauer M, Laursen $H$, Sorensen PS, Brück W, Lucchinetti C, Lassmann H (2006): Remyelination is extensive in a subset of multiple sclerosis patients. Brain $\underline{129}, 3165-3172$

Pedraza L, Fidler L, Staugaitis SM, Colman DR (1997): The active transport of myelin basic protein into the nucleus suggests a regulatory role in myelination. Neuron $\underline{18}, 579-589$

Pedre X, Mastronardi F, Bruck W, López-Rodas G, Kuhlmann T, Casaccia P (2011): Changed histone acetylation patterns in normal-appearing white matter and early multiple sclerosis lesions. J Neurosci $\underline{31}$, 3435-3445.

Pernet V, Joly S, Christ F, Dimou L, Schwab ME (2008): Nogo-A and myelin-associated glycoprotein differently regulate oligodendrocyte maturation and myelin formation. J Neurosci $\underline{28}, 7435-7444$ 
Pette M, Fujita K, Kitze B, Whitaker JN, Albert E, Kappos L, Wekerle H (1990): Myelin basic protein-specific T lymphocyte lines from MS patients and healthy individuals. Neurology $\underline{40}$, $1770-1776$

Poeck K, Hacke W: Neurologie, 12.aktualis. und erw. Auflage; Springer-Verlag Berlin 2006

Polman CH, Reingold SC, Edan G, Filippi M, Hartung HP, Kappos L (2005): Diagnostic criteria for multiple sclerosis: 2005 revisions to the "McDonald Criteria". Ann Neurol $\underline{58}, 840-$ 846

Polman CH, Reingold SC, Banwell B, Clanet M, Cohen JA, Filippi M, Fujihara K, Havrdova E, Hutchinson M, Kappos L et al. (2011): Diagnostic Criteria for Multiple Sclerosis: 2010 Revisions to the McDonald Criteria. Ann Neurol $\underline{69}$, 292-302

Prat A, Al-Asmi A, Duquette P, Antel JP (1999): Lymphocyte migration and multiple sclerosis: relation with the disease course and therapy. Ann Neurol $\underline{46}$, 253-256

Prineas JW, Connell F (1979): Remyelination in multiple sclerosis. Ann Neurol $\underline{5}, 22-31$

Prineas JW, Barnard RO, Kwon EE, Sharer LR, Cho ES (1993): Multiple sclerosis. Remyelination of nascent lesions. Ann Neurol $\underline{33}$, 137-151

Quarles RH (2007): Myelin-associated glycoprotein (MAG): past, present and beyond. J Neurochem 100, 1431-1448

Raine CS, Wu E (1993): Multiple sclerosis: remyelination in acute lesions. J Neuropathol Exp Neurol $\underline{52}, 199-204$

Rao SM, Leo GJ, Bernardin L, Unverzagt F (1991): Cognitive dysfunction in multiple sclerosis. I. Frequency, patterns and predictions. Neurology $\underline{41}, 685-691$

Reynolds R, Wilkin GP (1988): Development of macroglial cells in rat cerebellum. II. An in situ immunohistochemical study of oligodendroglial lineage from precursor to mature myelinating cell. Development 102, 409-425

Rosenberg GA, Dencoff JE, Correa N, Reinera M, Ford CC (1996): Effect of steroids on CSF matrix metalloproteinases in multiple sclerosis: relation to blood-brain barrier injury. Neurology $\underline{46}, 1626-1632$

Schuettengruber B, Simboeck E, Khier H, Seiser C (2003): Autoregulation of mouse histone deacetylase 1 expression. Mol Cell Biol 23, 6993-7004

Shen S, Li J, Casaccia-Bonnefil P (2005): Histone modifications affect timing of oligodendrocyte progenitor differentiation in the developing rat brain. J Cell Biol $\underline{169}, 577-589$

Shen S, Sandoval J, Swiss VA, Li J, Dupree J, Franklin RJM, Casaccia-Bonnefil P (2008): Age-dependent epigenetic control of differentiation inhibitors is critical for remyelination efficiency. Nat Neurosci 11, 1024-1034

Sher F, Rossler R, Brouwer N, Balasubramaniyan V, Boddeke E, Copray S (2008): Differentiation of neural stem cells into oligodendrocytes: Involvement of the polycomb group protein Ezh2. Stem Cells $\underline{26}$, 2875-2883 
Sim FJ, Zhao C, Penderis J, Franklin RJ (2002): The age-related decrease in CNS remyelination efficiency is attributable to an impairment of both oligodendrocyte progenitor recruitment and differentiation. J Neurosci 22, 2451-2459

Skegg DCG, Corwin PA, Craven RS, Malloch JA, Pollock M (1987): Occurrence of multiple sclerosis in the north and south of New Zealand. J Neurol Neurosurg Psychiatry $\underline{50}, 134-139$

Smith KJ, Kapoor R, Hall SM, Davies M (2001): Electrically active axons degenerate when exposed to nitric oxide. Ann Neurol $\underline{49}, 470-476$

Song MR, Ghosh A (2004): FGF2-induced chromatin remodeling regulates CNTF-mediated gene expression and astrocyte differentiation. Nat Neurosci $\underline{7}, 229-235$

Strasser-Fuchs S, Fazekas F, Flooh E, Kapeller P, Poltrum B, Offenbacher H (1997): Die Einstellung von Patienten mit multipler Sklerose zur Krankheitsaufklärung. Nervenarzt $\underline{68}$, 963-966

Swanborg RH, Whittum-Hudson JA, Hudson AP (2003): Infectious agents and multiple sclerosis-are Chlamydia pneumonia and herpes virus 6 involved? J Neuroimmunol $\underline{136}, 1-8$

Swanton JK, Fernando K, Dalton CM, Miszkiel KA, Thompson AJ, Plant GT, Miller DH (2006): Modification of MRI criteria for MS in patients with clinically isolated syndromes. J Neurol Neurosurg Psychiatry $\underline{77}, 830-833$

Tang X, Gao JS, Guan YJ, McLane KE, Yuan ZL, Ramratnam B, Chin YE (2007): Acetylation-dependent signal transduction for type I interferon receptor. Cell 131, 93-105

Tang YW, Sriram S, Li H, Yao SY, Meng S, Mitchell WM, Stratton CW (2009): Qualitative and quantitative detection of Chlamydophila pneumonia DNA in cerebrospinal fluid from multiple sclerosis patients and controls. PLoS ONE $\underline{4}$, e5200

Taplick J, Kurtev V, Kroboth K, Posch M, Lechner T, Seiser C (2001): Homo-oligomerisation and nuclear localisation of mouse histone deacetylase 1. J Mol Biol 308, 27-38

Targett MP, Sussman J, Scolding N,O'Leary MT, Compston DA, Blakemore WF (1996): Failure to achieve remyelination of demyelinated rat axons following transplantation of glial cells obtained from the adult human brain. Neuropathol Appl Neurobiol 22, 199-210

Thorpe JW, Mumford CJ, Compston DAS, Kendall BE, MacManus DG, McDonald WI, Miller DH (1994): British Isles survey of multiple sclerosis in twins: MRI. J Neurol Neurosurg Psychiatry $\underline{57}, 491-496$

Tintoré M, Rovira A, Martínez MJ, Rio J, Díaz-Villoslada P, Brieva L, Borrás C, Grivé E, Capellades J, Montalban X (2000): Isolated demyelinating syndromes: comparison of different MR imaging criteria to predict conversion to clinically definite multiple sclerosis. Am J Neuroradiol 21, 702-706

Trapp BD, Bernier L, Andrews SB, Colman DR (1988): Cellular and subcellular distribution of 2 ',3'-cyclic nucleotide 3 '-phosphodiesterase and its mRNA in the rat central nervous system. J Neurochem $\underline{51}, 859-868$

Trojaborg W, Petersen E (1979): Visual and somatosensory evoked cortical potentials in multiple sclerosis. J Neurol Neurosurg Psychiatry $\underline{42}, 323-330$ 
Uhthoff W (1890): Untersuchungen über die bei der multiplen Herdsklerose vorkommenden Augenstörungen. Arch Psychiatr Nervenkr 21, 55-116

Vallstedt A, Klos JM, Ericson J (2005): Multiple dorsoventral origins of oligodendrocyte generation in the spinal cord and hindbrain. Neuron $\underline{45}, 55-67$

Van den Wyngaert I, de Vries W, Kremer A, Neefs J, Verhasselt P, Luyten WH, Kass SU (2000): Cloning and characterization of human histone deacetylase 8. FEBS Lett $\underline{478}, 77-83$

Vaquero A, Tang X, Sternglanz R, Reinberg D (2007): NAD+-dependent deacetylation of H4 lysine 16 by class III HDACs. Oncogene $\underline{26}, 5505-5520$

Vass K, Lassmann H (1990): Intrathecal application of interferon gamma: progressive appearance of $\mathrm{MHC}$ antigens within the rat nervous system. Ann J Pathol 137, 789-800

Vega RB, Matsuda K, Oh J, Barbosa AC, Yang X, Meadows E, McAnally J, Pomajzl C, Shelton JM, Richardson JA, et al. (2004): Histone deacetylase 4 controls chondrocyte hypertrophy during skeletogenesis. Cell $\underline{119}, 555-566$

Warren KG, Catz I, Jeffrey VM, Carrol DJ (1986): Effect of methylprednisoloone on CSF IgG parameters, myelin basic protein and anti-myelin basic protein in multiple sclerosis exacerbations. Can J Neurol Sci 13, 25-30

Weinshenker BG, O'Brien PC, Petterson TM, Noseworthy JH, Lucchinetti CF, Dodick DW, Pineda AA, Stevens LN, Rodriguez M (1999): A randomized trial of plasma exchange in acute central nervous system inflammatory demyelinating disease. Ann Neurol $\underline{46}, 878-886$

Wilcox CE, Ward AMV, Evans A, Baker D, Rothlein R, Turk JL (1990): Endothelial cell expression of the intercellular adhesion molecule-1 (ICAM-1) in the central nervous system of guinea pigs during acute and chronic relapsing experimental allergic encephalomyelitis. $J$ Neuroimmunol $\underline{30}, 43-50$

Wolinsky JS (2006): The use of glatiramer acetate in the treatment of multiple sclerosis. Adv Neurol $\underline{98}, 273-292$

Woodruff RH, Franklin RJ (1999): The expression of myelin protein mRNAs during remyelination of lysolecithin-induced demyelination. Neuropathol Appl Neurobiol $\underline{25}, 226-235$

Woodruff RH, Fruttiger M, Richardson WD, Franklin RJ (2004): Platelet-derived growth factor regulates oligodendrocyte progenitor numbers in adult CNS and their response following CNS demyelination. Mol Cell Neurosci $\underline{25}, 252-262$

Yao YL, Yang WM, Seto E (2001): Regulation of transcription factor YY1 by acetylation and deacetylation. Mol Cell Biol 21, 5979-5991

Ye F, Chen Y, Hoang T, Montgomery RL, Zhao XH, Bu H, Hu T, Taketo MM, van Es JH, Clevers $\mathrm{H}$, et al. (2009): HDAC1 and HDAC2 regulate oligodendrocyte differentiation by disrupting the beta-catenin-TCF interaction. Nat Neurosci 12, 829-38

Zearfoss NR, Farley BM, Ryder SP (2008): Post-transcriptional regulation of myelin formation. Biochim Biophys Acta $\underline{1779}$, 486-494 
Zhang X, Yuan Z, Zhang Y, Yong S, Salas-Burgos A, Koomen J, Olashaw N, Parsons JT, Yang XJ, Dent SR, et al. (2007): HDAC6 modulates cell motility by altering the acetylation level of cortactin. Mol Cell 27, 197-213

Zhang Y, Kwon S, Yamaguchi T, Cubizolles F, Rousseaux S, Kneissel M, Cao C, Li N, Cheng HL, Chua K, et al. (2008): Mice lacking histone deacetylase 6 have hyperacetylated tubulin but are viable and develop normally. Mol Cell Biol 28, 1688-1701 


\section{Danksagung}

Zunächst möchte ich Herrn Prof. Dr. med Wolfgang Brück sowie Frau Prof. Dr. med Christine Stadelmann-Nessler dafür danken, mir diese Arbeit in der Abteilung der Neuropathologie ermöglicht zu haben.

Dabei gilt mein ganz besonderer Dank Frau Prof. Dr. med. Christine Stadelmann-Nessler, die mich mit ihrem Wissen und ihrer mitreißenden Art für das Thema begeistern konnte und in jeglicher Form unterstützte.

Ein weiterer Dank gilt Jasmin Reichl für die Hilfe beim Färben der Schnitte sowie Sven Müller für die Unterstützung bei der Sammlung der klinischen Daten.

Zuletzt möchte ich mich bei dem gesamten Team der Abteilung für Neuropathologie für die freundliche Aufnahme sowie stete Hilfsbereitschaft bei kleineren und größeren Problemen bedanken. 
